Willy Spannowsky

\title{
Das Handwerk im Bauplanungs- und Umweltrecht
}

Veränderte Rahmenbedingungen, aktuelle

Rechtsentwicklungen und Reformvorschläge

\section{Nomos}


Wirtschaft und Recht für Mittelstand und Handwerk

Studien und Dissertationen aus dem Ludwig-FröhlerInstitut für Handwerkswissenschaften

herausgegeben von

Prof. Dr. oec. publ. Gunther Friedl,

Technische Universität München

Prof. Dr. iur. Martin Burgi,

Ludwig-Maximilians-Universität München

Band 1 


\section{Willy Spannowsky \\ Das Handwerk im Bauplanungs- und Umweltrecht}

Veränderte Rahmenbedingungen, aktuelle Rechtsentwicklungen und Reformvorschläge 
Gefördert durch:

Bundesministerium
für Wirtschaft
und Energie

aufgrund eines Beschlusses des Deutschen Bundestage

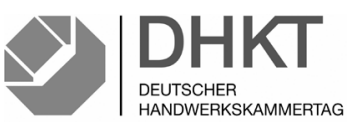

sowie die

Wirtschaftsministerien

der Bundesländer

Die Deutsche Nationalbibliothek verzeichnet diese Publikation in der Deutschen Nationalbibliografie; detaillierte bibliografische Daten sind im Internet über http://dnb.d-nb.de abrufbar.

ISBN 978-3-8487-6018-3 (Print)

ISBN 978-3-7489-0138-9 (ePDF)

1. Auflage 2019

(c) Nomos Verlagsgesellschaft, Baden-Baden 2019. Gedruckt in Deutschland. Alle Rechte, auch die des Nachdrucks von Auszügen, der fotomechanischen Wiedergabe und der Übersetzung, vorbehalten. Gedruckt auf alterungsbeständigem Papier. 


\section{Inhaltsverzeichnis}

$\begin{array}{ll}\text { A. Einleitung } & 11\end{array}$

B. Veränderte Rahmenbedingungen im Bereich des Handwerks

I. Veränderte Handwerksstrukturen und der damit verbundene Wandel der betrieblichen Erscheinungsformen

1. Strukturwandel mit räumlichem Differenzierungserfordernis

2. Handwerksbetriebe mit unterschiedlichem Flächenbedarf (Handwerksbetriebe eines bestimmten Typus als Helfer für kleine Montagen, gewerbeübergreifende Service-Handwerksbetriebe und mobile Generalisten-Handwerksbetriebe)

3. Handwerksbetriebe mit Bedarf für Lagerkapazitäten und digital vernetzte Handwerker mit geringerem

Lagerbedarf

II. Veränderungen der standortrelevanten Anforderungsprofile bezüglich der Entwicklung, Erhaltung und Erweiterung von Standorten für Handwerksbetriebe

III. Entwicklung, Erhaltung und Erweiterung von Standorten für Handwerksbetriebe nach dem geltenden städtebaurechtlichen Zulässigkeitssystem

1. Die Bedeutung der $\$ \$ 29$ bis 36 BauGB als Maßstäbe zur Beurteilung der bauplanungsrechtlichen Zulässigkeit von Handwerksbetrieben

2. Standortentwicklung für Handwerksbetriebe nach dem BauGB 2017

3. Die Bedeutung der in der BauNVO aufgeführten Baugebietstypen für die bauplanungsrechtliche Zulässigkeit von Handwerksbetrieben an bestimmten Standorten

4. Entwicklung, Erhaltung und Erweiterung von Standorten für Handwerksbetriebe in unbeplanten Gebieten innerhalb im Zusammenhang bebauter Ortsteile gem. $\$ 34$ BauGB 
5. Standortentwicklung auf der Basis von

Innenbereichssatzungen gem. $\$ 34$ Abs. 4 S. 1 Nr. 1 bis 3 BauGB

6. Standortentwicklung für Handwerksbetriebe im Außenbereich im Sinne von $₫ 35$ BauGB

7. Standortentwicklung für Handwerksbetriebe im Außenbereich auf der Basis einer sog. Außenbereichssatzung gem. $\$ 35$ Abs. 6 BauGB

8. Aufgabe und Funktion der Bauleitplanung bei der Standortentwicklung für Handwerksbetriebe

IV. Prinzipielle Eignung des städtebaurechtlichen Steuerungssystems der BauNVO zur Sicherstellung einer bedarfsgerechten und ausreichend differenzierten Standortentwicklung

V. Städtebaurechtliche Akzentverschiebungen mit Nachteilen für die Standortentwicklung für Handwerksbetriebe infolge veränderter Rahmenbedingungen?

C. Veränderte flächen- und standortbezogene Rahmenbedingungen im Bereich des Umweltrechts und deren Konsequenzen für die Entwicklung, Erhaltung und Erweiterung von Handwerksbetrieben

I. Rechtsentwicklungen im Bereich des flächen- und standortbezogenen Umweltvorsorgestandards und deren Konsequenzen in Bezug auf die Entwicklung, Erhaltung und Erweiterung von Standorten für Handwerksbetriebe

1. Einschränkung der Entwicklung von Standorten für Handwerksbetriebe im bisher ungenutzten Freiraum im Außenbereich

2. Einschränkung der Entwicklung von Standorten für Handwerksbetriebe in oder in der Nachbarschaft von Schutzgebieten

3. Einschränkung der Entwicklung von Standorten für Handwerksbetriebe infolge des Artenschutzes

4. Einschränkung der Entwicklung von Standorten für Handwerksbetriebe infolge der naturschutzrechtlichen Eingriffs-Ausgleichs-Regelung

5. Einschränkung der Entwicklung von Standorten für Handwerksbereiche infolge des standortrelevanten Lärmschutzes 
6. Einschränkung der Entwicklung von Standorten für Handwerksbetriebe infolge der standortrelevanten Luftreinhaltung

7. Einschränkung der Entwicklung von Standorten für Handwerksbetriebe infolge der Nachbarschaft zu Betriebsbereichen im Sinne von $₫ 3$ a Abs. 5a BImSchG

II. Rechtsentwicklungen im Bereich der verfahrensrechtlichen Umweltprüfungsanforderungen und Planungsverfahren

III. Konsequenzen veränderter umweltfachgesetzlicher und umweltfachplanerischer Anforderungen für die bauplanungsrechtliche Zulässigkeit von Handwerksbetrieben und die städtebaulich-planerische Standortentwicklung

1. Auswirkungen veränderter materieller und verfahrensmäßiger Prüfungsanforderungen und daraus abgeleitete Konsequenzen für das Städtebaurecht

2. Städtebaurechtliche Korrekturen der Innenentwicklungsstrategie in Bezug auf die städtebauliche Planung und Verfahrensanforderungen sowie die bauplanungsrechtlichen Zulässigkeitstatbestände

3. Städtebaurechtliche Korrekturen durch Veränderung der Anforderungen an das Planungsverfahren

D. Rechtsentwicklungen im Bauplanungsrecht und deren Konsequenzen für die Errichtung, Änderung und Erweiterung von Handwerksbetrieben

I. Die Bedeutung des Bauplanungsrechts für die Errichtung, Änderung und Erweiterung von Handwerksbetrieben

II. Rechtsentwicklungen in Bezug auf die Errichtung, Änderung, Erweiterung und Erneuerung von Handwerksbetrieben in verschiedenen gemeindlichen Entwicklungsbereichen

1. Rechtsentwicklungen bezüglich des unbeplanten Innenbereichs

2. Rechtsentwicklungen bezüglich des unbeplanten Außenbereichs

3. Rechtsentwicklungen im Bereich der städtebaulichen Planung 
E. Bedeutung und Tragweite der Baugebietstypisierung für die Erhaltung, Entwicklung und Sicherung von Standortpotentialen für Handwerks- und Gewerbebetriebe innerhalb des Systems der städtebaulichen Planung

I. Flächenvorsorge für Handwerksbetriebe im Rahmen der Flächennutzungsplanung

II. Das System der baugebietstypischen Differenzierung innerhalb der städtebaulichen Planung und der Planersatzregelungen und dessen Relevanz für die Zulässigkeit von Handwerksbetrieben

1. Die Bedeutung der Typisierung von Handwerksbetrieben und Baugebieten für die Wahl und Sicherung von Standorten für handwerksbetriebliche Vorhaben

2. Die bauplanungsrechtliche Zulässigkeit von Handwerksbetrieben nach ihrem typischen Erscheinungsbild innerhalb der verschiedenen Baugebiete

3. Die Zulässigkeit von Handwerksbetrieben bei Gemengelagen infolge Nutzungsmischung

4. Der Bestandsschutz bei Fortführung der Nutzungsmischung in Gemengelagen

5. Entschärfung der Gemengelagenproblematik durch die Fortentwicklung der planerischen allgemeinen und speziellen Feinsteuerungsmöglichkeiten

6. Die Begrenzung der planerischen Feinsteuerung durch den Gebietswahrungsanspruch

III. Anlassbezogene gesetzgeberische Systemkorrekturen auf der Basis von Übergangsregelungen zur Erleichterung der Unterbringung von Flüchtlingen und Asylanten und deren Konsequenzen für die Standortentwicklung von Handwerks- und Gewerbebetrieben

IV. Gesetzgeberische Systemkorrekturen zur Entwicklung und Erhaltung erweiterter Standortpotentiale zugunsten von Handwerks- und Gewerbebetrieben

1. Entschärfung der Gemengelagenproblematik durch die Einführung der urbanen Gebiete?

2. Wohnen neben dem Handwerksbetrieb? 
3. Entwicklung und Erhaltung von Standorten für Handwerksbetriebe im Rahmen städtebaulicher Gesamtmaßnahmen

4. Verbesserung der Standortqualität auf der Basis Privater Initiativen zur Stadtentwicklung

F. Denkbare weitergehende gesetzgeberische Steuerungsoptionen zur Sicherung und Schaffung erweiterter Standortpotentiale zugunsten von Handwerks- und Gewerbebetrieben

I. Förderung der Standortentwicklung zugunsten störender, aber nicht wesentlich störender Handwerksbetriebe in Baugebieten, welche „vorwiegend dem Wohnen dienen“, durch eine gesetzliche Einschränkung des Gebietserhaltungsanspruchs?

II. Förderung der Standortentwicklung für das Wohnen störender Handwerksbetriebe durch eine die Wohnnutzung einschränkende Modifikation des Gebietstyps „urbanes Gebiet"?

III. Erhaltung der Standortpotentiale an den Rändern der Städte und Gemeinden durch eine Abschaffung der wohnbaufördernden Planungserleichterungen mit Zugriffsmöglichkeiten auf diesen Bereich?

IV. Vorsorge hinsichtlich der Entwicklung von Standorten für Handwerksbetriebe durch die Raumordnungsplanung

G. Zusammenfassung in Thesen

Literaturverzeichnis 


\section{A. Einleitung}

Den Handwerksbetrieben kommt in Deutschland eine herausragende Bedeutung zu. Dies zeigt die folgende Übersicht über die Anzahl aller Handwerksbetriebe in Deutschland. Sie macht deutlich, dass es sich um einen Wirtschaftszweig handelt, der tendenziell im Zeitraum von 1997 bis 2017 einen zahlenmäßigen Anstieg der Betriebe aufwies. Es ist trotz leichter Rückgänge gegenüber dem Zeitraum von 2011 bis 2015 zu erwarten, dass diese tendenzielle Gesamtentwicklung und der damit verbundene Bedarf an geeigneten Standorten für Handwerksbetriebe weiterhin anhält.

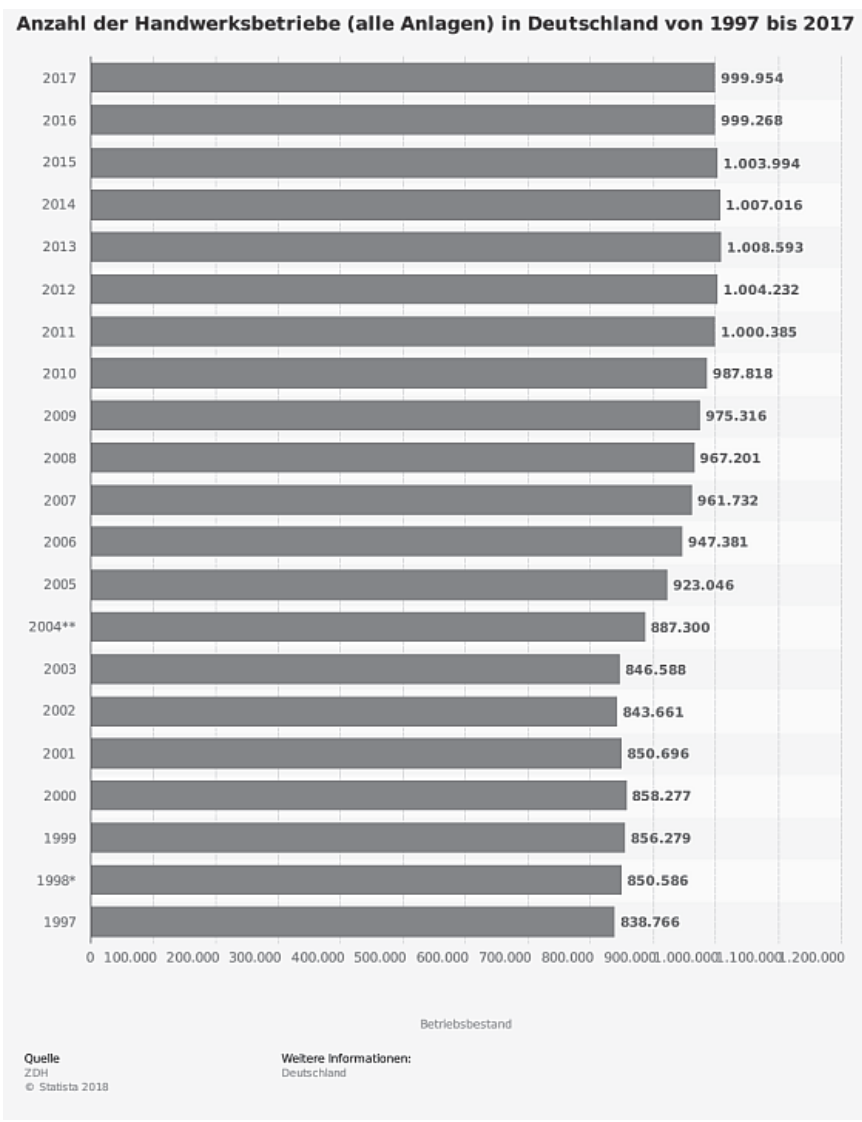




\section{A. Einleitung}

Handwerksbetriebe sind auf das ganze Bundesgebiet verteilt. Sie sind in Großstädten und Ballungsräumen ebenso wie in Städten und Gemeinden in ländlichen Räumen zu finden.

Nach der Datenstatistik des Statistischen Bundesamts waren im Durchschnitt des Jahres 2016 im Bereich des Handwerks 5.142.464 Personen beschäftigt. Dabei wurde ein Umsatz von 551.469.184 € ohne Umsatzsteuer erzeugt. ${ }^{1}$

Seit dem Inkrafttreten der Änderung der Handwerksordnung am 01.01.2004 wird zwischen zulassungspflichtigen und zulassungsfreien Handwerksbetrieben unterschieden. Ca. 80 Prozent aller Handwerksbetriebe gehören den zulassungspflichtigen Handwerksunternehmen an und rund 20 Prozent aller Handwerksbetriebe den zulassungsfreien. ${ }^{2}$ Zulassungspflichtige Handwerksbetriebe sind zum Beispiel Straßenbauer, Steinmetze und Steinbildhauer, Maler und Lackierer, Metallbauer, Karosserieund Fahrzeugbauer, Landmaschinenmechaniker, Bäcker, Konditoren, Augenoptiker, Zahntechniker (sog. Anlage A Handwerker). Zulassungsfreie Handwerksbetriebe sind beispielsweise Fliesen-, Platten- und Mosaikleger, Estrichleger, Metall- und Glockengießer, Schneidwerkzeugmechaniker, Textilreiniger, Gebäudereiniger (sog. Anlage B1- Handwerker) oder handwerksähnliche Gewerbebetriebe, wie z. B. Asphaltierer, Betonbohrer und -schneider, Metallschleifer und Metallpolierer, Metallsägen-Schärfer, Schnellreiniger, Bestattungsgewerbe, Fleischzerleger, Ausbeiner (sog. Anlage B2-Handwerker). ${ }^{3}$

Die herausragende Bedeutung, die dem Handwerk sowohl nach den Betriebszahlen, nach seiner sozio-ökonomischen Funktion als auch nach der Zahl und der Verteilung der Betriebe im Bundesgebiet für die Stadtentwicklung zukommt, spiegelt sich weder in der planungswissenschaftlichen noch in der städtebaurechtlichen Literatur wider. Es gibt erstaunlicher Weise gerade in neuerer Zeit nur vergleichsweise wenig Literatur zur städtebaulichen Standortentwicklung von Handwerksbetrieben. ${ }^{4}$ Dabei gibt es

1 Siehe dazu https://www.destatis.de/DE/ZahlenFakten/GesamtwirtschaftUmwelt/U nternehmenHandwerk/Handwerk/Handwerk.html\#Tabellen, abgerufen am 10.11.2018.

2 Dazu https://www.destatis.de/DE/ZahlenFakten/GesamtwirtschaftUmwelt/Untern ehmenHandwerk/Handwerk/AktuellStruktur.html, abgerufen am 10.11.2018.

3 Siehe zu den zulassungspflichtigen Handwerksbetrieben die Anlage 1 zur HwO und zu den zulassungsfreien Handwerksbetrieben und handwerksähnlichen Gewerbebetrieben die Anlage 2 zur HwO.

4 Dazu in neuerer Zeit Scheidler, GewArch Beilage WiVerw Nr. 02/2016, 65 ff.; ders. GewArch Beilage WiVerw Nr. 02/2018, 89 ff. und Kormann, GewArch 2010, $396 \mathrm{ff}$. 
gerade in neuerer Zeit angesichts sich anbahnender Veränderungen im Bereich der Handwerksbetriebsstruktur als auch angesichts der Veränderungen der tatsächlichen und rechtlichen Rahmenbedingungen, welchen die städtebauliche Planung bei der Stadt- und Gemeindeentwicklung und dabei auch der Standortentwicklung Rechnung tragen muss, drängende Fragen, welche vor allem die strategisch-politische und planungsrechtliche Ausrichtung des Städtebaurechts betreffen: Kann das städtebaurechtliche Steuerungssystem die handwerksbetriebliche Standortnachfrage der von dynamischen Veränderungen geprägten Handwerksbetriebe angesichts zunehmender Restriktionen im Bereich der städtebaulich-planerischen Flächenausweisung auch noch zukünftig in ausreichendem Maße befriedigen? Wird den Belangen der Handwerksbetriebe in der auf Schonung der Flächenressourcen, Nutzungsmischung und Deckung der vor allem in Ballungsräumen steigenden Wohnraumnachfrage ausgelegten Innenentwicklungsstrategie, wonach die städtebauliche Entwicklung vorrangig durch Maßnahmen der Innenentwicklung erfolgen soll ( $\mathbb{1}$ Abs. 5 S. 3 BauGB), hinreichend Rechnung getragen werden?

Der teils vom Gesetzgeber selbst, teils von den Gemeinden wahrgenommene städtebaurechtliche Gestaltungsauftrag des $\mathbb{1} 1$ Abs. 5 S. 1 BauGB, eine nachhaltige städtebauliche Entwicklung zu gewährleisten, verlangt, dass neben den vielfältigen städtebaulichen Belangen der verschiedensten Nutzungsinteressenten und den vielfältigen unterschiedlichen öffentlichen Belangen auch den wirtschaftlichen Bedürfnissen des Handwerks an der Erhaltung und Entwicklung geeigneter Standorte für die vielfältigen handwerklichen Betätigungsformen Rechnung getragen wird.

Obwohl die Standortentwicklung vorwiegend in den Aufgabenbereich der städtebaulichen Planung und somit in den Zuständigkeitsbereich der Städte und Gemeinden fällt, wird der rechtliche Rahmen der gewerblichen und damit auch der handwerksbetrieblichen Standortentwicklung mehr und mehr von europarechtlichen, insbesondere umwelt- und energierechtlichen Anforderungen, von den bundesgesetzlichen Vorgaben und Rahmensetzungen des Städtebaurechts und weniger denen des Raumordnungsrechts und der Raumordnungsplanung der Länder durch landesund regionalplanerische Festlegungen bestimmt.

Die Erfüllung der unter das städtebaurechtliche Nachhaltigkeitspostulat fallenden Aufgabe ist zunehmend schwieriger und komplexer geworden. Dies liegt zum einen daran, dass sich die Standortnachfrage und die räumlichen Bedürfnisse der Handwerksbetriebe in Bezug auf die Errichtung, Erweiterung, Änderung oder Verlagerung aufgrund weitreichender Veränderungsprozesse im Handwerk verändert haben. Zum anderen wird es ange- 


\section{A. Einleitung}

sichts veränderter Rahmenbedingungen im Städtebau- und Umweltrecht immer schwieriger, geeignete Standorte für die vielfältigen Handwerksbetriebstypen und die vielfältigen betrieblichen Formate der vielfältigen Handwerkslandschaft bereitzustellen. Die bundesgesetzlich verankerte Innenentwicklungsstrategie führt zwangsläufig dazu, dass im Rahmen der gemeindlichen Erforderlichkeitsprüfung im Sinne von $\$ 1$ Abs. 3 BauGB im Interesse des bundesrechtlich angestrebten Schutzes der Freiraumflächenressourcen Möglichkeiten der Nachverdichtung und Nutzungsmischung in Betracht gezogen werden müssen (vgl. auch $\$ 1$ a Abs. 2 BauGB).

Nicht nur deshalb, aber möglicherweise auch deshalb zeigen sich in Bezug auf die regionale Verteilung von Handwerksbetrieben signifikante räumliche Unterschiede zwischen Städten und ländlichen Räumen:

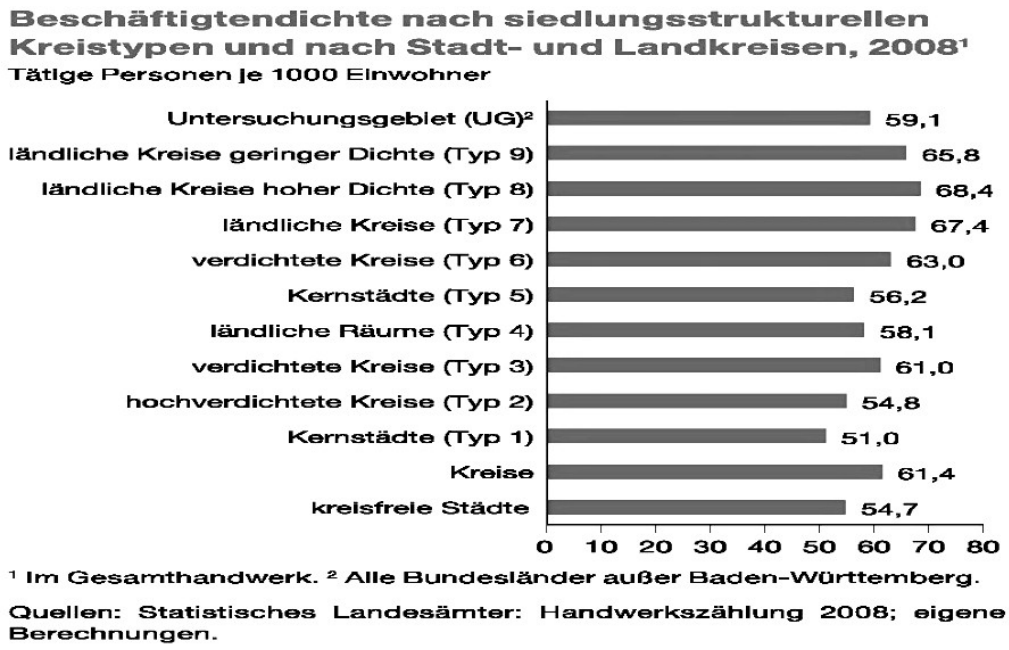

Auszug aus der Untersuchung von Klaus Müller, Strukturentwicklungen im Handwerk, Wirtschaftsdienst 2013/9, S. 636 (641).

Interessant ist insofern, dass Handwerksbetriebe in städtischen Räumen weniger zu finden sind als in ländlichen Räumen. Dies dürfte darauf zurückzuführen sein, dass der Standortwettbewerb für Handwerksbetriebe in ländlichen Räumen im Vergleich zu Handel und Industrie und anderen 
Nutzungen offenbar günstiger ausfällt als in Städten. ${ }^{5}$ Dazu kommt zunehmend auch der Faktor der Flächenknappheit in den städtischen Räumen und Ballungsräumen.

Dieser Trend dürfte sich noch verstärken. Denn aufgrund bestimmter planungsrechtlicher Änderungen sind zum Nachteil der handwerksbetrieblichen Standortentwicklung Verdrängungseffekte entstanden bzw. verstärkt worden. So zeichnet sich ab, dass sich die Konfliktsituationen zwischen sensiblen städtebaulichen Nutzungen und gewerblichen Nutzungen wegen der Zunahme von Nutzungskonkurrenzen vor allem im Innenbereich der Städte tendenziell eher verschärfen werden. Denn Nachverdichtung und Nutzungsmischung im Bereich der städtebaulichen Planung bedingen gerade für manche Handwerksbetriebe eine Steigerung der Konflikte mit sensiblen Nutzungen in der Nachbarschaft der Wohnbevölkerung und/oder anderer sensibler Nutzungen. Dazu kommen veränderte Rahmenbedingungen im umweltrechtlichen Bereich, die sich in erheblichem Maße auf die Eignung von Standorten für Handwerksbetriebe auswirken. So haben nicht nur allgemeine rechtliche Änderungen im Bereich des Lärmschutzes und der Luftreinhaltung erheblichen Einfluss auf die Standortsituation von Handwerksbetrieben, sondern auch Maßnahmen, die zur Eindämmung negativer Umweltbeeinträchtigungen in diesen Bereichen ergriffen werden. ${ }^{6}$ Ein aktuelles Beispiel hierfür bilden die verkehrsbezogenen Maßnahmen, die wegen Grenzwertüberschreitungen auf der Basis von Luftreinhalte- und Lärmminderungsplänen in der Verkehrspolitik ergriffen werden müssen. Dabei gerät der Gesundheitsschutz in Konflikt mit dem Interesse an der Förderung und Erhaltung der Mobilität in den Städten. Die zur Konfliktbewältigung notwendigen Maßnahmen können gerade auch für Handwerksbetriebe standortrelevante Auswirkungen haben. Aber auch andere Nutzungsbeschränkungen, wie z. B. das was-

5 Siehe dazu eingehender Klaus Müller, Strukturentwicklungen im Handwerk, in: Wirtschaftsdienst, Zeitschrift für Wirtschaftspolitik, 93. Jahrgang, 2013, Heft 9, S. 636 und dort vor allem Abbildung 5 und 6. Müller zieht daraus die gleichen Schlussfolgerungen; sowie http:/www.ifh.wiwi.uni-goettingen.de/de/content/auf-d em-land-mehr-handwerksbetriebe-als-den-st $\% \mathrm{C} 3 \% \mathrm{~A} 4 \mathrm{dten}$-ergebnisse-einer-untersu chung-\%C3\%BCber-regio, abgerufen am 10.11.2018, und www.ifh.wiwi.uni-goetti ngen.de/de/content/handwerksentwicklung-im-spannungsfeld-zwischen-stadt-undland-eine-empirische-analyse, abgerufen ebenfalls am 10.11.2018.

6 Dies führt wiederum zu der Folgefrage, ob und inwieweit bei einer Verhängung von Diesel-Verkehrsverboten unter dem Aspekt der Verhältnismäßigkeit zugunsten von Handwerkern Einschränkungen erforderlich sind; dazu BVerwG, Urt. v. 27.02.2018, SVR 2018, 271 (275) und Burgi/Pöhlmann, GewArch 2018, 361 ff. 


\section{A. Einleitung}

serhaushaltsrechtliche Planungs- und Bauverbot in Überschwemmungsgebieten können Auswirkungen auf Bestandsgebiete in den betroffenen Gebieten auslösen. Nutzungsbeschränkungen können überdies auch aus artenschutz- und gebietsschutzbezogenen Anforderungen herrühren, wenn sich ein Handwerksbetrieb in der Nachbarschaft geschützter Arten oder von Schutzgebieten oder in lärmintensiver Umgebung befindet.

$\mathrm{Da}$ es zu den Aufgaben der städtebaulichen Planung gehört, das Interesse an der Befriedigung der wirtschaftlichen und sozialen Nutzungsinteressen der Wohnbevölkerung und der Gewerbetreibenden mit den Belangen des Umweltschutzes in Einklang zu bringen, führen die vorstehend skizzierten Veränderungen im Bereich der Umweltvorsorge zu der zentralen Frage, wie sich der Wandel der umweltrechtlichen Rahmenbedingungen auf die Entwicklung der Standortsituation und die Befriedigung des Flächenbedarfs für Handwerksbetriebe auswirkt. Daraus resultiert schließlich die weitere konsekutive Frage, welche Schlussfolgerungen aus diesen für die Entwicklung der „Handwerkslandschaft" relevanten rechtlichen und tatsächlichen Veränderungen für den Bereich der städtebaulichen Planung und ggf. für die Entwicklung des Städtebaurechts abzuleiten sind.

Auch die Änderungen der rechtlichen Rahmenbedingungen im Bereich des Städtebaurechts selbst haben Konsequenzen für die Neuansiedlung von Handwerksbetrieben in den verschiedenen städtebaulichen Entwicklungsbereichen und Baugebieten und für die Änderung, Erweiterung oder Verlagerung von Bestandsbetrieben. Insofern sind die zahlreichen gesetzlichen Änderungen, welche allein im Jahr 2017 vorgenommen worden sind und die letztlich am 03.11.2017 zu einer Neufassung des BauGB geführt haben, von Bedeutung. $\mathrm{Zu}$ der Neufassung des BauGB führten folgende im Jahr 2017 vorgenommenen Änderungen des BauGB: Erstens Änderungen aufgrund des Gesetzes zur Umsetzung der Richtlinie 2014/52/EU im Städtebaurecht und zur Stärkung des neuen Zusammenlebens in der Stadt v. 4.5.2017 (BGBl. I S. 1057), das am 13.5.2017 in Kraft getreten ist, zweitens Änderungen aufgrund des am 02.06.2017 in Kraft getretenen Art. 6 des Gesetzes zur Anpassung des Umwelt-Rechtsbehelfsgesetzes und anderer Vorschriften an europa- und völkerrechtliche Vorgaben vom 29.05.2017 (BGBl. I S. 1298), drittens Änderungen aufgrund des Gesetzes zur weiteren Verbesserung des Hochwasserschutzes und zur Vereinfachung von Verfahren des Hochwasserschutzes v.30.06.2017 (BGBl. I S. 2193), das teils am 06.07.2017 und teils am 05.01.2018 in Kraft getreten ist, und viertens Änderungen aufgrund des Art. 2 Abs. 3 des Gesetzes zur Modernisierung des Rechts der Umweltverträglichkeitsprüfung v. 20.07.2017 (BGBl. I S. 2808), das am 29.07.2017 in Kraft getreten ist. 
Parallel zu diesen städtebaurechtlichen Gesetzesänderungen, die mit Änderungen der Baunutzungsverordnung (BauNVO) und der Planzeichenverordnung (PlanzVO) verbunden waren, kam es auch zu zahlreichen umweltfachgesetzlichen Änderungen und zu Änderungen des Raumordnungsgesetzes. Die umweltfachgesetzlichen Änderungen im Bereich des UVPG, des WHG und des BImSchG haben wiederum beträchtliche Rückwirkung auf das Städtebaurecht.

Aufgrund dieser umfangreichen gesetzlichen Änderungen sind nicht nur EU-rechtliche Richtlinienanforderungen in das nationale Städtebaurecht umgesetzt worden, sondern auch in strategischer Folgerichtigkeit im Interesse der Fortentwicklung der Innenentwicklungsstrategie Änderungen des $₫ 34$ BauGB im Bereich der bauplanungsrechtlichen Zulässigkeit von Vorhaben vorgenommen worden (siehe dazu unten B. III. 2., 4. und 8.). Wegen der Einführung des neuen Baugebietstyps urbanes Gebiet und der damit verbundenen Erleichterung bei der Planung von Mischnutzungen gab es auch Folgeänderungen im Bereich des vorsorgenden Lärmschutzes der TA Lärm und der Sportanlagenlärmschutzverordnung (18. BImSchV).

Nachdem mit dem Erlass EU-rechtlicher Anforderungen eher eine Verstärkung der Umweltvorsorge angestrebt wurde, die tendenziell an bestimmten vorbelasteten Standorten oder an Standorten mit sensiblen Nutzungen und Schutzfunktionen in der Nachbarschaft im Bereich der Neuansiedlung und Erweiterung von Gewerbebetrieben zu Beschränkungen führt, hat der Bundesgesetzgeber den Umweltvorsorgestandard, soweit es im Einklang mit dem EU-Recht in seiner gesetzlichen Entscheidungsmacht steht, in gewissem Maße reduziert. Dies gilt vor allem für den Bereich des Lärmschutzes durch Änderungen der TA Lärm und der Sportanlagenlärmschutzverordnung (18. BImSchV). Konsequenzen hat dies auch für die Zulässigkeit der Errichtung, Erweiterung und Änderung von Handwerksbetrieben, vor allem in Gemengelagen (dazu eingehender nachfolgend).

Da die bauliche Planung im Regelfall nicht lediglich auf Nachfrage reagiert, sondern die städtebauliche Entwicklung grundsätzlich über eine Angebotsplanung steuert, muss das bauplanungsrechtliche Zulässigkeitssystem so ausgelegt sein, dass es bedarfsgerecht auf die veränderte Nachfrage nach Flächen und Nutzungsmöglichkeiten für Handwerksbetriebe reagieren kann. Ob die Änderungen des Städtebaurechts diesem Anliegen Rechnung tragen und wenn ja, ob die vorgenommenen Änderungen ausreichend sind, ist Anlass der folgenden Analyse. 


\section{B. Veränderte Rahmenbedingungen im Bereich des Handwerks}

I. Veränderte Handwerksstrukturen und der damit verbundene Wandel der betrieblichen Erscheinungsformen

\section{Strukturwandel mit räumlichem Differenzierungserfordernis}

Während das Handwerksrecht von festgefügten Erscheinungsbildern der Handwerksbetriebe ausgeht und zwischen zulassungspflichtigen und zulassungsfreien Handwerksbetrieben sowie handwerksähnlichen Gewerbebetrieben unterscheidet, ${ }^{7}$ verändert sich die Struktur und das „,corporate design" der Gewerbebetriebe, welche Handwerkerleistungen anbieten. Der Strukturwandel beruht auf einem multikausalen Veränderungsprozess und ist entsprechend komplex. Nicht nur Fachkräftemangel und Nachfolgesorgen, sondern auch rasante Veränderungen der Rahmenbedingungen, stellen die Handwerksbetriebe und handwerksähnlichen Gewerbebetriebe vor Herausforderungen.

Die komplexen Veränderungsprozesse lassen sich in einer Trendbeschreibung wie folgt zusammenfassen: Durch die Digitalisierung werden die Vertriebswege verändert. Bauprodukte werden nicht mehr über die Handwerker, sondern zunehmend direkt bei den Herstellern bezogen. Auch die Handwerksleistungen werden nicht mehr überwiegend unmittelbar vor Ort eingekauft; die Bindung an den Handwerker vor Ort geht in

7 Siehe zum Begriff des zulassungspflichtigen Handwerksbetriebs $\mathbb{S} 1$ Abs. 1,2 $\mathrm{HwO}$ i. V. m. Anlage A zur HwO; zum zulassungsfreien Handwerksbetrieb $\mathbb{1} 18$ Abs. 1, 2 S. $1 \mathrm{HwO}$ i. V. m. Anlage B Abschnitt 1 zur HwO sowie zum handwerksähnlichen Gewerbe $\mathbb{} 18$ Abs. 2 S. 2 HwO i. V. m. Anlage B Abschnitt 2 zur HwO sowie Gabler, Wirtschaftslexikon, https:/wirtschaftslexikon.gabler.de/definition/ha ndwerk-51988/version-275139, am 12.10.2018 abgerufene Revision des Begriffs Handwerk v. 19.02.2018. In Anlage A zur HwO sind als zulassungspflichtige Handwerker 41 Handwerksbetriebe aufgeführt. Neben den klassischen Bauhandwerkern sind darunter auch Steinmetze, Boots- und Schiffbauer, Lackierer, Karosserie- und Fahrzeugbauer sowie Landmaschinenmechaniker. Betriebe, in denen die Tätigkeiten dieser Handwerksbereiche ausgeführt werden, können in nicht unerheblichem Umfang Lärm erzeugen und auch Luftschadstoffe freisetzen. 
den verschiedenen Handwerksbereichen in unterschiedlichem Umfang und unterschiedlich schnell mehr und mehr verloren.

Gemäß einer Analyse der Unternehmensberatung OC\&C Strategy, die auf der Basis von 1.250 Handwerksbetrieben in Deutschland, Frankreich und Polen durchgeführt wurde, dominieren in Deutschland im Handwerksbereich zwar mit 25 bis 33 Prozent noch die traditionellen Gewerbespezialisten, jedoch finden auch in Deutschland im Handwerksbereich Veränderungen in Richtung der "digital-begeisterten Spezialisten“ und der „Modernen Alleskönner" statt. ${ }^{8}$ Nach den Entwicklungsprognosen für den Bereich der „Handwerkerlandschaft“ gibt es schon jetzt eine Segmentierung und die Herausbildung von im Wesentlichen vier Handwerksdienstleistern: die Handwerksbetriebe, welche als Helfer für kleine Montagen fungieren, die Handwerksbetriebe, die als „klassische Gewerbespezialisten mit breitem Serviceangebot" in Erscheinung treten, die Handwerksbetriebe, die als „digital begeisterte Spezialisten“ und die Handwerksbetriebe, die als „Moderne Alleskönner“ beschrieben werden können.9

Durch die zunehmende, teilweise auch produktabhängige Spezialisierung wird die Zusammenarbeit zwischen den Handwerkern verändert. Teilweise führt diese Entwicklung dazu, dass manche Handwerksbetriebe wegen der Spezialisierung in einigen Bereichen nur noch Montageleistungen erbringen, teilweise bieten Handwerksbetriebe, wie z. B. bei kleineren Bauvorhaben, zunehmend gewerkeübergreifende Handwerksleistungen an und verändern ihre Kooperationsstrukturen, indem sie sich zusammenschließen.

Solche Strukturveränderungen im Bereich des Handwerks werden zunehmend stärker mit der Folge des Entstehens großer regionaler Unterschiede über die Nachfrageseite beeinflusst. Da es in einigen Bereichen schwierig ist, den Handwerkerbedarf zu decken, gibt es zum Beispiel im Bereich der Immobilienverwaltung in den unter Nachfragedruck stehenden Ballungsräumen den Trend, dass die Hausverwalter, um den Verlust der Verfügbarkeit spezialisierter Handwerksbetriebe auszugleichen, Kooperationsverbünde herstellen, welche zur Sicherstellung des Reparaturbedarfs kurzfristig in der Lage sind, gewerksübergreifend Handwerksleistungen erfüllen zu können.

8 Siehe dazu http://www.meistertipp.de/aktuelles/news/neues-handwerker-verhaltenbeeinflusst-bauzulieferer, abgerufen am 11.10.2018).

9 Siehe auch http://www.meistertipp.de/aktuelles/news/neue-handwerkertypen-wie-s ie-die-baubranche-veraendern, abgerufen am 11.10.2018. 
Die beschriebenen Strukturveränderungen, welche zu einem Wandel der betrieblichen Erscheinungsformen führen und auch die Handwerkerlandschaft mit ihren klassisch differenzierten Berufsbildern umgestalten, bedingen auch Veränderungen mit räumlichen und flächenbezogenen Auswirkungen. Diese Umbrüche können die Standorteignung der Handwerksbetriebe in Frage stellen und die Nachfrage nach geeigneten Flächen zur Ansiedlung von Handwerksbetrieben beeinflussen. Bislang sind die räumlichen Auswirkungen und die Konsequenzen für die bedarfsbezogene Flächenentwicklung, die durch die beschriebenen Veränderungsprozesse ausgelöst werden, kaum untersucht, obwohl die räumlichen Folgen vielseitig sind und auch die städtebauliche Planung dadurch vor neue Herausforderungen gestellt wird: Es wird dadurch nicht allein das gewerksspezifische Anforderungsprofil der Handwerksbetriebe verändert, durch das die Gewerbebetriebe, die Handwerksleistungen anbieten, unter Anpassungsdruck geraten; vielmehr sind im Städtebau auch in räumlich-planerischer, vor allem städtebaulicher Hinsicht Folgeerscheinungen festzustellen, die ihren Niederschlag in einer veränderten Nachfrage nach Gewerbeflächen finden.

Teilweise werden in der Nachbarschaft der Handwerksbetriebe keine Lagerflächen mehr benötigt, teilweise entsteht erhöhter Flächenbedarf, weil die Bereithaltung zusätzlicher Lagerflächen notwendig wird. In manchen dienstleistungsgeprägten Handwerksbereichen ist die Möglichkeit des Wohnens neben dem Betrieb für die Handwerksbetriebe ein Kriterium der Wettbewerbsfähigkeit, in anderen nicht.

Infolge der Veränderungsprozesse wird zudem die Abgrenzung zwischen Handwerksbetrieben und handwerksähnlichen Gewerbebetrieben einerseits sowie zwischen Industriebetrieben andererseits in Teilbereichen schwieriger. Charakteristisch für die handwerkliche Tätigkeit ist die selbständige Erwerbstätigkeit im Bereich der Be- und Verarbeitung von Stoffen, aber auch der Produktherstellung sowie im Reparatur- und Dienstleistungsbereich. Wegen der unterschiedlichen Rechtsfolgen hinsichtlich der städtebaulichen Zulässigkeit der Errichtung, Erweiterung und Änderung ist der Handwerksbetrieb, der eine Organisationsform der gewerblichen Wirtschaft ist, abzugrenzen von der industriellen Massenproduktion. Diese Abgrenzung kann im Einzelfall schwierig sein und wird infolge der Veränderungsprozesse zunehmend schwieriger, wenn Betriebe gewerksübergreifende Handwerksdienstleistungen anbieten und überdies auch in der Produktherstellung tätig sind. Die Abgrenzung richtet sich danach, ob nach dem Gesamtbild des Betriebs die industrielle oder die handwerks- 
mäßige Betriebsform überwiegt ${ }^{10}$ und ist damit einzelfallbezogen im Rahmen der Vorhabenzulassungsverfahren vorzunehmen. Das Städtebaurecht unterscheidet hingegen nach seiner spezifischen Zielsetzung zwischen nicht störenden, störenden, störenden, aber gebietsverträglichen, nicht wesentlich störenden, erheblich belästigenden Gewerbebetrieben und Gewerbebetrieben, die in anderen Baugebieten unzulässig sind (siehe $\mathbb{S} 4$ bis 9 BauNVO).

2. Handwerksbetriebe mit unterschiedlichem Flächenbedarf (Handwerksbetriebe eines bestimmten Typus als Helfer für kleine Montagen, gewerbeübergreifende Service-Handwerksbetriebe und mobile Generalisten-Handwerksbetriebe)

Der Flächenbedarf eines Handwerksbetriebs für kleine Montagen, zum Beispiel eines Elektrikers, der in einem Stadtquartier haushaltsnah Reparatur- und Installationsarbeiten ausführt, unterscheidet sich grundlegend von dem Flächenbedarf, der bei einem Handwerksbetrieb entsteht, der gewerbeübergreifend handwerksbetriebliche Serviceleistungen anbietet. Bei diesem kann bei dem Vorhandensein verschiedener handwerklicher Serviceeinheiten nicht nur der Flächenbedarf bezüglich des Bürogebäudes, nicht nur die Standorterreichbarkeit, sondern auch der Bedarf des Vorhandenseins einer guten digitalen Infrastruktur von herausragender Bedeutung sein. Nochmals anders dürfte der Flächenbedarf ausfallen, der für die Errichtung und Erweiterung mobiler Generalisten-Handwerksbetriebe entsteht. Denn bei diesen kann der Bedarf an Park-, Lager- und Fertigungshallen in unterschiedlicher Ausprägung bedeutsam sein. Weder der gewerbeübergreifende Service-Handwerksbetrieb noch der mobile GeneralistenHandwerksbetrieb werden im Normalfall, wenn sie die freie Flächenauswahl haben, eine Betriebsansiedlung in einem Wohnquartier anstreben.

10 Detterbeck HwO $₫ 1$ Rn. 24 mwN. und LG Offenburg, Urt. v. 15.09.2017, 5 O 54/16 KfH, GewArch 2018, 246 ff. bezüglich eines Großhandelsunternehmens für vertriebene Fleisch- und Wurstwaren; LAG Hamm, Urt. v. 25.01.2017, 3 Sa 958/16. 
3. Handwerksbetriebe mit Bedarf für Lagerkapazitäten und digital vernetzte Handwerker mit geringerem Lagerbedarf

In räumlicher Hinsicht von erheblicher Relevanz sind die Unterschiede zwischen den Handwerksbetrieben mit dem Bedarf für Lagerkapazitäten und den Handwerksbetrieben, welche keinen oder nur geringen Lagerbedarf haben. Mit dem Lagerbetrieb sind in der Regel Be- und Entladevorgänge und infolge der Warenanlieferung bzw. des Abtransports handwerklicher Produkte Lastkraftverkehr verbunden. Dadurch kann es zu Lärmund Luftschadstoffbelastungen in der Nachbarschaft kommen.

Wegen des dynamischen Wandels, der in der Handwerkslandschaft zu verzeichnen ist, kommt es auch in Bezug auf den Bedarf an Lagerflächen bei Handwerksbetrieben zu Veränderungen. So gibt es immer weniger Bäckereibetriebe, die lediglich für den örtlichen Bedarf produzieren. Vielmehr geht der Trend hin zu den regionalen Großbäckereien, die auf größeren Produktionsflächen Lager und Vertrieb organisieren müssen. Eine vergleichbare Entwicklung kann auch im Bereich der Metzgereibetriebe festgestellt werden. Solche Entwicklungen, die in einigen Handwerkszweigen auftreten, führen auch städtebaurechtlich zu Konsequenzen. Dabei ist städtebaurechtlich danach zu differenzieren, ob Flächen für die Neuansiedlung oder Flächen für einen Bestandsbetrieb benötigt werden oder umgekehrt, ob der Flächenbedarf für Bestandsbetriebe wegfällt.

II. Veränderungen der standortrelevanten Anforderungsprofile bezüglich der Entwicklung, Erhaltung und Erweiterung von Standorten für Handwerksbetriebe

Während bezüglich der klassischen Handwerksbetriebe, deren Erscheinungsbild unverändert geblieben ist, der Bedarf an Entwicklungs- und Erweiterungsflächen und an substanzerhaltenden baulichen Maßnahmen abgeschätzt werden kann und das städtebaurechtliche Planungs- und Zulassungssystem, wie nachfolgend verdeutlicht wird, eine Unterbringung aller Erscheinungsformen der handwerklichen Betriebstypen nach deren typischen Störgrad verteilt auf alle Gebietstypen gewährleistet, entstehen für die modernen gewandelten Handwerksbetriebstypen veränderte Ansprüche an den Raum.

Die Städte und Gemeinden werden aber sowohl in dem einen als auch in dem anderen Bereich wegen der Veränderungsprozesse im Handwerksbereich vor neue Herausforderungen gestellt. Wegen des Generationen- 
wechsels im Handwerksbereich, der sich zudem "im Schatten" einer geringer werdenden Zahl ausbildungsbereiter Nachwuchskräfte und veränderter Wettbewerbsbedingungen vollzieht, geht die Zahl der klassischen Handwerksbetriebstypen so stark zurück, dass sowohl in städtischen als auch in ländlichen Bereichen der Bedarf an Handwerkerleistungen teilweise nur schwer zu decken ist. Deshalb kann es ein Anliegen der Stadt- und Gemeindeentwicklung sein, in der Nähe von Wohngebietsquartieren Gewerbe- und Handwerksparks zu planen, um in städtischen Bereichen den Bedarf an haushaltsnahen und in ländlichen Bereichen den Regionalbedarf an Handwerks- und gewerblichen Dienstleistungen decken zu können. Wo solche handwerksbetrieblichen „Cluster" geplant werden, entstehen jedoch auch Folgeprobleme, die gelöst werden müssen. Denn dadurch werden schon allein durch den ansteigenden An- und Abfahrtsverkehr, aber auch durch die Kumulation verschiedener Handwerksbetriebe Umweltbelastungen ausgelöst, die zu Konflikten mit der Nachbarschaft führen können.

Die modernen Alleskönner, die spezialisierten Handwerksbetriebe im Bereich der Metallverarbeitung, die digital spezialisierten überörtlich tätigen Handwerksbetriebe mit Vergrößerungstendenz haben zudem oftmals anderen räumlichen Bedarf als die klassischen Handwerksbetriebe und prägen eigene Erscheinungsbilder aus (dazu oben unter B. I. 1. und unten E. II. 2.). Dies kann bei sich verändernden Bestandsbetrieben zu Konflikten mit der Nachbarschaft führen und lässt sich auch bei der Ausweisung der unterschiedlichen Baugebietstypen nicht immer vorhersehen.

Andererseits findet in Gewerbegebieten, in denen störende Handwerksbetriebe Standorte finden sollen, oftmals ein faktischer Verdrängungswettbewerb zwischen dem Einzelhandel und den Handwerksbetrieben statt, der, wenn städtebaulich nicht gesteuert und die Einzelhandelsentwicklung in den Gewerbegebieten nicht eingedämmt wird, angesichts der finanziellen Einsatzmöglichkeiten der Einzelhandelsbetriebe zum Nachteil der Handwerker ausgeht. ${ }^{11}$

Es besteht die Gefahr, dass sowohl für die notwendige Bildung handwerksbetrieblicher „Cluster“ als auch für die Handwerksbetriebe mit gewandeltem Anforderungsprofil, vor allem für solche, die nach ihrem Erscheinungsbild störende Betriebe sind, da und dort infolge der Flächenver-

$11 \mathrm{Zu}$ den damit zusammenhängenden Fragestellungen und begrenzten Steuerungsmöglichkeiten siehe VGH BW VBlBW 2013, $297 \mathrm{ff}$. sowie VG Saarland, Urt. v. 23.04.2008 - 5 k 386/07 -, juris und nachgehend OVG Saarland, BRS 74 Nr. 81 (2009). 
knappung, der Strategie der Innenentwicklung mit der Folge der Nachverdichtung und Nutzungsmischung und aufgrund weiterer Veränderungen der städtebaupolitischen Akzentsetzung keine geeigneten Standorte zur Deckung des handwerklichen Flächenbedarfs in ausreichender Zahl verfügbar sind. Soweit dies nicht nur im Einzelfall, sondern in zahlreichen Städten gehäuft auftritt, entsteht daraus ein branchenspezifisches Entwicklungsproblem.

Dies führt zu der einleitend aufgeworfenen Ausgangsfrage zurück, ob ein solches branchenspezifisches Entwicklungsproblem durch die Veränderung städtebaurechtlicher Eckpunkte, welche im Bereich der Standortentwicklung einen Verdrängungseffekt zum Nachteil der Handwerksbetriebe erzeugen, ausgelöst oder verstärkt worden ist.

III. Entwicklung, Erhaltung und Erweiterung von Standorten für Handwerksbetriebe nach dem geltenden städtebaurechtlichen Zulässigkeitssystem

1. Die Bedeutung der $\mathbb{S} 29$ bis 36 BauGB als Maßstäbe zur Beurteilung der bauplanungsrechtlichen Zulässigkeit von Handwerksbetrieben

Für die Errichtung und Erweiterung eines Handwerksbetriebs ist nach den Bauordnungen der verschiedenen Bundesländer grundsätzlich eine Baugenehmigung erforderlich. Bei größeren Betrieben, welche neben gewerksübergreifenden Handwerksleistungen auch Fertigungsprodukte herstellen, kann ggf. bei massenhafter industrieller Produktion auch eine immissionsschutzrechtliche Genehmigung erforderlich sein. Dies könnte z. B. gem. $\$ 4 \mathrm{BImSchG}$ sowie 4. BImSchV i. V. m. Nr.5.1 des Anhangs 1 zur 4. BImSchV bei einer Lackiererei der Fall sein, soweit die unter Nr. 5.1 des Anhangs 1 zur 4. BImSchV in Spalten 1 und 2 aufgeführten Mengen an eingesetzten Lösungsmitteln überschritten sind, und ebenso bei einem Metzgereibetrieb mit einer nach Nr.7.2 Spalte 2b des Anhangs 1 zur 4. $\mathrm{BImSchV}$ genehmigungsbedürftigen Schlachtanlage.

$\mathrm{Ob}$ ein Genehmigungsanspruch für die Errichtung, Erweiterung oder Änderung eines Handwerksbetriebs besteht, richtet sich, soweit es die $\mathrm{Zu}-$ lässigkeit eines solchen Vorhabens an einem bestimmten Standort anbelangt, nach den bauplanungsrechtlichen Zulässigkeitsbestimmungen der $\$ \mathbb{S} 29$ bis 36 BauGB. Um einen Handwerksbetrieb mit seinen baulichen Anlagen an einem bestimmten Standort in einer Gemeinde betreiben zu können, müssen die baulichen Anlagen und deren handwerkliche Nut- 
zung an dem vorgesehenen Standort bauplanungsrechtlich und nach dem einschlägigen Recht der Vorhabenzulassung zulässig sein.

\section{Standortentwicklung für Handwerksbetriebe nach dem BauGB 2017}

Für die Standortentwicklung, die in das Aufgabenfeld der für die städtebauliche Entwicklung zuständigen Gemeinden fällt, ist die bauplanungsrechtliche Zulässigkeit maßgebend, die nach den Vorschriften der $\$ \$ \$ 29$ bis 36 BauGB zu beurteilen ist.

Nach dem System des BauGB soll die Standortentwicklung grundsätzlich von den Gemeinden im Rahmen ihrer Planungshoheit mit den Mitteln der Bauleitplanung geleitet werden. Wenn es, wie nicht selten, unbeplante gemeindliche Bereiche innerhalb der Gemeinden gibt, für die kein Bebauungsplan existiert, richtet sich die bauplanungsrechtliche Zulässigkeit nach den gesetzlichen Planersatzregelungen der $\$ \$ \$ 34$ und 35 BauGB.

Im Bauplanungsrecht sind Handwerksbetriebe neben Gewerbebetrieben nur in $\$ 34$ Abs. $3 a$ S. 1 Nr. 1 und in $\$ 35$ Abs. 6 S. 2 BauGB erwähnt. Würde man nur die Vorschriften des BauGB zugrunde legen, könnte man aufgrund der Tatsache, dass Handwerks- und Gewerbebetriebe nebeneinander aufgeführt werden, zu der Schlussfolgerung verleitet sein, dass nach dem Städtebaurecht generell zwischen Handwerksbetrieben und Gewerbebetrieben zu unterscheiden sei. Schon die weiteren Vorschriften im BauGB, in denen nur das "Gewerbe“ begrifflich erwähnt ist, legen jedoch die Schlussfolgerung nahe, dass auch Handwerksbetriebe im Sinne der baurechtlichen Vorschriften Gewerbebetriebe sind. Denn soweit in $\$ 171 \mathrm{f}$. BauGB private Initiativen zur Stadtentwicklung geregelt sind, sind unter anderem auch "Gewerbezentren“ angesprochen, zu denen begrifflich auch Handwerksbetriebe gehören. Auch Handwerkszentren sind in diesem Sinne Gewerbezentren.

Soweit in der für eine Übergangszeit bis 31.12.2019 geltenden Sonderregelung für Flüchtlingsunterkünfte des $\$ 246$ Abs. 10 und Abs. 12 S. 1 Nr. 2 BauGB unter Bezugnahme auf die Baunutzungsverordnung (BauNVO) für in einem Bebauungsplan festgesetzte Gewerbegebiete die Zulassung von Aufnahmeeinrichtungen, Gemeinschaftsunterkünften oder sonstigen Unterkünften für Flüchtlinge oder Asylbegehrende erleichtert worden ist, ist mit den Gewerbegebieten ein in der BauNVO vorgesehener Baugebietstypus in Bezug genommen worden, in dem gem. $\$ 8$ Abs. 2 Nr. 1 BauNVO Gewerbebetriebe aller Art zulässig sind. Dies hatte zumindest in der Anfangszeit des am 26.11.2014 in Kraft getretenen $\$ 246$ Abs. 10 S. 1 BauGB 
zur Folge, dass auch Gebäude in einem Gewerbegebiet zu einer Gemeinschaftsunterkunft für Asylbegehrende und Flüchtlinge umgenutzt werden konnten. ${ }^{12}$

3. Die Bedeutung der in der BauNVO aufgeführten Baugebietstypen für die bauplanungsrechtliche Zulässigkeit von Handwerksbetrieben an bestimmten Standorten

a) Baugebietstypische Bestimmung der Zulässigkeit von Bauvorhaben

Die in den Vorschriften der $\mathbb{S} 1,2$ bis 9 BauNVO aufgeführten Baugebietstypen enthalten ein nach dem Störgrad differenziertes, speziell auf Handwerksbetriebe zugeschnittenes Zulässigkeitssystem. Werden die Baugebietstypen in einem Bebauungsplan festgesetzt, werden die Vorschriften der $\mathbb{S} 2$ bis 9 BauNVO nach Maßgabe des $₫ 1$ Abs. 3 S. 2 BauNVO Bestandteil des Bebauungsplans und bestimmen so über die Zulässigkeit eines Handwerksbetriebs innerhalb der geplanten Baugebiete.

Die Bestimmungen der $\mathbb{S} 2$ bis 9 BauNVO sind darüber hinaus auch dann für die bauplanungsrechtliche Zulässigkeitsbeurteilung relevant, wenn sich der für die Errichtung, Erweiterung oder Änderung eines Handwerksbetriebs (vgl. zum Vorhabenbegriff $\$ 29$ BauGB) vorgesehene Standort innerhalb des im Zusammenhang bebauten Ortsteils befindet und die Eigenart der näheren Umgebung des Vorhabens einem der Baugebiete entspricht, die in der BauNVO aufgeführt sind (zu den sog. faktischen Baugebieten siehe $\$ 34$ Abs. 2 BauGB).

12 Zur Nutzungsänderung für Flüchtlingsunterkünfte im Gewerbegebiet siehe BVerwG, Beschl. v. 27.02.2018, NVwZ 2018, 836 Rn. 7; OVG Münster, Beschl. v. 25.10.2018, 10 A 2167/17, BeckRS 2018, 26727; zum Entwurf des Gesetzes über Maßnahmen im Bauplanungsrecht zur Erleichterung der Unterbringung von Flüchtlingen und seiner Begründung siehe BT-Drucks. 18/2752 v. 08.10.2014; zum Entwurf des Asylverfahrensbeschleunigungsgesetzes BT-Drucks. 18/6185 v. 28.09.2015 und zur Rechtsentwicklung Spannowsky, in: Spannowsky/Uechtritz, BauGB, Kommentar, 43. Edition, Stand 01.11.2018, Rn. 7 ff. 
b) Von der Gebietsversorgungsfunktion abhängige Toleranzschwelle betrieblicher Störungen

In Bezug auf die Kleinsiedlungsgebiete und die allgemeinen Wohngebiete sind die Handwerksbetriebe gem. $₫ 2$ Abs. 2 Nr. 2 sowie $₫ 4$ Abs. 2 Nr. 2 BauNVO neben den der Versorgung dienenden Läden, Schank- und Speisewirtschaften ausdrücklich als in der Regel zulässige Nutzungen aufgeführt, aber nur, soweit sie nicht störend sind und der Gebietsversorgung dienen (Gebietsversorgungsklausel). Zulässig sind in allgemeinen Wohngebieten danach z. B. Handwerksbetriebstypen wie Friseure, Metzger und Bäcker klassischer Prägung, nicht aber Großbäcker oder Schlachtbetriebe. ${ }^{13}$

Anders ist die Zulässigkeit von nicht störenden Handwerksbetrieben nach der Regel- Ausnahme-Systematik der gebietstypischen Zulässigkeits-

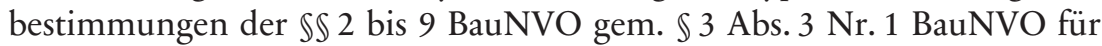
reine Wohngebiete geregelt. Gem. $\$ 3$ Abs. 3 Nr. 1 BauNVO gehören Handwerksbetriebe nicht zu der generell und ausschließlich in reinen Wohngebieten zulässigen gebietstypischen Hauptnutzungsart des Wohnens. Dazu zählen lediglich Wohngebäude und Anlagen zur Kinderbetreuung, die den Bedürfnissen der Bewohner eines Gebiets dienen. Nicht störende Handwerksbetriebe können in reinen Wohngebieten nur im Wege einer Ausnahme im Sinne von $\$ 31$ Abs. 1 BauGB zugelassen werden, wenn sie zusätzlich der Deckung des täglichen Bedarfs für die Bewohner des Gebiets dienen (Bedarfsdeckungsklausel). Diese Bedarfsdeckungsklausel dient dem Schutz der Wohnruhe in einem reinen Wohngebiet und ist enger als die Gebietsversorgungsklausel, welche die Zulässigkeit von Handwerksbetrieben in Kleinsiedlungsgebieten und allgemeinen Wohngebieten bestimmt. Auch nicht störende Handwerksbetriebe sind daher in reinen Wohngebieten nur sehr eingeschränkt zulässig, weil selbst nicht störende Handwerksbetriebe unter bestimmten Voraussetzungen nur ausnahmsweise und nur dann zulässig sind, wenn sie der gebietsbezogenen Deckung des täglichen Bedarfs dienen. In einem reinen Wohngebiet ist der Schutz der Wohnruhe im weitest gehenden Umfang ausgeprägt. Infol-

13 Siehe dazu Kormann, Zur Situation von Handwerksbetrieben nach geltendem Bauplanungsrecht, GewArch 2010, 396 (399); Scheidler, Abweichungen vom Bebauungsplan für Handwerks-, Gewerbe- und Industriebetriebe, GewArch Beilage WiVerw Nr. 02/2016, 65 (76) und Fickert/Fieseler, BauNVO, Köln, 1995, $\$ 2$ BauNVO, Rn. 20. 
gedessen sind gewerbliche Anlagen in reinen Wohngebieten auch nicht ausnahmsweise zulässig. ${ }^{14}$

c) Unterscheidung zwischen störenden und nicht störenden Handwerksbetrieben im Hinblick auf die Gebietsverträglichkeit

Ausschlaggebend für die Verträglichkeit von Handwerksbetrieben in Kleinsiedlungsgebieten, reinen und allgemeinen Wohngebieten ist die Unterscheidung zwischen störenden und nicht störenden Handwerksbetrieben. So können Steinmetz- und Zimmereibetriebe, Kfz-Werkstätten, Schlossereien und Schreinereien, Tischlereien und Lackierbetriebe grundsätzlich schon deshalb nicht zugelassen werden, weil sie unter Berücksichtigung des Primärzwecks dieser Baugebietstypen grundsätzlich als störende Handwerksbetriebe einzustufend sind..$^{15}$

Für die Einstufung als wesentlich störende Betriebe ist in der Regel nicht das konkrete Vorhaben, sondern nach einer typisierenden Betrachtung das Erscheinungsbild der typischen Nutzungsweise maßgebend. ${ }^{16} \mathrm{Da}-$ bei kann der mit dem Betrieb typischerweise verbundene $\mathrm{Zu}$ - und $\mathrm{Ab}$ gangsverkehr nach der Rechtsprechung des BVerwG Bedeutung erlangen. Typischerweise erzeugen störende Handwerksbetriebe Lärm, Staub oder Gerüche und es entstehen betriebsbedingt typischerweise Be- und Entladevorgänge.

Lediglich bei atypischen Fallgestaltungen kann ausnahmsweise die Beurteilung als nicht störender Handwerksbetrieb gerechtfertigt sein. ${ }^{17}$ Dies ist dann der Fall, wenn der konkrete Betrieb in der Weise von einem gebietsunverträglichen Typus abweicht, dass er nach seiner Art und Betriebsweise nicht den anlagentypischen Belästigungsgrad aufweist. ${ }^{18}$

14 OVG Bln-Bbg, BeckRS 2012, 48745 und Hornmann, in Spannowsky/Hornmann/ Kämper (Hrsg.), BauNVO, 2018, \$3 Rn. 19.

15 So BayVGH, Urt. v. 15.03.2017, 2 N 15.619, juris Rn. 44.

16 Siehe BayVGH, Beschl. v. 06.02.2017, 15 ZB 16.398 unter Hinweis auf BVerwG, Beschl. v. 09.10.1990, 4 B 121.90, NVwZ 1991, 267.

17 So BVerwG, Urt. v. 07.05.1971, IV C 76.68, NJW 1971, 1626 bezüglich einer Tischlerei.

18 Vgl. BVerwG, NVwZ 1993, 987; BVerwG 2014, 2080 und OVG Lüneburg, BauR $2015,947 \mathrm{f}$. 
d) Kombination von Gebietsversorgungsfunktion und Störgrad zur Bestimmung der Gebietsverträglichkeit von Handwerksbetrieben in Dorfgebieten

In Dorfgebieten gehören der Versorgung des Gebiets dienende Handwerksbetriebe unabhängig von ihrem Störungsgrad allgemein zur gebietstypischen charakteristischen Hauptzwecksetzung. Insofern ist im Rahmen des $₫ 5$ BauNVO bezüglich Dorfgebieten eine interessante Differenzierung zwischen Handwerksbetrieben vorgenommen worden, die der Versorgung der Bewohner des Gebiets dienen, und nicht wesentlich störenden Handwerksbetrieben, die keine gebietsbezogene Versorgungsfunktion aufweisen. Während Handwerksbetriebe, die der Versorgung des Gebiets dienen, störend und sogar wesentlich störend sein dürfen, ohne dass ihre Zulässigkeit im Dorfgebiet berührt wird (z. B. eine Kfz-Werkstatt mit Gebietsversorgungsfunktion), ${ }^{19}$ gilt für Gewerbebetriebe und Handwerksbetriebe ohne Gebietsversorgungsfunktion eine Einschränkung. Gewerbebetriebe und Handwerksbetriebe ohne Gebietsversorgungsfunktion sind danach nur allgemein zulässig, wenn sie nicht wesentlich störend sind. Dies ist mit der Folge verbunden, dass in einem Dorfgebiet sowohl nicht wesentlich störende als auch störende Handwerksbetriebe zulässig sind; letztere aber nur, soweit sie der Versorgung der Bevölkerung des Gebiets dienen. Dazu können für Dorfgebiete typische „Dorfschmieden“, Zimmereien, Tischlereien, Schlossereien und Landmaschinenreparaturwerkstätten gehören. ${ }^{20}$

e) Bestimmung der Gebietsverträglichkeit von Handwerksbetrieben ausschließlich nach dem Störungsgrad in besonderen Wohngebieten, Misch-, Kern-, urbanen Gebieten und Gewerbegebieten

Eine erweiterte Zulässigkeit innerhalb der Kategorie der Wohngebiete gibt es für Handwerksbetriebe in Gebieten zur Erhaltung und Entwicklung der Wohnnutzung gem. $\$ 4$ a BauGB. In diesen Gebieten können neben den nicht wesentlich störenden, unter dem Begriff „sonstige Gewerbebetriebe“ erfassten Handwerksbetrieben, auch Handwerksbetriebe mit einem gewis-

19 Siehe dazu VGH Mannheim, GewArch 2002, $497 \mathrm{f}$.

20 Dazu mit weiteren Beispielen Karber, in: Spannowsky/Hornmann/Kämper

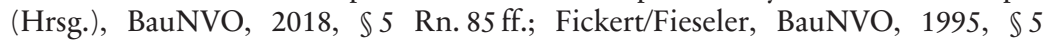
Rn. 19.1 ff.; Kormann, GewArch 2010, 396 (399) und Scheidler, GewArch Beilage WiVerw Nr. 02/2016, 65 (80). 
sen Störpotential zulässig sein, soweit sie sich nach der besonderen Eigenart des besonderen Wohngebiets als mit der Wohnnutzung vereinbar im Sinne von verträglich erweisen, wie z. B. kleinere Kfz-Werkstätten und Installationsbetriebe. ${ }^{21}$

Die Zulässigkeit von Handwerksbetrieben in Misch- und Kerngebieten richtet sich nur nach dem Störungsgrad des Betriebs (siehe $\$ 6$ Abs. 2 Nr. 4 und $\$ 7$ Abs. 2 Nr. 3 BauNVO). Eine den generellen Zulässigkeitstatbestand und die gebietstypische Hauptnutzungsart einschränkende Gebietsversorgungs- bzw. Bedarfsdeckungsklausel ist bezüglich der Misch- und Kerngebiete - anders als bei den Kleinsiedlungsgebieten, den allgemeinen Wohngebieten und den Dorfgebieten - nicht vorhanden; auch nicht in Gestalt einer Bestimmung der ausnahmsweise zulässigen Nutzungsarten wie bei reinen Wohngebieten nach $₫ 3$ Abs. 2 Nr. 1 BauGB. D. h., dass in Misch- und Kerngebieten nicht wesentlich störende Handwerksbetriebe zulässig sind, soweit sie als gewerbliche Nutzung mit der im Mischgebiet prinzipiell gleichrangig als Hauptnutzungsart angestrebten Wohnnutzung und im Kerngebiet mit den gebietstypisch erstrebten Hauptnutzungsarten, der Unterbringung von Handelsbetrieben sowie der zentralen Einrichtungen der Wirtschaft, der Verwaltung und der Kultur, vereinbar sind. Aufgrund der gebietstypischen Nutzungsmischung ist der vorsorgende Schutz der Wohnnutzung gebietstypisch reduziert. ${ }^{22}$ Wegen des bezweckten Nebeneinanders von gewerblicher Nutzung und Wohnnutzung muss seitens der Wohnnutzung ein höherer Störungsgrad geduldet werden als in den primär dem Wohnen dienenden Gebieten.

Aus der Regelungssystematik der BauNVO erschließt sich, dass Handwerksbetriebe, die nicht schon aufgrund ihrer expliziten Erwähnung in bestimmten baugebietstypischen Zulässigkeitstatbeständen als zulässige Nutzungsform geregelt sind, städtebaurechtlich in die Kategorie der Gewerbebetriebe fallen, die generell in Gewerbegebieten zulässig sein sollen. Denn die Gewerbegebiete erfüllen für Handwerksbetriebe, welche die Wohnnutzung wesentlich stören, eine Auffangfunktion. Die Wohnnutzung wesentlich störende Handwerksbetriebe sind danach wie sonstige störende Gewerbebetriebe, welche die Wohnnutzung wesentlich stören, generell in Gewerbegebieten zulässig. Sie dürfen nur nicht den höchsten Störgrad, der nach dem Regelungssystem der BauNVO für die Klassifizierung von Ge-

21 Hornmann, in: Spannowsky/Hornmann/Kämper (Hrsg.), BauNVO 2018, $\mathbb{4} 4$ a, beschreibt diese als „wohnnutzungskonforme Gewerbebetriebe“.

22 Mischgebiet ist ein Standort sowohl für gewerbliche wie für Wohnnutzung (dazu BVerwG, NVwZ 1986, 643). 
werbebetrieben bestimmt ist, erreichen, den der erheblichen Belästigung. Gewerbebetriebe, welche mit erheblichen Belästigungen verbunden sind, und die deshalb in anderen Baugebieten unzulässig sind, sind gem. $\mathbb{} 8$ Abs. 1 i. V. mit $\mathbb{9}$ Abs. 1 BauNVO in Industriegebieten zulässig. Dagegen scheidet die Anwendung von Sondergebieten für die Unterbringung von Handwerksbetrieben grundsätzlich aus, da diese Baugebietskategorie nur zur Anwendung kommen darf, wenn sich das in Betracht kommende „sonstige Sondergebiet“ im Sinne des $\$ 10$ Abs. 1 BauNVO von den Baugebieten nach den $\mathbb{S} 2$ bis 10 BauNVO wesentlich unterscheidet. ${ }^{23}$ Bei der Planung eines Gewerbe- bzw. Handwerksparks wäre dies nicht der Fall, weil dafür die Ausweisung eines Gewerbegebiets zur Verfügung steht.

f) Das urbane Gebiet - ein gemischtes Baugebiet ohne typisierende Festlegung des Umfangs der Nutzungsmischung

Hinzugekommen ist neuerdings der Baugebietstyp des urbanen Gebiets, der regelungssystematisch gem. $\$ 6$ a BauNVO zwischen dem Mischgebiet und dem Gewerbegebiet eingegliedert worden ist. Dies ist mit der Folge verbunden, dass der Störungsgrad in Bezug auf die Lärmemissionen, die von einem Handwerksbetrieb ausgehen, in einem urbanen Gebiet größer sein kann als in einem Mischgebiet.

Was im Mischgebiet wegen der erstrebten Gleichrangigkeit von Wohnen und Gewerbe mit dem Wohnen nicht mehr vereinbar ist, kann in einem urbanen Gebiet, soweit dieses stärker gewerblich geprägt ist und soweit dieses nach dem Erscheinungsbild der Nutzungsmischung stärker einem Gewerbegebiet ähnelt, zulässig sein, wenn der Störgrad nicht den Grad einer wesentlichen Störung des gebietstypischen Wohnens in einem urbanen Gebiet oder gar den einer erheblichen Belästigung erreicht, die auch in einem Gewerbegebiet unzulässig wäre.

Bei einem urbanen Gebiet, das nach Art und Umfang eine sehr unterschiedliche Nutzungsmischung zwischen verschiedenen Hauptnutzungen aufweisen kann, resultiert daraus, dass die Grenze des zumutbaren Störgrads im Baugenehmigungsverfahren nicht unabhängig von der konkreten gebietsprägenden Nutzungsmischung bestimmt werden kann, eine Unsicherheit in Bezug auf die rechtliche Zulässigkeit eines Gewerbe- bzw. Handwerksbetriebs im Einzelfall. Es kann gebietstypisch lediglich festgehalten werden, dass dadurch, dass für urbane Gebiete die Lärmvorsorge

23 Vgl. dazu OVG Schleswig, NordÖR 2002, 155 ff. 
durch die Annäherung der Tag-Lärmwerte an diejenigen für Kern- und Gewerbegebiete im Vergleich zum Mischgebiet reduziert worden ist, auch für lärmintensivere Handwerksbetriebe die Standorteignung in urbanen Gebieten eher als in Mischgebieten gegeben sein kann. Es stellt sich daher die Frage, für welche Handwerksbetriebe diese Lockerung der Lärmwerte Bedeutung erlangen kann.

Für die Bestimmung der Gebietsverträglichkeit von Handwerksbetrieben in urbanen Gebieten ist zunächst einmal maßgebend, dass in diesen Gebieten im Vergleich zu Mischgebieten nur eine wohnnutzungsbezogene Absenkung des Umweltvorsorgestandards in Bezug auf den Lärm vorgenommen worden ist. Daraus folgt, dass z. B. ein Lackierbetrieb, der im Mischgebiet wegen seiner Staub- und Lösungsmittelemissionen wegen der vorhandenen Wohnnutzung nicht gebietsverträglich und deshalb unzulässig ist, ${ }^{24}$ auch in einem urbanen Gebiet, das überwiegend von der Wohnnutzung geprägt ist, nicht bessergestellt ist. Anders kann dies aber in urbanen Gebieten sein, welche überwiegend von der gewerblichen Nutzung geprägt sind.

Durch die Einführung der urbanen Gebiete ist der Gebietswahrungsanspruch im Verhältnis zwischen gewerblicher Nutzung und Wohnnutzung in seiner innergebietlichen Tragweite in Bezug auf Lärm eingeschränkt worden. Er kann nur noch eine äußerste Zumutbarkeitsgrenze markieren und dürfte nur zu aktivieren sein, wenn das gebietstypische Wohnen mit seiner in Bezug auf Lärm herabgesetzten Schutzwürdigkeit unzumutbar durch das jeweilige Vorhaben eingeschränkt wird.

Die Schlussfolgerung, wonach die Schutzwürdigkeit des Wohnens und damit die Reichweite des Gebietswahrungsanspruchs in Bezug auf das urbane Gebiet im Vergleich zu anderen Gebietstypen, in denen das Wohnen zu den gebietsprägenden Hauptnutzungen gehört, reduziert ist, resultiert aus der systematischen Abstufung der Schutzwürdigkeit des gebietstypischen Wohnens vom reinen Wohngebiet, über das allgemeine und besondere Wohngebiet, über das Dorf-, Kern- und Mischgebiet (60 dB (A)) hin zum urbanen Gebiet (63 dB (A)).

24 Siehe dazu VG Augsburg, Urt. v. 09.05.2016, Au 5 K 15.1027, juris. 
g) Veränderte Systematik der Gebietstypen mit Konsequenzen für die Schutzwürdigkeit des Wohnens

Die Systematik der Gebietstypen zeigt, dass die Schutzwürdigkeit des gebietstypischen Wohnens davon abhängt, welcher zulässige Störungsgrad dem jeweiligen Gebietstyp zugeordnet ist, wobei sich die Gebietstypen diesbezüglich danach unterscheiden, welche Arten gebietstypischer Nutzungen überhaupt und in welchem Umfang diese nach der BauNVO gebietstypisch zulässig sind.

Davon ausgehend ist die Schutzwürdigkeit des Wohnens in einem urbanen Gebiet in Bezug auf die Lärmvorsorge im Vergleich zu den Gebieten, deren Charakter typischerweise durch das Wohnen mitgeprägt wird, am geringsten. Lediglich in Gewerbegebieten, in denen nur das betriebsbezogene Wohnen oder vorübergehend und ausnahmsweise die Unterbringung von Flüchtlingen und Asylbegehrenden vorgesehen ist, ist die Schutzwürdigkeit des Wohnens noch weiter reduziert. ${ }^{25}$

Nach der Rechtsprechung ist hinsichtlich der Gebietsverträglichkeit eines Betriebstyps nicht ausschlaggebend, dass der betreffende Handwerksbetrieb die mit der Nutzung verbundenen immissionsschutzrechtlich vorgegebenen Lärmwerte einhalten kann; ${ }^{26}$ wenn er dies nicht kann, spräche diese Tatsache bei einem urbanen Gebiet allerdings gegen seine Gebietsverträglichkeit. Denn kann ein Gewerbebetrieb die für das urbane Gebiet maßgeblichen erhöhten Immissionsrichtwerte von $63 \mathrm{~dB}(\mathrm{~A})$ nicht einhalten, bewegt sich der Betrieb für das Dauerwohnen bereits jenseits des gesundheitsrelevanten Grenzbereichs (dazu unten E. II. 1.).

Für die Gebietsverträglichkeit eines Handwerks- und Gewerbebetriebs ist, wenn der Betrieb, dessen Zulässigkeit zu beurteilen ist, die immissionsschutzrechtlich vorgegebenen Lärmwerte einhält, nach der Rechtsprechung maßgebend, ob sich der räumliche Umfang, die Größe des Einzugsbereichs des Handwerksbetriebs, die Art und Weise der Betriebsvorgänge, der vorhabenbedingte An- und Abfahrtsverkehr, die zeitliche Dauer der Auswirkungen und ihre Verteilung auf Tages- und Nachzeiten des Handwerksbetriebs noch im gebietsverträglichen Rahmen bewegt. ${ }^{27}$

25 Siehe dazu VGH München, Urt. v. 14.02.2018, 9 BV 16.1694, BeckRS 2018, 2372 und OVG Münster, Beschl. v. 23.02.2015, 7 B 1343/14, KommJur 2015, 149.

26 So ausdrücklich BVerwG, NVwZ 2002, 1118f. und VG Augsburg, Urt. v. 10.11.2010, Au 4 K 10.665, juris Rn. 28.

27 So zutreffend das VG Augsburg, Urt. v. 10.11.2010, Au 4 K 10.665, juris Rn. 68. 
Bei einem urbanen Gebiet dürfte aber ein zusätzlicher Prüfungsschritt hinzukommen. Ob ein bestimmter Handwerks- oder Gewerbebetriebstyp in Bezug auf ein urbanes Gebiet die erforderliche Gebietsverträglichkeit aufweist, dürfte zudem davon abhängen, welche konkrete Ausprägung das jeweilige urbane Gebiet aufweist. Denn es ist nach $\$ 6$ a BauNVO eine groBe Bandbreite gebietstypischer Erscheinungsformen eines urbanen Gebiets möglich. So kann das eine urbane Gebiet weitgehend von Gewerbebetrieben geprägt sein, das andere weitgehend vom Wohnen, ein weiteres wiederum von den ebenfalls unter die Hauptnutzungsarten dieses Gebietstyps fallenden sozialen, kulturellen und anderen Einrichtungen.

Es könnte folglich ausgehend von dem beschriebenen System der Gebietstypisierung in einem urbanen Gebiet durchaus vorkommen, dass ein metallverarbeitender Betrieb mit spezialisierten Angeboten, der bislang unter dem Aspekt der Gebietsverträglichkeit als ein das Wohnen im Mischgebiet wesentlich störender Gewerbebetrieb betrachtet worden ist, ${ }^{28}$ in einem urbanen Gebiet zulässig ist, in dem der gewerbliche Anteil groß ist, soweit er innerhalb dieses Gebiets nicht gerade in der Nachbarschaft zum Wohnen untergebracht werden soll. Bei einem überwiegend vom Wohnen geprägten urbanen Gebiet dürfte dies nach den differenzierten Maßstäben der Gebietsverträglichkeit vor dem Hintergrund der zu beachtenden gesundheitskritischen Schwelle anders zu beurteilen sein.

4. Entwicklung, Erhaltung und Erweiterung von Standorten für Handwerksbetriebe in unbeplanten Gebieten innerhalb im Zusammenhang bebauter Ortsteile gem. $\$ 34$ BauGB

In einem unbeplanten Innenbereich im Sinne von $\$ 34 \mathrm{Abs.} 1 \mathrm{BauGB}$, also in einem Entwicklungsbereich innerhalb eines im Zusammenhang bebauten Ortsteils, für den es keinen Bebauungsplan gibt, richtet sich die bauplanungsrechtliche Zulässigkeit hinsichtlich der Art der baulichen Nutzung gem. $\$ 34$ Abs. 2 BauGB dann, wenn die Eigenart der näheren Umgebung einem der in $\$ \$ 1$ Abs. 2, 2 bis 9 genannten Baugebiete entspricht, allein nach den für die Baugebietstypen gemäß der BauNVO geltenden $\mathrm{Zu}-$ lässigkeitsbestimmungen.

Der Gesetzgeber hat damit für den Fall, dass die faktische Gebietsentwicklung innerhalb eines im Zusammenhang bebauten Ortsteils, für den es keinen Bebauungsplan gibt, einem Baugebietstyp entspricht, entschie-

28 Siehe dazu VG Augsburg, Urt. v. 10.11.2010, Au 4 K 10.665, juris Rn. 68. 
den, dass die Zulässigkeit von Vorhaben, die in einem solchen Gebiet innerhalb des Innenbereichs realisiert werden sollen, nach den gleichen Beurteilungsmaßstäben zu beurteilen ist, wie wenn die Gemeinde das Baugebiet planerisch in einem Bebauungsplan festgesetzt hätte.

Dies hat für die Beurteilung der bauplanungsrechtlichen Zulässigkeit von Handwerksbetrieben in einem faktischen Baugebiet im Innenbereich im Sinne des $\$ 34$ Abs. 2 BauGB zur Folge, dass ein Handwerksbetrieb, der seiner Art nach gemäß der Gebietszuordnung innerhalb des jeweiligen Baugebietstyps allgemein zulässig wäre, ohne weiteres auch in einem solchen faktischen Baugebiet zulässig ist. Ist dies bei einem bestimmten Vorhaben nicht der Fall, ist $₫ 31$ BauGB gem. $\$ 34$ Abs. 2 Hs. 2 BauGB auch auf die Zulässigkeit von Vorhaben im faktischen Baugebiet anwendbar. D. h., dass das Vorhaben, wenn es ausnahmsweise in dem Baugebiet zulässig sein kann, unter den Voraussetzungen des $\$ 31$ Abs. 1 BauGB im faktischen Baugebiet zugelassen werden kann. Eine Befreiung kann nur unter engeren Voraussetzungen in Betracht kommen, scheidet jedoch aus, wenn der sich aus der tatsächlich vorhandenen Bebauung ergebende Gebietscharakter verändert wird.

Dabei ist jedoch zu beachten, dass dann, wenn die faktisch vorzufindende Nutzungsmischung der eines urbanen Gebiets entspricht, demjenigen, welcher in einem solchen Gebiet die Zulässigkeit für einen Handwerksbetrieb erstrebt, die Erleichterung der gemäß $₫ 34$ Abs. 2 BauGB vorgesehenen Zulässigkeitsbeurteilung nach der Art der baulichen Nutzung aufgrund der gesetzlichen Regelung gem. $\$ 245 \mathrm{c}$ Abs. 3 BauGB nicht zugutekommt. Denn nach dieser Bestimmung gilt $\$ 34$ Abs. 2 BauGB für urbane Gebiete gerade nicht. Angesichts des unstrukturierten und quantitativ nicht feststehenden Mischungsverhältnisses, das in einem urbanen Gebiet auftreten kann, wurde mit der gesetzlichen Festlegung gem. $\$ 245$ c Abs. 3 BauGB der Gefahr der "Sprengung" des Zulässigkeitsrahmens und der Preisgabe der Systematik der Regelungsstruktur des $\$ 34$ BauGB dadurch begegnet, dass die Anwendbarkeit des $\$ 34$ Abs. 2 BauGB ausgeschlossen wurde. Dies bedeutet, dass die Beurteilung der Zulässigkeit von Vorhaben im Fall des Vorhandenseins einer faktischen Nutzungsmischung, falls eine Zuordnung des Gebiets zu einem der anderen typisierten gemischten Gebiete der BauNVO nicht möglich ist, anhand des in $\$ 34$ Abs. 1 BauGB festgelegten Beurteilungsmaßstabs, ob sich das Vorhaben in die nähere Umgebung einfügt, erfolgen muss.

Unter dem Aspekt der Flexibilität der Beurteilung der Zulässigkeit nach der Art der baulichen Nutzung bringt die Einzelfallbetrachtung nach $\$ 34$ Abs. 1 BauGB andererseits zwar einen gewissen, aber keinen wesentlichen 
Vorteil. Denn auch dann, wenn in einem typisierten faktischen Baugebiet bestimmte Handwerksbetriebe in dem bebauungsplanerisch festgesetzten bzw. faktischen Baugebiet nicht generell zulässig sind, ist nicht ausgeschlossen, dass das Vorhaben nicht gleichwohl ausnahmsweise zulässig sein oder im Einzelfall eine Befreiung im Sinne von $\$ 31$ Abs. 2 BauGB (ggf. i.V.m. $\$ 34$ Abs. 2 Hs. 2 BauGB) in Betracht kommen kann. Für die notwendige Flexibilität sorgt insofern $\mathbb{3} 31$ BauGB, der nach Abs. 1 zum einen die Möglichkeit der Zulassung von Ausnahmen bei Vorliegen eines der in den $\mathbb{S} 2$ bis 9 BauNVO geregelten Ausnahmeregelungen eröffnet, und der nach Abs. 2 zum anderen auch Befreiungen im Einzelfall ermöglicht. Es müssen hierfür jedoch nicht nur die Voraussetzungen einer Ausnahme im Sinne von $₫ 31$ Abs. 1 BauGB oder einer Befreiung im Sinne von $\$ 31$ Abs. 2 BauGB erfüllt sein, sondern es muss vielmehr auch der Gebietscharakter bei der Zulassung von Abweichungen gewahrt bleiben. Dies führt bei der Zulassung von Abweichungen in faktischen Baugebieten zugunsten störender Betriebe zur Aktivierung des Gebietswahrungsanspruchs zugunsten von Hauptnutzern, welche wegen ihrer Sensibilität geschützt sind.

Nach Einführung des urbanen Gebiets ist es infolgedessen in Zukunft im Fall des Vorliegens einer faktischen Bebauung, welcher dem Gebietscharakter eines urbanen Gebiets entspricht, weitgehend ausgeschlossen sein, einen störenden Handwerksbetrieb mit der Begründung als unzulässig zu betrachten, der Gebietscharakter werde verändert. Denn - anders als bei einem Mischgebiet - wird eine ungefähre Gleichverteilung der Durchmischung im Verhältnis von Wohnnutzung und gewerblicher Nutzung nicht vorausgesetzt. Lässt sich eine Gebietszuordnung nicht vornehmen, ist der Beurteilungsmaßstab gem. $\$ 34$ Abs. 1 BauGB allein aus der in der näheren Umgebung des Vorhabens vorhandenen tatsächlichen Bebauung zu entnehmen. Dabei geht es nicht um die Wahrung eines irgendwie gearteten Gebietscharakters, sondern vielmehr darum, dass in der Umgebungssituation des Vorhabens keine bodenrechtlich beachtlichen Spannungen ausgelöst werden dürfen.

Bezüglich des an der tatsächlichen Umgebungsbebauung ausgerichteten Kriteriums des Einfügens ist überdies eine gesetzliche Lockerung dadurch herbeigeführt worden, dass ein Vorhaben selbst dann, wenn es dem aus der Umgebungsbebauung abzuleitenden Beurteilungsmaßstab hinsichtlich der Art und des Maßes der baulichen Nutzung, der Bauweise und der Grundstücksfläche, die überbaut werden soll, nicht entspricht, noch als mit dem Erfordernis des Einfügens vereinbar angesehen werden kann, falls es seiner Art nach bestimmte erwünschte städtebauliche Zwecke erfüllt. 
Gem. $\int 34$ Abs. 3a S. 1 BauGB kann nämlich unter anderem in Bezug auf Handwerksbetriebe von dem Erfordernis des Einfügens abgewichen werden, wenn das Vorhaben der Erweiterung, Änderung, Nutzungsänderung oder Erneuerung eines zulässigerweise errichteten Handwerksbetriebs dient. Diese Zulässigkeitserweiterung zur Förderung der Erhaltung von Gewerbe- und Handwerksbetrieben in Gemengelagen wurde bereits mit dem BauGB 2004 vorgesehen.

Während durch die Zulässigkeitserweiterung in $\$ 34$ Abs. 3a S. 1 Nr. 1a BauGB die Nutzungsänderung von einer Gewerbe- und Handwerksnutzung hin zur Wohnnutzung ermöglicht wird, ist eine Umnutzung in umgekehrter Richtung, also von der Wohnnutzung zur Gewerbe- und Handwerksnutzung, davon nicht erfasst. Es handelt sich bei der die Wohnnutzung privilegierenden Zulässigkeitsbestimmung des $\$ 34$ Abs.3a S. 1 Nr. 1a BauGB allerdings durchaus um eine systemkonforme gesetzliche Wertung, weil es dann, wenn stattdessen gesetzlich die erweiterte Umnutzung von einer Wohnnutzung in Richtung Gewerbe- und Handwerksnutzung zugelassen würde, konfliktbedingt eher zu bodenrechtlich beachtlichen Spannungen kommen könnte. Im Rahmen der gesetzlichen Planersatzregelung des $₫ 34$ BauGB ließe sich dann aber ein solcher Konflikt - anders als durch die Bebauungsplanung - in der Regel nicht bewältigen. Eine weitere Lockerung des gesetzlichen Beurteilungsmaßstabs des Einfügens in die nähere Umgebung dürfte daher kaum zu rechtfertigen sein. Insofern sind der gesetzlichen Erweiterung des Zulässigkeitsmaßstabs des $\$ 34$ Abs. 1 BauGB zugunsten der erweiterten Zulassung von Gewerbeund Handwerksbetrieben im Innenbereich Grenzen gesetzt.

5. Standortentwicklung auf der Basis von Innenbereichssatzungen gem.

\34 Abs. 4 S. 1 Nr. 1 bis 3 BauGB

Die Funktion der sog. Innenbereichssatzungen im Sinne von $\mathbb{3} 34$ Abs. 4 S. 1 Nr. 1 bis Nr. 3 BauGB besteht darin, für die Zulässigkeitsbestimmung von Vorhaben, welche in bestimmten Bereichen, die an den im Zusammenhang bebauten Ortsteil angrenzen, verwirklicht werden sollen, den Beurteilungsmaßstab des $₫ 34$ BauGB zur Anwendung zu bringen. Dazu können deklaratorisch klarstellend bestimmte Bereiche als dem Innenbereich zugehörend festgelegt werden und unter bestimmten Voraussetzungen bebaute Bereiche im Außenbereich als im Zusammenhang bebaute Ortsteile festgelegt und einzelne Außenbereichsflächen in die im Zusammenhang bebauten Ortsteile einbezogen werden. Ist der Beurteilungsmaß- 
stab des $₫ 34$ BauGB durch eine solche Innenbereichssatzung zur Anwendung gebracht worden, kommen hinsichtlich der Zulässigkeit von Handwerksbetrieben prinzipiell die gleichen gesetzlichen Beurteilungsmaßstäbe zur Anwendung, wie sie oben dargelegt worden sind. Allerdings handelt es sich bei den Entwicklungs- und Ergänzungssatzungen im Sinne von $\$ 34$ Abs. 4 S. 1 Nr. 2 und 3 BauGB um Planungsinstrumente. Denn diesbezüglich besteht die Möglichkeit, dass unter anderem auch einzelne Festsetzungen zur Art der baulichen Nutzung getroffen werden können. Es können also in den Innenbereichssatzung nach $₫ 34$ Abs. 4 S. 1 Nr. 2 und 3 BauGB auch planerische Festsetzungen zur Zulässigkeit von Handwerksbetrieben getroffen werden.

\section{Standortentwicklung für Handwerksbetriebe im Außenbereich im Sinne von $\$ 35$ BauGB}

Dagegen besteht für den Außenbereich, also für unbeplante Flächen im Freiraum, die nicht in einem zusammenhängend bebauten Ortsteil liegen, die aus $₫ 35$ BauGB abzuleitende grundsätzliche Regelungsvermutung, wonach nicht privilegierte oder begünstigte Außenbereichsvorhaben sonstige Vorhaben sind, die im Regelfall wegen des Vorliegens einer Beeinträchtigung öffentlicher Belange unzulässig sind. Denn wie Wohngebäude so sind auch die baulichen Anlagen eines Handwerksbetriebs nach der Regelungssystematik des $\$ 35$ BauGB sonstige, D. h. nicht privilegierte, Vorhaben im Sinne von $\$ 35$ Abs. 2 BauGB mit der Folge, dass solche Vorhaben im Außenbereich unzulässig sind, wenn auch nur einer der in $\$ 35$ Abs. 3 S. 1 BauGB umfangreich aufgelisteten öffentlichen Belange beeinträchtigt wird. Es gibt zwar unter den engen Voraussetzungen der sog. begünstigten Vorhaben im Sinne von $\$ 35$ Abs. 4 BauGB auch die Möglichkeit, einen zulässigerweise errichteten gewerblichen Betrieb zu erweitern, jedoch sind die Möglichkeiten zur Standortentwicklung für Handwerksbetriebe im Außenbereich nach dem BauGB eingeschränkt.

Dazu kommen weitere naturschutzrechtliche und raumordnungsrechtliche Beschränkungen, welche zu einer Einschränkung der kommunalen Planungshoheit führen (vgl. $\ 1$ Abs. 3 BauGB, beispielsweise i. V. mit $\$ 78$ WHG, $\mathbb{S} 34$ und $36 \mathrm{BNatSchG}$, und $\mathbb{} 1$ Abs. 4 BauGB i. V. mit entsprechenden Zielen der Raumordnung). Bezüglich des Raumordnungsrechts ist für die städtebauliche Entwicklung vor allem die bundesgesetzliche Planungsanforderung des $\$ 2$ Abs. 2 Nr. 6 S. 3 ROG von Bedeutung, die mit dem am 29.11.2017 in Kraft getretenen Änderungsgesetz zum Raumord- 
nungsgesetz in Gestalt eines bundesgesetzlichen Grundsatzes der Raumordnung in das ROG eingefügt worden ist. Gem. $\$ 2$ Abs. 2 Nr. 6 S. 3 ROG ist die erstmalige Inanspruchnahme von Freiraum für Siedlungs- und Verkehrszwecke zu verringern; und zwar insbesondere durch quantifizierte Vorgaben zur Verringerung der Flächeninanspruchnahme sowie durch die vorrangige Ausschöpfung der Potenziale für andere Maßnahmen zur Innenentwicklung der Städte und Gemeinden sowie zur Entwicklung vorhandener Verkehrsflächen. Diese Planungsanforderung ist vor allem an die Träger der Raumordnungsplanung, aber auch an die Städte und Gemeinden adressiert.

7. Standortentwicklung für Handwerksbetriebe im Außenbereich auf der Basis einer sog. Außenbereichssatzung gem. $\$ 35$ Abs. 6 BauGB

Mittels einer Außenbereichssatzung kann für bebaute Bereiche im Außenbereich, die nicht überwiegend landwirtschaftlich geprägt sind und in denen eine Wohnbebauung von einigem Gewicht vorhanden ist, durch Satzung der Zulässigkeitsrahmen in gewissem, aber beschränktem Umfang erweitert werden. Gem. $\ 35$ Abs. 6 S. 2 BauGB kann die Satzung auch zur Förderung von Vorhaben kleinerer Handwerks- und Gewerbebetriebe eingesetzt werden. Auf diese Weise kann eine Ortsteilentwicklung ausgelöst werden, soweit dies in Einklang mit raumordnungsplanerischen Vorgaben und etwaigen naturschutzrechtlichen Beschränkungen gebracht werden kann. Jedoch können mittels einer Außenbereichssatzung nur die Zulässigkeitsvoraussetzungen für „kleinere“ Handwerks- und Gewerbebetriebe im Außenbereich geschaffen werden, wo bereits ein gewisser Bestand an Wohnbebauung vorhanden ist. Daraus folgt wiederum, dass an diesen Standorten im Geltungsbereich einer Außenbereichssatzung nur kleinere Handwerks- und Gewerbebetriebe, die mit der vorhandenen Wohnnutzung in Einklang gebracht werden können, zulässig sein können. ${ }^{29}$

29 Ebenso Scheidler, Bauen im Außenbereich auf der Grundlage einer Satzung nach $\$ 35$ Abs. 6 BauGB, ZfBR 2018, 444 f.; ders., Die bauplanungsrechtliche Zulässigkeit kleinerer Handwerks- und Gewerbebetriebe auf Grundlage einer Außenbereichssatzung, GewArch 2018, 455 ff. und Decker, in: Simon/Busse, Bayerische Bauordnung, 131. EL Oktober 2018, Art. 82, Rn. 41 ff. 
8. Aufgabe und Funktion der Bauleitplanung bei der Standortentwicklung für Handwerksbetriebe

Nach dem geltenden Städtebaurecht kommt der Bauleitplanung bei der Standortentwicklung für Handwerksbetriebe eine zentrale Rolle zu. Die Aufgabe der Bauleitplanung besteht darin, geeignete Standorte für diese Nutzung verfügbar zu machen. Bauleitplanung soll ihre Funktion vor allem dann entfalten, wenn über die gesetzlichen Planersatzregelungen und die städtebaulichen Innenbereichs- oder Außenbereichssatzungen, welche den Anwendungsbereich der Maßstabsfunktion der gesetzlichen Planersatzregelungen erweitern, keine bauplanungsrechtliche Zulässigkeit für die Errichtung, Erweiterung oder Änderung von Handwerksbetrieben gegeben ist. In diesem Fall kann Baurecht nur durch einen Bebauungsplan geschaffen werden; für die städtebauliche Entwicklung ist in diesem Fall die Bauleitplanung erforderlich ( $\int 1$ Abs. 3 BauGB). Dies heißt im Umkehrschluss, dass eine Bauleitplanung entbehrlich ist, je größer der Anwendungsbereich der bauplanungsrechtlichen Zulässigkeitstatbestände der $\iint 34$ und 35 BauGB ist.

Der Anwendungsbereich dieser Vorschriften ist entgegen der ursprünglichen Zwecksetzung bei Erlass des BBauG, die auch noch bisher in der Systematik des BauGB seinen Niederschlag findet, wonach die Bauleitplanung der Regelfall und die $\$ \mathbb{S} 34$ und 35 BauGB die Ausnahme bilden sollten, im Laufe der neueren Entwicklung des Städtebaurechts immer weiter zulasten des Regelfalls der Bauleitplanung ausgedehnt worden:

a) Sowohl durch unmittelbare Ausweitung des Anwendungsbereichs des \34 Abs. 1 BauGB im Wege der Vergrößerung der Abweichungsmöglichkeiten nach $\$ 34$ Abs. 3a BauGB als auch

b) durch Erweiterung der Möglichkeiten der Nutzungsmischung und Umnutzung wegen der Nichtanwendbarkeit des $\ 34$ Abs. 2 BauGB auf urbane Gebiete (wegen $\$ 245$ c Abs. 3 BauGB). Da bei einem urbanen Gebiet nicht nur die Wohnnutzung und die gewerbliche Nutzung als gebietsprägende Hauptnutzungen benannt sind, sondern auch soziale, kulturelle und andere Einrichtungen, die die Wohnnutzung nicht wesentlich stören, zu den Gebietszweck bestimmenden Hauptnutzungen gehören, ist eine weitgehende Nutzungsmischung im Rahmen des Anwendungsbereichs des $\mathbb{3} 34$ Abs. 1 BauGB ohne baugebietstypische Determinierung gem. $\$ 34$ Abs. 2 BauGB möglich.

Ausschlaggebend ist aber, dass auch tatsächlich eine entsprechende strukturprägende Bebauung, an die angeknüpft werden kann, vorhanden ist und dass auch die weiteren Voraussetzungen des $\$ 34$ BauGB erfüllt sind. 
Dies gilt nicht nur im Anwendungsbereich des gesetzlichen Zulässigkeitstatbestands des $\$ 34$ Abs. 1 und 2 BauGB, sondern auch in dem planerisch durch eine Innenbereichssatzung nach $\$ 34$ Abs. 4, 5 BauGB erweiterten Anwendungsbereich. ${ }^{30}$

Auch bei einer unterschiedlichen gemischten Bebauung, bei der die Art der Nutzung vom Mischgebiet bis zum Industriegebiet reicht, bestimmt eine vorhandene Bebauung den Zulässigkeitsmaßstab, soweit die vorhandene Nutzung den Bereich mitprägt, in dem das Vorhaben verwirklicht werden soll. ${ }^{31}$

Dadurch, dass Nutzungsmischung im Anwendungsbereich des $\$ 34$ BauGB in stärkerem Maße zum Tragen gebracht werden kann, verbleibt für die Bauleitplanung die Aufgabe der Konfliktbewältigung, wenn diese unter Berücksichtigung des Rücksichtnahmegebots auf der Basis der Konditionalnorm des $\$ 34$ BauGB nicht herbeigeführt werden kann, also insbesondere dann, wenn zur Konfliktbewältigung flexiblere planerische Lösungen insbesondere durch den Einsatz der Feinsteuerungsmöglichkeiten der Bauleitplanung nach den $₫ 1$ Abs. 4 bis 10 BauNVO notwendig sind.

Mittels der Bauleitplanung kann prinzipiell für jeden Handwerksbetrieb ein für dessen Standortwahl geeignetes Baugebiet verfügbar gemacht werden, allerdings nicht in jeder Gemeinde, da nicht überall Industrie- und Gewerbegebiete, aber auch nicht überall urbane Gebiete ausgewiesen werden können.

Die Ausweisung dieser Gebiete unterliegt einer Reihe von Beschränkungen. So können z. B. aus dem naturschutzfachlichen Gebietsschutz, dem Hochwasserschutz oder auch der Nachbarschaft reiner Wohngebiete und/ oder aus raumstrukturellen raumfunktionellen Belangen der Raumordnung Ausschlussgründe für eine handwerkliche Nutzung an einem bestimmten Standort herrühren.

Bezüglich der Ausweisung urbaner Gebiete resultiert eine Beschränkung daraus, dass die Nutzungsmischung zwischen den in $\$$ 6a Abs. 1 BauNVO aufgeführten Hauptnutzungsarten zu einer den Gebietstyp nach dieser Vorschrift prägenden Bestimmung gemacht worden ist. Da die in der allgemeinen Zweckbestimmung aufgeführten Nutzungsarten den Gebietstypus prägen, müssen diese in dem geplanten Baugebiet nicht nur vorgesehen, sondern auch realisierbar sein.

30 So BVerwG, ZfBR 2018, 479 und Spannowsky, in: Spannowsky/Uechtritz (Hrsg.), BauGB, 3. Aufl., 2018, $\$ 34$ Rn. 32, Rn. 87 und Rn. 88.1.

31 Siehe dazu BVerwG, DVBl. 1995, 515 und Spannowsky, in: Spannowsky/Uechtritz (Hrsg.), BauGB, 3. Aufl., 2018, $\$ 34$ Rn. 32.3 sowie Rn. 35. 
Das Vorhandensein einer Nutzungsmischung zwischen Wohn- und Gewerbenutzung sowie kulturellen und sozialen Einrichtungen ist typisch für städtische Gebiete. Es drängt sich daher die Frage auf, ob urbane Gebiete im Sinne von $\$$ 6a Abs. 1 BauNVO nur in Städten ausgewiesen werden können. Dies ist meiner Ansicht nach zu verneinen. ${ }^{32}$ Sofern nicht ausgeschlossen ist, dass in einem Baugebiet in Gemeinden in ländlichen Räumen eine derartige Nutzungsmischung herbeigeführt werden kann, ist die Ausweisung von urbanen Gebieten auch in ländlichen Räumen nicht ausgeschlossen. Aus $\ 6$ a BauNVO lässt sich eine Begrenzung auf städtische Gebiete nicht entnehmen. Diese Begrenzung hätte dadurch herbeigeführt werden können, dass man die urbanen Gebiete zunächst nur experimentell begrenzt auf Städte, die bestimmte, raumordnungsrechtlich festgelegte Raumfunktionen erfüllen, als befristete Gestaltungsmöglichkeit für eine Übergangszeit eingeführt hätte.

IV. Prinzipielle Eignung des städtebaurechtlichen Steuerungssystems der BauNVO zur Sicherstellung einer bedarfsgerechten und ausreichend differenzierten Standortentwicklung

Insgesamt betrachtet hat sich das städtebauliche System der vom Trennungsgrundsatz ausgehenden, an Gebietstypen ausgerichteten, differenzierenden Standortentwicklung bewährt, weil damit weiterhin flexibel und situationsgerecht auf die Veränderungen im Bereich des Handwerks und der städtebaulichen Planung reagiert werden kann und weil, solange dabei das Trennungsprinzip als Richtschnur dient, Nutzungskonflikte vermieden und, falls sich solche dennoch abzeichnen, eine Konfliktvermeidung bzw. -lösung durch planerische Feinsteuerung in der Regel möglich ist. Dabei ermöglichen im Einzelfall die Ausnahme- und Befreiungsregelungen im Sinne von $\$ 31$ BauGB und das Rücksichtnahmegebot eine situationsgerechte Vorhabenzulassung. Das urbane Gebiet durchbricht diese Ordnungsstruktur in gewisser Weise, weil ohne weitergehende Feinsteuerung nicht absehbar ist, welche Mischung das Gebiet aufweisen wird. Dies dürfte in der Regel, vor allem in lärmvorbelasteten oder sonstwie umwelt-

32 Soweit Hornmann in: Spannowsky/Hornmann/Kämper (Hrsg.), BauNVO, Kommentar, 2018, $\mathbb{5} 6 \mathrm{a}$ Rn. 1 formuliert hat, urbane Gebiete seien typische städtische Gebiete, bleibt die Frage, ob dies lediglich eine Beschreibung des typischen Erscheinungsbilds dieser Gebiete ist oder ob daraus, wie manche meinen, eine Beschränkung auf städtische Gebiete abgeleitet werden soll. 
schutzrechtlich eingeschränkten Bereichen dazu führen, dass die Festsetzung des urbanen Gebiets ohne gleichzeitige innergebietliche Feinsteuerung zu Konflikten zwischen den Nachbarnutzungen führen wird. Es besteht zudem die Wahrscheinlichkeit, dass Mischgebiete von den urbanen Gebieten verdrängt werden, weil bei der Gebietsfestlegung die Lärmvorsorge eine vergleichsweise geringere Rolle spielt als bei dem Mischgebiet und weil zudem - anders als beim Mischgebiet - eine annähernd gleichgewichtige Verteilung der Nutzungsmischung auf Wohnen und die Unterbringung nicht wesentlich störender Gewerbebetriebe für die Ausweisung eines urbanen Gebiets nicht vorausgesetzt wird. Ob damit tatsächlich eine Erleichterung verbunden ist, ist aber letztlich zu bezweifeln, weil es im Regelfall erforderlich sein dürfte, dass mit der Festsetzung eines urbanen Gebiets gleichzeitig feinsteuernde Regelungen getroffen werden ${ }^{33}$ und weil zudem sichergestellt sein muss, dass - anders als bei einem Mischgebiet auch kulturelle und soziale oder sonstige Einrichtungen zum Bestandteil des gebietstypischen Nutzungsmix gehören. ${ }^{34}$

V. Städtebaurechtliche Akzentverschiebungen mit Nachteilen für die Standortentwicklung für Handwerksbetriebe infolge veränderter Rahmenbedingungen?

Obgleich die vorstehende Analyse des städtebaurechtlichen Steuerungssystems an sich positiv ausgefallen ist, werden neuerdings städtebaurechtliche Akzentverschiebungen erkennbar, die sich weniger auf die bebauungsplanerische Steuerung der Errichtung, Erweiterung und Änderung von Handwerksbetrieben innerhalb des gebietstypologisch differenzierten Systems (dazu vorstehend unter IV.) als vielmehr auf die Flächenverfügbarkeit und die Möglichkeit der kurzfristigen Mobilisierung des künftig erforderlichen zusätzlichen Standortpotentials auswirken. Denn diesbezüglich bestehen zunehmend Restriktionen, welche ihre Ursachen in umweltrechtlichen Anforderungen haben (dazu nachfolgend unter C.). Während dies aber in der Regel sachlich gerechtfertigte und daher hinnehmbare Einschränkungen sind, die oftmals aus dem EU-Recht herrühren und wegen des Primats des EU-Rechts nicht disponibel sind, sind Restriktionen, die auf eine ge-

33 So offenbar auch Hornmann, in: Spannowsky/Hornmann/Kämper, BauNVO, 2018, \$ 6a Rn. 49c.

34 Die damit zusammenhängenden Fragen bergen eine Planungsunsicherheit in sich, da sie bislang höchstrichterlich nicht geklärt sind. 
setzliche Änderung städtebaurechtlicher Anreizstrukturen zurückgehen, durch die der Wettlauf um Flächen zum Nachteil der Standortentwicklung für Gewerbe- und Handwerksbetriebe unter veränderte Vorzeichen gestellt worden ist, durchaus kritisch zu betrachten. Denn in der Nutzungskonkurrenz zwischen Wohnnutzung einerseits sowie Handwerksund Gewerbeflächen andererseits im Randbereich der Städte und Gemeinden hat die Wohnnutzung in neuerer Zeit „die Nase vorne“ (wird unten unter C. III. und D. näher ausgeführt). 


\section{Veränderte flächen- und standortbezogene Rahmenbedingungen im Bereich des Umweltrechts und deren Konsequenzen für die Entwicklung, Erhaltung und Erweiterung von Handwerksbetrieben}

I. Rechtsentwicklungen im Bereich des flächen- und standortbezogenen Umweltvorsorgestandards und deren Konsequenzen in Bezug auf die Entwicklung, Erhaltung und Erweiterung von Standorten für Handwerksbetriebe

Veränderungen im Bereich des Gesundheitsschutz- und Umweltvorsorgestandards, die zum Teil aus Rechtsentwicklungen im Bereich des EURechts, zum Teil aber auch aus Rechtsentwicklungen im nationalen Recht herrühren, haben nicht nur erheblichen Einfluss auf die städtebauliche Planung und Vorhabenzulassung, sondern auch zwangsläufig auf die Geeignetheit von Standorten für die Ansiedlung, Erweiterung und Änderung von Handwerksbetrieben.

In städtebaurechtlicher Hinsicht ist dabei zwischen Standortentwicklungen im Außenbereich, in den an den Außenbereich angrenzenden Entwicklungsbereichen und im Innenbereich zu unterscheiden. Denn werden gewerbliche Entwicklungen in den Außenbereich bzw. raumstrukturell gesehen nach der raumordnungsrechtlichen Terminologie, in den Freiraum hineingeführt, sind Konflikte mit den strenger geschützten Umweltschutzgütern, insbesondere mit Schutzgebieten und Arten-, Gewässer- und Trinkwasser- sowie Landschaftsschutzgebieten, vorprogrammiert, da sensible Umweltschutzgüter eher in der mehr oder weniger unberührten Natur zu finden sind.

Dagegen gibt es im bebauten Bestand eher Konflikte mit benachbarten Wohnnutzungen und anderen sensiblen Nutzungen sowie erhöhte Konflikte in lärm- und luftschadstoffvorbelasteten Gebieten. Es kann aber auch Konflikte mit belästigenden gewerblichen Nutzungen in der Nachbarschaft von Handwerksbetrieben geben, etwa wenn sich in der Nachbarschaft Betriebsbereiche nach $₫ 3$ Abs. 5a BImSchG im Sinne der SEVESOIII-Richtlinie befinden.

Konsequenzen hat andererseits die Absenkung des Umweltvorsorgestandards durch die im Zusammenhang mit der Ausweisung urbaner Gebiete erfolgte Erhöhung der für solche Gebiete tagsüber geltenden Immissions- 
richtwerte durch Änderung der TA Lärm ${ }^{35}$ und der Sportanlagenlärmschutzverordnung ${ }^{36}$ (dazu eingehender unten E. II. 4 und IV. II. 1.).

Anders als im Bereich der Lärmvorsorge verfügt der nationale Gesetzgeber dagegen hinsichtlich des Schutzes vor Luftschadstoffbelastungen in Bezug auf die Standardsetzung über keine Dispositionsspielräume mehr, soweit Grenzwerte für bestimmte Luftschadstoffe EU-rechtlich festgelegt und in zahlreichen Städten so weit überschritten sind, dass nach Maßgabe des EU-Rechts auch Handlungspflichten bestehen. Zudem zieht insofern auch der verfassungsrechtliche Grundrechtsschutz Schranken (dazu näher unten C. I. 6.).

\section{Einschränkung der Entwicklung von Standorten für}

Handwerksbetriebe im bisher ungenutzten Freiraum im Außenbereich

Soweit Neubaugebiete in bisherigen Freiräumen ausgewiesen und damit erstmals Freiflächen für Siedlungs- und Verkehrszwecke in Anspruch genommen werden sollen, um den Bau von Handwerks- und sonstigen Gewerbebetrieben zu ermöglichen, gibt es wachsende Beschränkungen wegen des von der Bundesregierung aufgrund ihrer Nachhaltigkeitsstrategie und nach der Koalitionsvereinbarung angestrebten Schutzes der Freiraumressourcen. ${ }^{37}$ Es besteht die Tendenz, dass die Wohnbauflächenentwick-

35 Siehe dazu die Allgemeine Verwaltungsvorschrift zur Änderung der Sechsten Allgemeinen Verwaltungsvorschrift zum Bundes-Immissionsschutzgesetz (Technische Anleitung zum Schutz gegen Lärm - TA Lärm) v. 01.06.2017.

36 Sportanlagenlärmschutzverordnung (18. BImSchV) v. 08.06.2017 (BGBl. I S. 1468).

37 Gemäß der Nachhaltigkeitsstrategie der Bundesregierung aus dem Jahre 2002 sollte Flächenverbrauch bis zum Jahr 2020 auf täglich 30 Hektar reduziert werden. Nachdem dieses Ziel der Reduzierung der Inanspruchnahme von Freiraumressourcen nicht erreicht wird, hat die Bundesregierung in der Neuauflage der Nachhaltigkeitsstrategie aus dem Jahr 2016 eine „verschärfte Festlegung“ von "unter 30 Hektar" pro Tag bis zum Jahr 2030 getroffen. Dementsprechend enthält das integrierte Umweltprogramm des Bundesumweltministeriums aus dem Jahre 2016 das Ziel, dass bezüglich der Flächeninanspruchnahme im Jahr 203020 Hektar pro Tag erreicht werden sollen (siehe zu den Zielen und Indikatoren www.umweltbundesamt.de/ziele-indikatoren, 11. März 2016 und Nachhaltige Entwicklung: Flächenverbrauch - Worum geht es? (www.bmub.bund.de/themen /nachhaltigkeit/internationales/nachhaltige-entwicklung/strategie-und-umsetzung /reduzierung-des-flaechenverbrauchs)). 
lung vor der Entwicklung neuer Handwerks- und Gewerbeflächen bevorzugt wird.

Die mit dem 30-ha-Ziel umrissene Nachhaltigkeitsstrategie zum Schutz der Freiraumressourcen hat in dem bundesgesetzlichen Grundsatz der Raumordnung des $\$ 2$ Abs. 2 Nr. 6 S. 3 ROG 2017 ihren Niederschlag gefunden. Danach sind die Raumordnungsplanungsträger gehalten, Freiflächen für Siedlungs- und Verkehrszwecke zu verringern und zwar in der Weise, dass in Raumordnungsplänen quantifizierte Vorgaben zur Verringerung der Flächeninanspruchnahme gesetzt und die Potentiale für die Wiedernutzbarmachung von Flächen, für die Nachverdichtung und für andere Maßnahmen zur Innenentwicklung der Städte und Gemeinden sowie zur Entwicklung vorhandener Verkehrsflächen vorrangig ausgeschöpft werden. Außerdem gibt es seit einiger Zeit Überlegungen zur Einführung flächenpolitischer ökonomischer Steuerungsmittel, um dadurch stärkere Anreize zur Eindämmung der Inanspruchnahme der Freiraumflächenressourcen zu schaffen. Diese Bestrebungen haben ihren Niederschlag auch in der Koalitionsvereinbarung gefunden. In der Koalitionsvereinbarung für die laufende 19. Legislaturperiode sind in Bezug auf die flächenpolitische Steuerung folgende Festlegungen getroffen worden:

„Unser Ziel ist es, den Flächenverbrauch bis zum Jahr 2030 auf maximal $30 \mathrm{Hektar} / \mathrm{Tag}$ zu halbieren. Wir prüfen, mit welchen zusätzlichen planungsrechtlichen und ökonomischen Instrumenten das Ziel erreicht werden kann. “38 Hindernisse bei der Brachflächenaktivierung sollen überprüft und, soweit möglich, bis 2021 ausgeräumt werden. ${ }^{39}$ Im Koalitionsvertrag wird außerdem klargestellt, dass auch beim Ausbau von Erneuerbare-Energien-Anlagen sowie beim Netzausbau die Flächeninanspruchnahme gering zu halten ist. ${ }^{40}$

Wenn demzufolge die quantitative bundesgesetzliche Zielsetzung ernst genommen wird, dürften Neuausweisungen von Gewerbe- und Handwerksgebieten im bisherigen Freiraum nur noch in deutlich reduziertem Umfang möglich sein, vor allem, wenn man bedenkt, dass zur Deckung des fehlenden Wohnraumbestands in Ballungsräumen und wachsenden Städten auf der Basis des $\$ 13 \mathrm{~b}$ BauGB zunächst befristet bis zum 31.12.2019 Verfahrenserleichterungen zur Schaffung von Wohnnutzungspotentialen im Wege der begrenzten Inanspruchnahme von Außenbereichsflächen, die sich an im Zusammenhang bebaute Ortsteile anschlie-

38 Siehe dazu in der Koalitionsvereinbarung die Randziffern 4040 bis 4051 .

39 Siehe dazu in der Koalitionsvereinbarung die Randziffern 5314 bis 5320.

40 Siehe dazu in der Koalitionsvereinbarung die Randziffern 6604 bis 6609. 
ßen, eingeführt worden sind. Da gegenwärtig auf Wunsch mehrerer Landesregierungen eine Verlängerung dieser verfahrensbeschleunigenden Planungsregelung zur begrenzten Inanspruchnahme von Freiraumpotentialen diskutiert wird, stellt sich die Folgefrage, ob diese Politik der erleichterten Wohnflächenentwicklung in den Außenbereich hinein zum Nachteil der Entwicklung von Gewerbe- und Industrieflächen betrieben wird. Denn wenn das bis zum Jahr 2030 angestrebte Ziel der Reduzierung der Flächeninanspruchnahme erreicht werden soll, geht die Privilegierung der Wohnbauflächenentwicklung in den Außenbereich hinein zwangsläufig zu Lasten der Gewerbe- und Industrieflächenentwicklung.

\section{Einschränkung der Entwicklung von Standorten für}

Handwerksbetriebe in oder in der Nachbarschaft von Schutzgebieten

Die Entwicklung von Standorten in oder in der Nachbarschaft zu Schutzgebieten, die in der Regel im Freiraum, oftmals auch angrenzend an den Siedlungsgebieten liegen, ist nur eingeschränkt möglich und hängt maßgebend von dem Schutzstatus des benachbarten Schutzgebiets ab.

Befindet sich das potentielle Entwicklungsgebiet in einem festgesetzten Überschwemmungsgebiet, gilt gem. $\$ 78$ Abs. 1 WHG ein grundsätzliches Planungs- und Bauverbot. Zudem ist die Errichtung oder Erweiterung baulicher Anlagen nach den $\$ \mathbb{S} 30,33,34$ und 35 BauGB gem. $\$ 78$ Abs. 4 WHG untersagt. Dieser wasserrechtliche Verbotstatbestand gilt folglich sowohl für den Innen- als auch für den Außenbereich und auch dann, wenn eine Neubaufläche in einem festgesetzten Überschwemmungsgebiet auf der Basis eines Bebauungsplans ausgewiesen werden soll.

Ausgewiesene Wasserschutzgebiete begründen differenzierte Nutzungsbeschränkungen. In den Schutzzonen I und II ist die Ausweisung von Handwerks- und Gewerbeflächen generell ausgeschlossen. Die Ausweisung beschränkter Gewerbegebiete kommt allenfalls in der Schutzzone III in Betracht.

Weitgehende Beschränkungen für die Entwicklung von Standorten für handwerkliche und gewerbliche Nutzungen lösen auch Schutzgebiete nach dem BNatSchG, namentlich die Naturschutzgebiete, Nationalparke, Biosphärenreservate, Landschaftsschutzgebiete, Naturparke, gesetzlich geschützten Biotope sowie die FFH- und die Europäischen Vogelschutzgebiete aus. Die mit den genannten Schutzgebieten verbundenen Beschränkungen und daraus resultierenden Planungsanforderungen sind differenziert und unterschiedlich streng. Sie führen wegen der Konflikte mit den räum- 
lich geschützten Naturgütern vor allem im Freiraum zu einer erheblichen räumlichen Einschränkung geeigneter Standorte für handwerkliche und gewerbliche Nutzungen.

3. Einschränkung der Entwicklung von Standorten für Handwerksbetriebe infolge des Artenschutzes

Der besondere Artenschutz hat nicht nur für die Standortentwicklung im Außenbereich Bedeutung. Er kann auch zu Hindernissen für die städtebauliche Planung führen, kann aber auch noch der Vorhabenzulassung entgegenstehen oder diese zumindest erschweren. In der Regel werden die für besondere Arten relevanten Auswirkungen bei gewerblichen und industriellen Nutzungen, insbesondere infolge damit zusammenhängender Emissionen und Verkehrsbelastungen, größer sein als bei der reinen Wohnnutzung. Der Konflikt mit dem Artenschutz kann zwar oftmals durch geeignete Vermeidungs- und Ausgleichsmaßnahmen bewältigt bzw. ausgeräumt werden, jedoch muss dafür, wenn solche Maßnahmen erforderlich sind, Aufwand in zeitlicher und finanzieller Hinsicht einkalkuliert werden.

4. Einschränkung der Entwicklung von Standorten für Handwerksbetriebe infolge der naturschutzrechtlichen EingriffsAusgleichs-Regelung

Die naturschutzrechtliche Eingriffs-Ausgleichs-Regelung hat generell Bedeutung bei der Ausweisung größerer Flächen im Außenbereich, soweit sie nicht in den Anwendungsbereich des $\mathbb{1} 13 \mathrm{~b}$ BauGB fallen. Da die Planungserleichterungen des $\$ 13 \mathrm{~b}$ BauGB auf die Wohnflächenentwicklung in unmittelbarem Anschluss an den im Zusammenhang bebauten Ortsteil beschränkt sind, sind bei der erforderlichen planerischen Ausweisung von Baugebieten im Außenbereich für Handwerks-, Gewerbe- und Industriebetriebe die speziellen städtebaulichen Eingriffs-Ausgleichs-Regelungen gem. $\mathbb{S} \mathbb{S} 1 \mathrm{a}$ Abs. 3 i. V. mit $\mathbb{S} \mathbb{S} 13 \mathrm{a}$ BauGB, 5 Abs. 2a, 9 Abs. 1a, 11 Abs. 1 Nr.2, 135a bis 135c und 200a BauGB anzuwenden. Dadurch entsteht zusätzlicher Aufwand, sowohl in zeitlicher als auch in finanzieller Hinsicht. 
5. Einschränkung der Entwicklung von Standorten für Handwerksbereiche infolge des standortrelevanten Lärmschutzes

Der standortrelevante Lärmschutz hat sowohl im Außen- als auch im Innenbereich Bedeutung und kann zu Einschränkungen der Standorteignung führen. Im Innenbereich und bei der bauleitplanerischen Innenentwicklung können Lärmkonflikte vor allem mit den menschlichen Nachbarschaftsnutzungen entstehen, wobei die größte Einschränkung von benachbarten reinen Wohngebieten ausgeht, da deren Schutzstatus aus den oben angeführten Gründen besonders hoch ist. Aber auch im Außenbereich kann der Lärmschutz, vor allem im Zusammenhang mit dem Habitats- und Artenschutz, Bedeutung erlangen und zu erhöhten Standortanforderungen führen, zumal lärmbedingte Störungen sowohl im Rahmen der FFH-Verträglichkeitsprüfung als auch im Rahmen der Umweltprüfung zu berücksichtigten und im Fall erheblicher Beeinträchtigungen der Erhaltungsziele und der Schutzzwecke zu vermeiden bzw. abzustellen sind.

6. Einschränkung der Entwicklung von Standorten für Handwerksbetriebe infolge der standortrelevanten Luftreinhaltung

Die Luftreinhalteproblematik weist in Deutschland hohe Aktualität und Brisanz deshalb auf, weil die Europäische Kommission bereits im Jahr 2013 die Anträge deutscher Behörden auf Fristverlängerung zur Einhaltung der Grenzwerte ab 01.01.2015 in Bezug auf 33 von 57 deutschen Gebieten abgelehnt hatte. Dazu kommt unabhängig davon, dass für NO2 und Benzol die maximal mögliche Fristverlängerung 2015 endete. Zwischenzeitlich hat die Europäische Kommission von Deutschland die Intensivierung der Maßnahmen zur Einhaltung der Luftqualitätsrichtlinie verlangt und Vertragsverletzungsverfahren Nr. 2015/2073 mit dem Aufforderungsschreiben zur Abgabe einer begründeten Stellungnahme eingeleitet, da die Grenzwerte in vielen Städten um ein Vielfaches überschritten sind. Nachdem die Bundesregierung bereits mehrere begründete Stellungnahmen zu den Mahnschreiben der Europäischen Kommission abgegeben hatte, hat diese zwischenzeitlich den EuGH angerufen. Auch diese Problematik wirkt sich in den genannten Städten, aber auch in anderen Bereichen auf die Entwicklung von Standorten für Handwerksbetriebe aus. 
Der $\mathrm{EuGH}^{41}$ hat insofern klargestellt, dass EU-rechtlich erreicht werden soll, dass Maßnahmen in einem Aktionsplan vorgesehen werden, die geeignet sind, die Gefahr der Überschreitungen der Grenzwerte auf ein erreichbares Minimum zu reduzieren, um damit schrittweise $\mathrm{zu}$ einem Stand unterhalb dieser Werte zu gelangen. Entgegen einer Entscheidung des BVerwG aus dem Jahr $2007^{42}$ hat der EuGH bereits in seiner oben genannten Entscheidung vom 25.07.2008 klargestellt, dass Betroffene auch die Erstellung eines Aktionsplans gegen Feinstaub erzwingen können. ${ }^{43}$

In Bezug auf die Luftreinhalteanforderungen dürfte künftig, vor allem in den Städten und Gemeinden, in denen die auf der Basis der Luftrahmenqualitätsrichtlinie 96/62/EG und der Richtlinie über Luftqualität und saubere Luft in Europa 2008/62/EG vorgegebenen und in der 39. BImSchV umgesetzten Schadstoffgrenzwerte deutlich überschritten sind (dazu $\mathbb{S} 1$ Nr. 1, 15, 33, 2 bis 8 der 39. BImSchV), nicht nur mit Verkehrsbeschränkungen zu rechnen sein, ${ }^{44}$ die auch Handwerksbetriebe treffen können, sondern auch mit betriebsbezogenen Einschränkungen; auch wenn diesem Aspekt bislang im Städtebaurecht noch nicht hinreichend Rechnung getragen worden ist. Denn diesbezüglich müssen gem. $\$ 47$ Abs. 4 S. 1 BImSchG und nach der vorliegenden Rechtsprechung ausgehend von dem Verhältnismäßigkeitsprinzip alle Verursacher von Luftschadstoffemissionen verursacheradäquat zu den erforderlichen Maßnahmen herangezogen werden $^{45}$. Bei der Standortplanung für Handwerks-, Gewerbe- und Industriebetriebe ist daher zu beachten, dass unter Verhältnismäßigkeitsgesichtspunkten die Maßnahmen nicht allein an die Verkehrsteilnehmer und mit-

41 EuGH, Urt. v. 25.07.2008, C-237/07, Rn. 47, EuZW 2008, 573 und noch stringenter aufgrund der Auslegung nach dem „effet utile" bei langanhaltender Überschreitung und Nichtstun nationaler Behörden Urt. v. 19.11.2014, C-404/13, NVwZ 2015, 419, das Großbritannien betraf.

42 Beschl. v. 29.03.2007, 7 C 9/06, NVwZ 2007, 695.

43 Dazu ausführlicher auch Murswiek in seiner Urteilsbesprechung JuS 2009, 74 und Couzinet, DVBl. 2008, 754.

44 Siehe dazu EuGH, EuZW 2008, 573 und EuGH NVwZ 2015, 419 sowie https://w ww.greenpeace.de/sites/www.greenpeace.de/files/publications/2015_06_18_mahn schreiben_eu_kommission.pdf, abgerufen am 20.10.2016. Entgegen einer Entscheidung des BVerwG aus dem Jahr 2007 (Beschl. v. 29.03.2007, 7 C 9/06, NVwZ 2007, 695) hat der EuGH bereits in seiner oben genannten Entscheidung vom 25.07.2008 klargestellt, dass Betroffene auch die Erstellung eines Aktionsplans gegen Feinstaub erzwingen können (dazu ausführlicher auch Murswiek in seiner Urteilsbesprechung JuS 2009, 74 und Couzinet, DVB1. 2008, 754).

45 Siehe dazu BVerwG, Beschl. v. 11.07.2012, BeckRS 2012, 55003 Rn.9 und OLG NRW, UPR 2011, 192 Rn. 52. 
telbar an die Fahrzeughersteller adressiert sein dürfen. Denn unter Verhältnismäßigkeitsgesichtspunkten ist im Rahmen der Rechtsschutzverfahren relevant, ob die zuständige Behörde alle Verursacherquellen ermittelt hat. Dazu gehört, dass sie nicht nur die auf den Verkehr zurückgehenden Luftbelastungen ermittelt und diesen mit Maßnahmen begegnet. Sie muss vielmehr auch die von gewerblichen und industriellen Anlagen ausgehenden Luftbelastungen in einem Gebiet erfassen und im Luftreinhalteplan entsprechend des jeweiligen Verursacheranteils Maßnahmen gegenüber den betreffenden Emittenten vorsehen. Denn die Maßnahmen müssen nach der Rechtsprechung auf der ersten Stufe der Luftreinhalteplanung entsprechend des Verursacheranteils unter Beachtung des Grundsatzes der Verhältnismäßigkeit gegen alle Emittenten gerichtet sein. ${ }^{46}$ Zudem muss auch auf der zweiten Stufe das Maßnahmenbündel grundsätzlich gegen alle Verursacher unter Berücksichtigung der jeweiligen Emissionsquelle festgelegt worden sein. ${ }^{47}$ Die Rechtsprechung stellt insofern - ausgehend von dem Verursacherprinzip - hohe Ermittlungsanforderungen insofern auf, als eine "fundierte Ursachenanalyse“ 48 vorgenommen worden sein muss. Dabei sind auch die Verursachungsanteile von Verursachern einzubeziehen, die sich nicht innerhalb des Plangebiets befinden, die aber auf dieses in Form von Luftschadstoffbelastungen einwirken. ${ }^{49}$ Umstritten ist hingegen, $\mathrm{ob}$ und inwieweit auch allgemeine Hintergrundbelastungen zu erfassen sind, die sich bestimmten Verursachern nicht eindeutig zuordnen lassen. Die Heranziehung einzelner Verursacher kann andererseits im Einzelfall unangemessen sein, weil deren Verursachungsanteil irrelevant ist oder deren Inanspruchnahme in Relation zur Zweckerreichung, bei der auch der Aufwand zu berücksichtigen ist, außer Verhältnis steht (Zweck-Mittel-Relation). Im Rahmen der planerischen Umweltvorsorge sind diese Aspekte nur mittelbar von Bedeutung, müssen aber bei der Standortplanung für Handwerks- und Gewerbebetriebe in kritischen Bereichen berücksichtigt werden und können im Einzelfall die Standorteignung in Frage stellen oder Einschränkungen bei der Entwicklung von Standorten für Handwerksbetriebe mit sich bringen.

46 So ausgehend von $\$ 47$ Abs. 4 S. 1 BImSchG ausdrücklich BVerwG, Beschl. v. 11. Juli 2012, 3 B 79/11, BeckRS 2012, 55003, Rn. 9.

47 So VG Düsseldorf, Urt. v. 08. 12. 2009, 3 K 3720/09, BeckRS 2010, 45395.

48 Ebenso Jarass, BImSchG, $\$ 47$ Rn. 18a und BVerwGE 128, 278 Rn. 26.

49 So zutreffend ebenso Jarass a. a. O. 
7. Einschränkung der Entwicklung von Standorten für Handwerksbetriebe infolge der Nachbarschaft zu Betriebsbereichen im Sinne von $₫ 3$ a Abs. 5a BImSchG

Mit dem Gesetz zur Umsetzung der Richtlinie 2014/52/EU im Städtebaurecht und zur Stärkung des neuen Zusammenlebens in der Stadt v. 04.05.2017 (BGBl I S. 1057) wurden auch die Anforderungen der SevesoIII-Richtlinie in das BauGB 2017 umgesetzt. ${ }^{50}$ Beabsichtigt ist damit ein verbesserter Schutz sensibler Nutzungen in der Nachbarschaft gefährlicher Betriebsbereiche im Sinne von $₫ 3$ a Abs. 5 BImSchG vor den im Katastrophenfall von solchen Betrieben ausgehenden Gefahren. Den Mitgliedstaaten ist gem. Art. 13 Abs. 1 der Richtlinie 2012/18/EU die Aufgabe zugewiesen, sicherzustellen, dass dem Ziel, schwere Unfälle zu verhüten und ihre Folgen für die menschliche Gesundheit und die Umwelt zu begrenzen, in ihren Politiken der Flächenausweisung oder Flächennutzung oder anderen einschlägigen Politiken im Sinne der Richtlinie Rechnung getragen wird.

Es stellt sich die Frage, ob dieser Schutz lediglich der Wohnnutzung oder auch der handwerklichen Nutzung dient. Dies ist zu bejahen, wenn die handwerkliche Nutzung in engem räumlichem Zusammenhang mit der Wohnnutzung zugelassen wird, nicht auch, wenn Handwerksbetriebe in Gewerbegebieten errichtet oder erweitert werden sollen, es sei denn es befinden sich öffentlich genutzte Örtlichkeiten in der Umgebung. Denn gem. Art. 13 Abs. 1c) der Richtlinie 2012/18/EU fällt die Pflicht zur Überwachung neuer Entwicklungen in der Nachbarschaft von Betrieben im Sinne der Seveso-III-Richtlinie in den Aufgabenbereich der mitgliedstaatlichen Flächenausweisungspolitik. Dementsprechend ist diese Aufgabe in Deutschland aufgrund des BauGB 2017 der städtebaulichen Planung und somit dem gemeindlichen Aufgabenbereich zugeordnet worden.

Handwerksbetriebe können infolgedessen nicht nur in Wohngebieten, sondern unter Umständen auch in Gewerbegebieten Beschränkungen ausgesetzt sein, die nunmehr gem. $\$ 9$ Abs. 1 Nr. 23c BauGB und gem. $\$ 9$ Abs. 2c BauGB städtebaurechtlich in der Nachbarschaft von Betriebsbereichen gem. $\ 3$ a Abs. 5 BImSchG vorgesehen werden können, um Störfälle zu vermeiden oder deren Folgen zu mindern.

50 Umsetzung der Richtlinie 2012/18/EU des Europäischen Parlaments und des Rates vom 4. Juli 2012 zur Beherrschung der Gefahren schwerer Unfälle mit gefährlichen Stoffen, zur Änderung und anschließenden Aufhebung der Richtlinie 96/82/EG des Rates (ABl. L 197/1 vom 24.7.2012, S. 1), der sog. Seveso-III-Richtlinie. 
II. Rechtsentwicklungen im Bereich der verfahrensrechtlichen Umweltprüfungsanforderungen und Planungsverfahren

Auch in verfahrensrechtlicher Hinsicht haben sich die Umweltprüfungsanforderungen verändert. Formalisierte Umweltprüfungsanforderungen sind vor allem bei der Neuausweisung von Baugebieten im Außenbereich zu erfüllen.

Die Umweltprüfanforderungen müssen nach Maßgabe der Anlage 1 zum BauGB im Rahmen der Umweltprüfung erfüllt werden, die nach $\$ 2$ Abs. 4 BauGB zu einer generellen Anforderung des Planungsverfahrens geworden ist, von der lediglich unter den Voraussetzungen der $\mathbb{S} 13$, 13a und 13b BauGB beschränkte Ausnahmen bezüglich geringfügiger Planänderungen und -ergänzungen, bezüglich kleiner und mittelgroßer Bebauungspläne der Innenentwicklung und bezüglich der Entwicklung kleiner, sich unmittelbar an einen im unmittelbaren Zusammenhang bebauten Ortsteil anschließender Bereiche zugelassen sind.

Gemäß $\ 2$ Abs. 4 S. 1 BauGB i. V. mit der Anlage 1 zum BauGB müssen alle relevanten Umweltbelange und insbesondere die Auswirkungen auf die oben genannten EU-rechtlich hervorgehobenen Umweltbelange ermittelt und in einem Umweltbericht beschrieben werden. Auf der Basis der Richtlinie 2014/52/EU wurde die Anlage 1 zum BauGB durch die Bekanntmachung vom 03.11.2017 (BGBl. I S. 3634) neugefasst. Infolge der Auflistung der zu prüfenden Belange sind die Mindestprüfungsanforderungen präzisiert worden, so dass infolgedessen die Gefahr einer beachtlichen Unvollständigkeit des Umweltberichts besteht, wenn Ermittlungen zu den aufgelisteten Aspekten nicht angestellt und eine Beschreibung zu diesen Punkten unterblieben ist. Dazu kommt die ausdrückliche Ergänzung des Katalogs der Abwägungsbelange in $₫ 1$ a Abs. 6 BauGB um Nr.7j aufgrund des Änderungsgesetzes zur Umsetzung der Richtlinie 2014/52/EU im Städtebaurecht und zur Stärkung des neuen Zusammenlebens in der Stadt v. 04.05.2017. Die Auswirkungen, die aufgrund der Anfälligkeit der nach dem Bebauungsplan zulässigen Vorhaben für schwere Unfälle oder Katastrophen zu erwarten sind, müssen nunmehr ebenfalls im Umweltbericht dokumentiert werden.

Diese Umweltprüfanforderungen erschweren die Ausweisung neuer Handwerksgebiete im Außenbereich und erhöhen den Zeit- und Sachaufwand. Es liegt auf der Hand, dass deshalb die Entwicklung von Handwerksflächen im Innenbereich bzw. im Rahmen der bauleitplanerischen Innenentwicklung eine größere Bedeutung erlangt. 
III. Konsequenzen veränderter umweltfachgesetzlicher und umweltfachplanerischer Anforderungen für die bauplanungsrechtliche Zulässigkeit von Handwerksbetrieben und die städtebaulich-planerische Standortentwicklung

Die Analyse der veränderten umweltfachgesetzlichen und umweltfachplanerischen Anforderungen lässt erhebliche, teils materiell-rechtliche und teils verfahrensrechtliche umweltbedingte rechtliche Restriktionen erkennen, welche die Planungsspielräume für die Entwicklung von Standorten für Handwerksbetriebe räumlich-differenziert in unterschiedlichem Maße einschränken. Festzustellen sind veränderte materielle und verfahrensmäßige Prüfungsanforderungen, die sich sowohl auf die bauplanungsrechtlichen Zulässigkeitstatbestände als auch auf die städtebauliche Planung auswirken. Dadurch werden vor allem die städtebaulichen Planungsspielräume zur Entwicklung von Freiraumflächen im Außenbereich für den Zweck der Entwicklung von Gewerbe- und Handwerksflächen eingeschränkt, weil bei diesen die negativen Umweltauswirkungen im Regelfall weiter reichen als bei der reinen Wohnnutzung.

Während in den in den 1990er Jahren noch eine rechtssystematische Statusbeschreibung in der Weise gezeichnet werden konnte, dass das deutsche Baurecht eher materiellrechtlich ausgerichtet ist und in verfahrensmäßiger Hinsicht durch das EU-Recht aufgeladen wird, ${ }^{51}$ weil das Verfahren nach der Konzeption des europäischen Verwaltungsrechts einen gewichtigen selbständigen Stellenwert erlangt, ${ }^{52}$ werden inzwischen materielle Standards mehr und mehr auch auf europäischer Ebene gesetzt. ${ }^{53}$ Dies wird vor allem in den Bereichen der Luftreinhalteanforderungen deutlich, ${ }^{54}$ wo inzwischen der Grundrechtsschutz durch die verbindliche Festlegung von Grenzwerten auf europäischer Ebene auch gegenüber den Mitgliedstaaten gewährleistet wird. Dazu kommen zunehmend umweltfachplanerische Anforderungen, insbesondere im Bereich des Hochwasserschutzes, des Wasserrechts und der Luftreinhaltung, welche maßnahmenbezogene Anforderungen begründen und damit Abwägungsanforderungen konkretisieren, welche über $\$ 1$ Abs. 6 Nr. $7 \mathrm{~g}$ ) BauGB im Rahmen der Bauleitplanung erhöhte Berücksichtigungsanforderungen begründen.

51 Siehe dazu Classen, NJW 1995, 2457, 2459 f. und Kment, EuR 2006, $201 \mathrm{f}$.

52 Zur Rechtsprechung des EuGH und dem daraus resultierenden Stellenwert des EU-Verfahrensrechts siehe Sobotta, ZUR 2018, 174.

53 Zum Grundrechtsschutz durch Verfahrensrecht Seitz, EuZW 2015, 273.

54 Siehe Spannowsky, ZfBR 2018, 25. 
Dadurch, dass die genannten EU-rechtlich geleiteten Planungsanforderungen wegen des Anwendungsvorrangs des EU-Rechts für den städtebaurechtlichen Gesetzgeber nicht zur Disposition stehen, ist der Gesetzgeber darauf beschränkt, die für ihn veränderbaren Eckpunkte der gesetzlichen Rahmensetzungen so zu verändern, dass die unterschiedlichen Nutzungsinteressen möglichst optimal zur Entfaltung gebracht werden. Es stellt sich daher die Frage, ob dies bezüglich der Handwerks- und Gewerbeentwicklung in sachgerechter Weise und im erforderlichen Umfang geschehen ist.

1. Auswirkungen veränderter materieller und verfahrensmäßiger Prüfungsanforderungen und daraus abgeleitete Konsequenzen für das Städtebaurecht

Der im Städtebaurecht verankerte strategische Vorrang der Innenentwicklung vor der Außenentwicklung (vgl. $\$ 1$ Abs. 5 S. 3 i. V. mit $\mathbb{\$} 1 \mathrm{a}$ Abs. 2 BauGB) und die Lockerung dieses Grundsatzes zugunsten der Wohnbauflächenentwicklung durch die zeitlich befristete Einfügung des $\mathbb{S} 13 \mathrm{~b}$ BauGB sowie die wachsenden umweltfachlichen Anforderungen schränken die Möglichkeiten der Standortentwicklung für Handwerksbetriebe im Außenbereich ein. Dazu kommen Umweltprüfanforderungen, die vor allem bei städtebaulichen Planungen, welche zu einer Freirauminanspruchnahme im Außenbereich führen, mit einem erhöhten Zeit- und Kostenaufwand verbunden sind.

Im Bereich der bauplanungsrechtlichen Zulässigkeitstatbestände der $\$ \$ 34$ und 35 BauGB war infolge der zunehmenden umweltrechtlichen Anforderungen vor allem eine Veränderung in Bezug auf die Auslegung des Rücksichtnahmegebots, das nach ständiger Rechtsprechung seinen Ausdruck in dem Erfordernis des Einfügens gefunden hat, zu verzeichnen. ${ }^{55}$ Kritisch zu betrachten ist insofern jedoch die Ausdehnung der gesetzlichen Abweichungsregelung des $\$ 34$ Abs. 3a BauGB, da sich die Abweichungsge-

55 Siehe bezüglich der Begrenzung des Rücksichtnahmegebots durch die Aspekte der Vorbelastung das BVerwG, BVerwGE 88, 210 und zur Grenze des Grundrechtsschutzes VGH München, BeckRS 2017, 111581 und BeckRS 2017, 111580 und VG München, BeckRS 2016, 113039 bei unzumutbaren Geräusch- oder sonstigen Immissionen sowie Spannowsky, in: Spannowsky/Uechtritz, BauGB, 3. Aufl., 2018, $\mathbb{3} 34$ Rn. 5 bezüglich des Rücksichtnahmegebots beim Vorhandensein eines Störfallbetriebs sowie Spannowsky/Porger, Die Auswirkungen von Truppenübungsplätzen, in: Schriften zur Raumordnung und Landesplanung, Bd. 9, 2002, 44. 
setzgebung auf die Grenzlinie zubewegt, welche durch das Rücksichtnahmegebot und den Gebietswahrungsanspruch sowie durch die Schutzmaßstäbe, welche bezüglich des grundrechtsbewährten Lärmschutzes und der Luftreinhaltung zu beachten sind. Die auf den Zulässigkeitstatbestand des $\$ 34$ Abs. 3a BauGB gestützte Zulässigkeit von Vorhaben genießt deshalb und wegen deren Einzelfallabhängigkeit nur eine erheblich eingeschränkte Verlässlichkeit. Dies ist auch unter dem Aspekt der Planungssicherheit nicht unbedenklich.

2. Städtebaurechtliche Korrekturen der Innenentwicklungsstrategie in Bezug auf die städtebauliche Planung und Verfahrensanforderungen sowie die bauplanungsrechtlichen Zulässigkeitstatbestände

Dadurch, dass der Innenentwicklung der Vorrang gegeben wurde, ist in den Ballungsräumen ein städtebaulicher Nachverdichtungsprozess ausgelöst worden. Dieser hat jedoch vor allem zu einem Anwachsen der Wohnbaueinheiten geführt, ohne dass die haushaltsnahen Handwerksbetriebe in gleichem Maße zahlenmäßig vermehrt wurden.

Soweit mit der Strategie der Förderung der Innenentwicklung auch eine Nutzungsmischung herbeigeführt wurde, führt dies im Bereich der Innenentwicklung tendenziell zu einer Verschärfung der Nutzungskonflikte. Es war daher notwendig, die Zulässigkeitshürden, die einer Um- und Mischnutzung im Innenbereich entgegenstanden, durch eine Lockerung der bauplanungsrechtlichen Zulässigkeitstatbestände abzubauen und durch eine Reduzierung des hohen Umweltvorsorgeniveaus für gemischte Bauflächen in noch vertretbarem Umfang zu verkleinern. Städtebaurechtlich ist auf die mit den beschriebenen erhöhten Umweltschutzanforderungen für Freiraumentwicklungen im Außenbereich verbundenen Restriktionen dadurch begegnet worden, dass mit der Neufassung des BauGB 2017 die Umweltvorsorgestandards für den Bereich der Innenentwicklung hinsichtlich der gemischten Nutzungen reduziert wurden, indem einerseits ein neuer gemischter Baugebietstyp, die urbanen Gebiete, eingeführt wurde und für diese die gebietstypisch zu tolerierenden Lärmvorsorgewerte im Bereich der Tag-Werte reduziert wurden (dazu näher unten). Damit wird ermöglicht, dass in solchen Gebieten Wohnnutzung und nicht erheblich störende handwerkliche Nutzung zusammengeführt werden können.

Es bleiben jedoch Probleme, soweit Standorte für störende und belästigende Handwerks- und Gewerbebetriebe benötigt werden. Diesbezüglich sind im Bereich der Innenentwicklung kaum Flächenpotentiale zu finden 
und dadurch, dass mit $₫ 13 \mathrm{~b}$ BauGB die Entwicklung von Randflächen der Siedlungsbereiche zur Schaffung von Wohnbauflächen erleichtert wurde, sind die danach verbleibenden Potentialflächen für die gewerbliche Entwicklung zur Schaffung von Standorten für störende und belästigende Handwerks- und Gewerbebetriebe reduziert worden.

\section{Städtebaurechtliche Korrekturen durch Veränderung der Anforderungen an das Planungsverfahren}

Nachdem bei der Umsetzung der Richtlinie 2001/42/EG im Jahr 2004 zunächst eine generelle Umweltprüfung für alle Bauleitpläne eingeführt worden war und von dem den Mitgliedstaaten in der Richtlinie gem. Art. 3 Abs. 3 eingeräumten Beurteilungsermessen bezüglich kleiner lokaler Gebiete kein Gebrauch gemacht worden war, fand im Jahr 2006 die Korrektur in der Weise statt, dass der Anwendungsbereich des vereinfachten Verfahrens des $₫ 13$ BauGB erweitert und $\ 13$ a BauGB neu eingeführt wurde. Mit dem BauGB 2017 wurde schließlich aufgrund des $\$ 13$ b BauGB, zunächst zeitlich bis 31.12.2019 begrenzt, der Anwendungsbereich des $\mathbb{1} 13 \mathrm{a}$ BauGB mit den verfahrenserleichternden Anreizfunktionen auf unmittelbar an im Zusammenhang bebaute Ortsteile angrenzende Bereiche im Außenbereich ausgedehnt. Die letztgenannte Änderung ist umstritten, da sie nicht im Einklang mit der Strategie der Innenentwicklung steht und teilweise auch bezweifelt wird, ob sie noch von dem den Mitgliedstaaten nach der Richtlinie eingeräumten Beurteilungsermessen gedeckt ist. Auch wenn $\int 13 \mathrm{~b}$ BauGB meiner Ansicht nach mit dem EU-Recht durchaus noch in Einklang zu bringen sein dürfte, da es sich um „kleine lokale Gebiete“ im Sinne des Art. 3 Abs. 3 der Richtlinie 2001/42/EG handelt, die im Anwendungsbereich des $\mathbb{1} 13 \mathrm{~b}$ BauGB ohne Umweltprüfung und ohne Anwendung der Eingriffs-Ausgleichs-Regelung entwickelt werden können, ist zweifelhaft, ob sich diese Regelung unter dem Aspekt einer nachhaltigen Raumentwicklung mit den Zielsetzungen des Flächensparens und den Zielsetzungen einer ausgewogenen, auch den handwerks- und gewerbebetrieblichen Interessen gerecht werdenden Strategie der nachhaltigen Flächenentwicklung vereinbaren lässt. ${ }^{56}$ Denn die Planungserleichterungen,

56 Der Anwendungsbereich ist allerdings eingeschränkter, als es auf den ersten Blick aussieht. Bei der Anwendung der Verfahrensvorschriften der $\mathbb{S} \$ 13 \mathrm{a}$ und $13 \mathrm{~b}$ BauGB sind nämlich auch die Vorschriften des UVPG zu beachten, welche aufgrund des Gesetzes zur Modernisierung des Rechts der Umweltverträglichkeits- 
die mit der Anwendung des $₫ 13 \mathrm{~b}$ BauGB bei der Inanspruchnahme von an den Siedlungskörper angrenzenden Außenbereichsflächen für die Entwicklung von Wohnbauflächen verbunden sind, lassen sich allenfalls in den Ballungsräumen mit der anhaltend hohen, kaum zu befriedigenden Flächennachfrage rechtfertigen. Aber gerade dort sind kaum mehr ausreichende Flächen vorhanden, sodass sich gerade auch dort die Flächenverknappung in Kombination mit dem Verdrängungseffekt der Wohnbebauung besonders schwerwiegend zulasten der Gewerbe- und Handwerksgebietsentwicklung auswirkt. Deshalb sollte die Regelung des $₫ 13 \mathrm{~b}$ BauGB nach dem Ablauf der gesetzlichen Befristungsregelung nicht in das Dauerrecht überführt werden.

prüfung v. 20.07.2017 (BGBl. I S. 2808), das am 29.07.2017 in Kraft getreten ist, neugefasst worden sind. Daraus ergeben sich Beschränkungen bezüglich der Anwendung der $\mathbb{S} 13 \mathrm{a}$ und $13 \mathrm{~b}$ BauGB, vor allem bezüglich der Erweiterung von Vorhaben und bezüglich kumulierender Vorhaben. Siehe dazu Spannowsky, ZfBR 2018, 544. 


\section{Rechtsentwicklungen im Bauplanungsrecht und deren Konsequenzen für die Errichtung, Änderung und Erweiterung von Handwerksbetrieben}

Nachdem in den vorstehenden Teilen dieser Abhandlung die Veränderungen der Rahmenbedingungen beschrieben wurden, die auch zu einer Korrektur des Städtebaurechts geführt bzw. diese veranlasst haben, ist im Folgenden näher zu beleuchten, ob und inwieweit nach geltendem Städtebaurecht den handwerksbetrieblichen Interessen Rechnung getragen werden kann. Dabei steht die Analyse der bauplanungsrechtlichen Zulässigkeitstatbestände und deren Auslegung im Vordergrund. Denn gerade auch die jüngsten Weichenstellungen im Städtebaurecht durch die Änderungen aufgrund des Gesetzes zur Umsetzung der Richtlinie 2014/52/EU im Städtebaurecht und zur Stärkung des neuen Zusammenlebens in der Stadt v. 4.5.2017 haben zu Akzentverschiebungen geführt, die zum Teil auch bei der sachlogischen und systematischen Auslegung der bauplanungsrechtlichen Zulässigkeitstatbestände eine Rolle spielen.

I. Die Bedeutung des Bauplanungsrechts für die Errichtung, Änderung und Erweiterung von Handwerksbetrieben

Wenn in einem unbeplanten gemeindlichen Innen- oder Außenbereich die gesetzlichen Zulässigkeitstatbestände der $\$ \mathbb{S} 34$ und 35 BauGB oder wenn in einem beplanten Gemeindegebiet planerische Festlegungen einer städtebaulichen Satzung oder eines Bebauungsplans der bauplanungsrechtlichen Zulässigkeit eines handwerklichen Vorhabens entgegenstehen, kann die Zulässigkeit eines handwerklichen Betriebs allein durch die Bauleitplanung begründet werden. In diesem Fall ist die Bauleitplanung zur Schaffung von Baurecht für den betreffenden Handwerksbetrieb, der am Bau einer baulichen Anlage auf einem Grundstück interessiert ist, um eine Betriebsstätte herstellen zu können, erforderlich im Sinne von $\mathbb{} 1$ Abs. 3 BauGB. Es muss dazu ein Bebauungsplan aufgestellt, geändert, erweitert oder aufgehoben werden (siehe $\mathbb{1} 1$ Abs. 8 BauGB), um die bauplanungsrechtliche Zulässigkeit zugunsten der handwerklichen Nutzung herbeizuführen. Es kommt dann vor allem darauf an, für diese Art der baulichen Nutzung einen Baugebietstypus festzusetzen oder durch planerische Fein- 
steuerung nach den $\$ ₫ 1$ Abs. 4 bis 10 BauNVO so zu modifizieren, dass für die Errichtung, Erweiterung oder Änderung eines Handwerksbetriebs ein planerischer Zulässigkeitstatbestand gegeben ist. Da die Freiräume im Außenbereich nicht mehr in dem Maße wie noch in früherer Zeit zur Angebotsschaffung auf der grünen Wiese zur Verfügung stehen (siehe dazu die Ausführungen oben unter C. I. 1.), muss im Interesse der nachhaltigen wirtschaftlichen Entwicklung, der die Gemeinden im Rahmen der auf Nachhaltigkeit ausgerichteten städtebaulichen Entwicklungsaufgabe ebenfalls verpflichtet sind (siehe $\$ 1$ Abs. 5 S. 1 BauGB), sichergestellt werden, dass im Siedlungsbereich ausreichende Potentiale für die handwerkliche Nutzung geschaffen werden können bzw. dass geeignete Flächen nicht für andere Zwecke umgenutzt werden.

Aufgrund der auf Nutzungsmischung angelegten Strategie der Innenentwicklung, zu der sich der Bundesgesetzgeber in $\$ 1$ Abs. 5 S. 3 BauGB bekannt hat, sind die räumlichen Entwicklungspotentiale für die handwerkliche Nutzung im Bereich der Innenentwicklung zwar in begrenztem Umfang ausgedehnt worden, indem

a) zur Verwirklichung der Strategie der Innenentwicklung der Anwendungsbereich des $\$ 34 \mathrm{BauGB}$ und indem

b) durch gesetzliche Änderungen der BauNVO und durch Reduzierung des Lärmvorsorgestandards die planerischen Gestaltungsmöglichkeiten erweitert worden sind (dazu nachfolgend unter D. II. 1). Ob und inwieweit dies ausreicht, um die notwendigen handwerklichen Entwicklungspotentiale zu erhalten und zu fördern, bedarf einer weiteren Analyse der durch die Gesetzesänderung ausgelösten Korrekturen des Planungssystems und der damit zusammenhängenden Folgewirkungen. Dabei muss, wie bereits oben dargelegt, auch berücksichtigt werden, dass durch die Einfügung des $\mathbb{1 3}$ b BauGB eine auch in einem gewissen Widerspruch zur Innenentwicklungsstrategie stehende Entwicklungsoption zulasten des Freiraums und zugunsten der Wohnnutzung herbeigeführt worden ist.

II. Rechtsentwicklungen in Bezug auf die Errichtung, Änderung, Erweiterung und Erneuerung von Handwerksbetrieben in verschiedenen gemeindlichen Entwicklungsbereichen

1. Rechtsentwicklungen bezüglich des unbeplanten Innenbereichs

Die in $\$ 34$ Abs. 3a BauGB vorgesehene Möglichkeit der Erleichterung der bauplanungsrechtlichen Zulässigkeit der Erweiterung, Änderung, Nut- 
zungsänderung oder Erneuerung von zulässigerweise errichteten Gewerbeund Handwerksbetrieben im unbeplanten Innenbereich ist eine Konsequenz der Innenentwicklungsstrategie. Solche Betriebe sollen an ihren Standorten im Innenbereich erhalten werden. Deshalb ist sowohl für die Erweiterung als auch für die Änderung und die Nutzungsänderung von Handwerksbetrieben eine erweiterte Abweichungsmöglichkeit von Erfordernis des Einfügens in den umgebungsprägenden Rahmen vorgesehen. Mit dieser Abweichungsmöglichkeit vom Erfordernis des Einfügens sind die bauplanungsrechtlichen Zulässigkeitsschranken bei Nichteinhaltung des durch die prägende tatsächliche Umgebungsbebauung gebildeten Beurteilungsmaßstabs im Interesse der bestandswahrenden Maßnahmen zugunsten der Handwerks- und Gewerbebetriebe verschoben worden. ${ }^{57}$

Die Zulassung einer Abweichungsmöglichkeit über den durch das Kriterium des Einfügens gezogenen Zulässigkeitsrahmen hinaus hat zur Folge, dass ein Vorhaben zur Erweiterung, Änderung, Nutzungsänderung oder zur Erneuerung eines Handwerks- oder Gewerbebetriebs am bisherigen Standort im unbeplanten Innenbereich im Einzelfall durchaus die Grenze, wonach beachtliche bodenrechtliche Spannungen nicht ausgelöst werden dürfen, überschreiten kann; denn dadurch wird die Abweichungsmöglichkeit im Einzelfall nicht ausgeschlossen.

Allerdings ist auch diese Abweichungsmöglichkeit begrenzt:

a) Durch die Abweichung darf für Nachbarn keine unzumutbare Beeinträchtigung entstehen.

b) Öffentliche Belange dürfen nicht unangemessen und ohne Kompensation vernachlässigt werden.

c) Die Abweichung darf nicht in der Nachbarschaft eine Vorbildwirkung in der Weise begründen, dass durch summative Effekte die vorhandene Umgebungsstruktur so erheblich verändert wird, dass zur Bewältigung der entstehenden Konflikte oder wegen der zu erwartenden Umweltauswirkungen eine förmliche Planung erforderlich wird.

Davon ausgehend hat das VG Cottbus ${ }^{58}$ die auf die Abweichungsmöglichkeit des $\$ 34$ Abs. 3a BauGB gestützte Umnutzung eines ehemaligen Schlosserei-Gebäudes zu Büroarbeitsräumen für Pensionsgäste mit der Begründung als unzulässig beurteilt, dass durch die bauliche Erweiterung der vorhandenen Hauptnutzung in den hinteren, alleine durch Nebengebäude geprägten Quartiersbereich hinein die vorhandene Bebauungsstruktur in

57 Dazu Spannowsky, in: Spannowsky/Uechtritz, BeckOK/BauGB, 2017, 3. Aufl., $\$ 34 \mathrm{Rn} .78$.

58 Siehe VG Cottbus, Urt. v. 20.09.2018, 3 K 1273/16, juris Rn. 45. 
dem betreffenden Bereich wegen der Vorbildwirkung grundlegend verändert werden könnte. In der vom VG Cottbus zu beurteilenden Fallgestaltung befanden sich in der Nachbarschaft mehrere bauliche Anlagen, die in ähnlicher Weise hätten umgestaltet werden können, sodass sich infolgedessen mit dem erstrebten Vorhaben die Umstrukturierung des Gebiets anzubahnen drohte.

\section{Rechtsentwicklungen bezüglich des unbeplanten Außenbereichs}

Im unbeplanten Außenbereich gilt als Planersatzregelung $₫ 35$ BauGB, ein Zulässigkeitstatbestand, der von dem Grundgedanken beherrscht wird, dass im unbeplanten Außenbereich grundsätzlich nur privilegierte Vorhaben und sonstige Vorhaben nur ausnahmsweise zulässig sein sollen. Neben den privilegierten und den sonstigen Vorhaben gibt es im Außenbereich noch „begünstigte Vorhaben“. Diese sind teilprivilegiert, weil ihnen bestimmte in Absatz 3 aufgeführte Belange, die Darstellungen des jeweiligen Flächennutzungsplans oder Landschaftsplans, die natürliche Eigenart der Landschaft, das Entstehen, die Verfestigung oder Erweiterung einer Splittersiedlung, anders als den „sonstigen Vorhaben“, nicht entgegengehalten werden können. Die erweiterte Zulässigkeit begünstigter Außenbereichsvorhaben resultiert daraus, dass eine Erhaltung zulässigerweise errichteter Bauvorhaben im Außenbereich im Interesse städtebaulicher Substanzwahrung ermöglicht werden soll. In dem abschließenden Katalog der begünstigten Außenbereichsvorhaben des $\$ 35$ Abs. 4 BauGB ist unter S. 1 Nr. 6 auch die bauliche Erweiterung von Gewerbebetrieben aufgeführt. Dazu zählen auch Handwerksbetriebe. Es kann sich dabei durchaus auch um lärmintensivere Handwerksbetriebe, wie Tischler-, Schreiner- und Steinmetzbetriebe, handeln. Die Erweiterung solcher Bestandsbetriebe im Außenbereich ist jedoch begrenzt; zulässig sind lediglich angemessene Erweiterungen. Dabei ist geklärt, dass in die Angemessenheitsbeurteilung nicht auch etwaige benachbarte Wohngebäude, die mit dem Betriebsgebäude in Verbindung stehen, einbezogen werden dürfen, sondern dass vielmehr die Angemessenheit der Erweiterung lediglich ausgehend von dem vorhandenen gewerblichen Betriebsgebäude zu beurteilen ist. Dabei werden üblicherweise Erweiterungen um 25 bis $30 \%{ }^{59}$ und mitunter sogar $50 \%{ }^{60}$ gebilligt.

59 Siehe VGH München, BRS 42 Nr. 92 und OVG Lüneburg BRS 38 Nr. 103.

60 Siehe in dem vom BVerwG zu beurteilenden Revisionsfall BVerwG, NVwZ-RR 1994, 371. 
Das BVerwG hat dabei jedoch betont, dass der Maßstab der Angemessenheit der Erweiterung eines begünstigten Außenbereichsvorhabens nach $\$ 35$ Abs. 1 Nr. 6 BauGB auf städtebaulich relevante Bewertungsmerkmale zu beziehen sei und hat daher zutreffend hervorgehoben, dass die Erweiterung eines Handwerksbetriebs demzufolge nicht erst dann unangemessen sein könne, wenn dieser zu einem industriellen Betrieb werde. Maßgeblich könnten unter städtebaulichen Gesichtspunkten vor allem Veränderungen in Bezug auf den An- und Auslieferungsverkehr sein.

Ob bestimmte Handwerksbetriebe im Einzelfall aufgrund einer mitgezogenen Privilegierung als ortsgebundene Außenbereichsvorhaben im Sinne von $₫ 35$ Abs. 1 Nr. 3 BauGB privilegiert sein können, ist nicht geklärt. So könnten etwa Steinmetzbetriebe, welche im Umfeld eines Steinbruchs errichtet werden, als ortsgebundene, mit einem Steinbruch verknüpfte Handwerksbetriebe zulässig sein. $\mathrm{Ob}$ und inwieweit eine solche ortsgebundene Betriebseinheit, die als Außenbereichsvorhaben privilegiert sein könnte, im Einzelfall gegeben sein kann, hängt nach den Kriterien, welche das BVerwG ${ }^{61}$ in Bezug auf einen Kiesabbaubetrieb, die Kiesaufbereitung bis hin zur Herstellung von Transportbeton entwickelt hat, maßgeblich davon $a b$, ob ein sachlich-funktioneller Zusammenhang zwischen einem Steinbruch und einem Steinmetzbetrieb in dem Sinne gegeben sein kann, dass es sich dabei seinem Erscheinungsbild nach um eine typische Kombinationsform eines Gesamtbetriebs in Gestalt einer ortsgebundenen Steinbruch- und Gesteinsfertigung handelt.

Eine erweiterte Zulässigkeit von kleineren Handwerksbetrieben im Außenbereich kann auch durch eine Außenbereichssatzung im Sinne von $\$ 35$ Abs. 6 S. 1 und 2 BauGB begründet werden. ${ }^{62}$ Aus der Formulierung des $\$ 35$ Abs. 6 S. 2 BauGB, wonach diese Satzung ,auch auf Vorhaben erstreckt werden“ kann, „die kleineren Handwerks- und Gewerbebetrieben dienen“, ist jedoch abzuleiten, dass die Satzung nicht primär dem Zweck der Schaffung von Standorten für kleine Handwerks- und Gewerbebetriebe zu dienen bestimmt ist und daher auch nicht ausschließlich diesem Zweck dienen darf. Vielmehr wird zur Bestimmung der Zulässigkeit einer Außenbereichssatzung angeknüpft an die Voraussetzungen, welche in $\$ 35$ Abs. 6 S. 1 BauGB aufgeführt sind. Es können danach durch eine Außenbereichssatzung die Zulässigkeitshindernisse im Außenbereich für solche Bereiche reduziert werden, die nicht überwiegend landwirtschaftlich geprägt

61 Siehe BVerwG, NJW 1977, $119 \mathrm{f}$.

62 Dazu allgemein Söfker, in: Spannowsky/Uechtritz, BauGB, Kommentar, 3. Aufl., 2018, \$35 Rn. 165. 
sind und in denen eine Wohnbebauung von einigem Gewicht vorhanden ist. Und nur wenn diese Voraussetzungen erfüllt sind, soll auch eine Erstreckung auf Vorhaben möglich sein, die kleineren Handwerks- und Gewerbebetrieben dienen. Der Steuerungseffekt einer Außenbereichssatzung besteht darin, dass den genannten Vorhaben, obwohl sie eigentlich sonstige, also nicht-privilegierte Vorhaben sind, bestimmte Belange, die dem Schutz des Außenbereichs dienen, nicht entgegengehalten werden können. Es werden dadurch folgende Zulässigkeitshindernisse ausgeschaltet: Dass solche Vorhaben im Geltungsbereich einer Außenbereichssatzung einer Darstellung im Flächennutzungsplan über Flächen für die Landwirtschaft oder Wald widersprechen und dass die Entstehung oder Verfestigung einer Splittersiedlung zu befürchten ist. Für Vorhaben, für die auf der Basis einer Außenbereichssatzung eine Zulässigkeitserleichterung geschaffen wird, bleibt es allerdings bei dem Erfordernis des $\$ 35$ Abs. 1 BauGB, wonach ein Vorhaben nur zulässig ist, wenn auch die ausreichende Erschließung gesichert ist. Die Voraussetzungen hierfür können ebenfalls aufgrund der Außenbereichssatzung geschaffen werden.

Die Herbeiführung erleichterter Zulässigkeitsvoraussetzungen für kleinere Handwerksbetriebe im Außenbereich auf der Grundlage des $\$ 35$ Abs. 6 S. 1 BauGB ist durchaus ein nicht unbedeutendes Planungsinstrumentarium zur Schaffung der Standortvoraussetzungen für kleinere Handwerksbetriebe, zumal die individualrechtliche Rechtsschutzkontrolle bezüglich Außenbereichssatzungen eingeschränkt ist, da private Belange, die sich auf das Rücksichtnahmegebot stützen ließen, bei dem Erlass einer Außenbereichssatzung grundsätzlich nicht in die Abwägung einzustellen sind und infolgedessen eine Antragsbefugnis Privater mangels geschützter Individualrechtsposition grundsätzlich ausgeschlossen ist. ${ }^{63}$ Freilich bleibt davon unberührt, dass der bauordnungs- bzw. der immissionsschutzrechtlichen Genehmigung eines solchen Vorhabens Belange des Gesundheitsschutzes bzw. mit dem Rücksichtnahmegebot nicht im Einklang stehende Lärmschutzbelange entgegengehalten werden können. Dies wird durch die Außenbereichssatzung nicht ausgeschlossen. Dadurch, dass über eine Außenbereichssatzung nur für „kleinere Handwerksbetriebe“ die Zulässigkeitsvoraussetzungen geschaffen werden können, wird der Ausnahmetatbestand, der durch die Außenbereichssatzung geschaffen werden kann, eingegrenzt und zugleich sichergestellt, dass nicht der Rahmen für ihrer

63 So ausdrücklich BayVGH, Urt. v. 07.08.2017, 2 N 14.1936, juris Rn. 33 im Anschluss an das OVG NRW, BauR 2015, 1982; ebenso Söfker, in: Ernst/Zinkahn/ Bielenberg, BauGB, Stand: 01.02.2017, $\$ 35$ Rn. 170. 
Größe nach im Außenbereich prägende gewerbliche Siedlungsstrukturen entstehen und dass auch nicht der Rahmen für UVP-pflichtige Vorhaben geschaffen wird. Letzteres wird zudem durch die Anwendungsvoraussetzung des $₫ 35$ Abs. 6 S. 4 Nr. 2 BauGB sichergestellt, wonach die Aufstellung einer Außenbereichssatzung ausgeschlossen ist, soweit damit die $\mathrm{Zu}$ lässigkeit von UVP-pflichtigen Vorhaben begründet wird.

\section{Rechtsentwicklungen im Bereich der städtebaulichen Planung}

Das Städtebaurecht bietet für die an den Handwerksmeisterbetrieben ausgerichteten bisherigen Standortanforderungen differenzierte Gestaltungsmöglichkeiten. Dabei kann grundsätzlich sämtlichen bisherigen Bedürfnissen durch eine sachgerechte Zuordnung zu den verschiedenen Baugebietstypen Rechnung getragen werden.

Angesichts der Flächenknappheit in Ballungsräumen, der grundsätzlichen regionalplanerischen Konzentration der Gewerbeflächenentwicklung auf Ober- und Mittelzentren und der Verschärfung der Konfliktsituation an den Stadträndern durch die Bevorzugung der Entwicklung von Wohnnutzungen in der Nachbarschaft von Gebieten, die bisher Gewerbe- und Handwerksbetrieben vorbehalten waren, stellt sich jedoch die Frage, ob und inwieweit in Anbetracht der neueren Entwicklungen im Handwerksbereich in Richtung der „digital-begeisterten Spezialisten“ und der „Modernen Alleskönner" in naher Zukunft noch in ausreichendem Maße Gewerbeflächen für solche Handwerksbetriebe verfügbar sind.

Oftmals fehlen in den Stadtquartieren die für die Verwaltung von Wohnungseigentümergemeinschaften erforderlichen Handwerksbetriebe, weshalb die Hausverwaltungen, die selbst über einen Handwerker-Pool verfügen, Wettbewerbsvorteile gegenüber denjenigen haben, die den Bedarf über ortsansässige Handwerksbetriebe decken müssen. Für „Moderne Alleskönner", die eine größere Betriebsstruktur aufweisen und dementsprechend grundsätzlich auch auf größere Flächenangebote mit einem häufigen An- und Auslieferungsverkehr für ihren Handwerksbetrieb angewiesen sind, müssen geeignete Standorte für eine derartige Clusterbildung geschaffen werden. Dies kann auch erforderlich sein, um Handwerkscluster zur wohnungsnahen Versorgung von Stadtquartieren mit Handwerkerleistungen sicherstellen zu können. Bei den digital-begeisterten Spezialisten ist dies in der Regel anders, da diese in der Regel nicht auf Lagerhaltung angewiesen sein werden. Daher dürfte dort in der Regel auch der An- und Auslieferungsverkehr begrenzt sein. 
Angesichts der Strategie der Innenentwicklung mit der damit verbundenen Nutzungsmischung ist ausgehend von den absehbaren Veränderungen der Rahmenbedingungen im Bereich der Handwerksbetriebe mit einer Verschärfung der Gemengelagenproblematik, mit dem Risiko zunehmender Restriktionen für Handwerksbetriebe in den Bestandsstrukturen und auch mit dem Fehlen ausreichender Standortangebote für solche Betriebe zu rechnen.

Dies macht es erforderlich, den städtebaurechtlichen Rahmen daraufhin zu überprüfen,

a) ob er die notwendige Flexibilität aufweist, die durch die Veränderungen der Rahmenbedingungen ausgelösten Herausforderungen bewältigen zu können,

b) ob das städtebaurechtliche Systemgefüge zu diesem Zweck noch an der einen oder anderen Stelle nachjustiert werden muss und/oder

c) ob das Bewusstsein der Planungsträger für die Notwendigkeit der Schaffung geeigneter Standortangebote für Handwerksbetriebe geschärft werden muss. 


\section{E. Bedeutung und Tragweite der Baugebietstypisierung für die Erhaltung, Entwicklung und Sicherung von Standortpotentialen für Handwerks- und Gewerbebetriebe innerhalb des Systems der städtebaulichen Planung}

\section{Flächenvorsorge für Handwerksbetriebe im Rahmen der Flächennutzungsplanung}

Ob und inwieweit in den Flächennutzungsplänen für Handwerksbetriebe Flächen bereitgehalten werden können, hängt von einer Reihe von Rahmenbedingungen $a b$, insbesondere davon, ob und inwieweit naturschutzund wasserrechtliche Rahmenbedingungen die räumlichen Entwicklungspotentiale für die Ausweisung von Gewerbeflächen einschränken, ob und inwieweit angesichts der raumordnungsrechtlichen Anforderung die Neuinanspruchnahme von Freiraumflächen regionalplanerisch eingeschränkt ist und ob und inwieweit tatsächlich noch verkehrsmäßig gut erschließbare Entwicklungspotentiale vorhanden sind. Von Bedeutung kann insofern sein, ob bei der Umwandlung von Konversionsflächen nicht nur an die Wohnbauflächen-, sondern auch an das Erfordernis einer Gewerbeflächenentwicklung zur Ansiedlung von Handwerksbetrieben gedacht wird. Dabei muss sowohl an die haushaltsnahen Handwerksleistungen als auch an lärmintensivere Handwerksbetriebe mit An- und Auslieferungsverkehr gedacht werden. Um eine nachhaltige Sicherung einer differenzierten Handwerksstruktur gewährleisten zu können, muss gerade auf der Ebene der Flächennutzungsplanung die räumlich differenzierte Bereithaltung geeigneter Standorte für die unterschiedlichen Handwerksbetriebe sichergestellt werden. Wie in neuerer Zeit informelle Energiekonzepte und Einzelhandelskonzepte in der Phase der Vorbereitung der Bauleitplanung eine zunehmende Bedeutung erlangt haben, liegt es nahe, im Vorfeld größerer Änderungen des Flächennutzungsplans auch ein flächenbezogenes Handwerks- und Gewerbekonzept zu erarbeiten bzw. herstellen zu lassen, damit für diese Gewerbetreibenden eine zukunftsfähige Flächenentwicklung und Standortvorsorge in gebotenem Umfang zum Tragen kommen kann. Davon kann auch der Wert von Wohnimmobilien abhängen, da damit nicht nur die haushaltsnahen Handwerksleistungen sichergestellt, sondern auch wohnortnahe Arbeitsplätze geschaffen werden. 
Mit den neueren Gesetzesänderungen zur Förderung der Nutzungsmischung sind Strukturveränderungen ausgelöst worden, die sowohl Bedeutung für die Flächennutzungsplanung als auch für das Entwicklungsgebot des $₫ 8$ Abs. 2 S. 1 BauGB haben. Kommunale Gestaltungsspielräume werden dadurch zwar einerseits im Interesse der Förderung der Nutzungsmischung erweitert, andererseits wird die Steuerungsfunktion des Flächennutzungsplans mit seiner vorprogrammierenden, gemeindlichen Selbstbindungswirkung eingeschränkt. Insofern ist von Bedeutung, dass urbane Gebiete auf der Basis eines Bebauungsplans sowohl aus einer flächennutzungsplanerischen Darstellung von Wohnbau-, von gemischten Bau- als auch von Gewerbeflächen entwickelt werden können. Das mit der Vorprogrammierung durch den Flächennutzungsplan korrespondierende Entwicklungsgebot hat damit seine Aussagekraft in gewissem Umfang eingebüßt, ist durch die Einführung urbaner Gebiete gewissermaßen „verwässert" worden.

Diese Schlussfolgerung resultiert daraus, dass es nach der Rechtsprechung des BVerwG ${ }^{64}$ ausreicht, wenn der Flächennutzungsplan seine Funktion als städtebauliches Steuerungsinstrument „im Großen und Ganzen" behält. Deshalb ist ein Sondergebiet Abfallentsorgung wegen seiner Wesensverwandtschaft als mit der Ausweisung einer gewerblichen Fläche im Einklang stehend ${ }^{65}$ und die Einbindung eines nicht-großflächigen Einzelhandelsbetriebs und eines Gartencenters sowie die Entwicklung eines allgemeinen Wohngebiets aus einer gemischten Baufläche noch als mit der Ausweisung einer Wohnbaufläche im Flächennutzungsplan vereinbar, oder zumindest nicht als beachtliche Beeinträchtigung der geordneten städtebaulichen Entwicklung im Sinne des $\$ 214$ Abs. 2 Nr. 2 BauGB ${ }^{66}$ beurteilt worden. Bezüglich der Entwicklung eines allgemeinen Wohngebiets aus einer gemischten Baufläche ist dies damit begründet worden, dass auch die gemischte Baufläche gem. $\$ 6$ Abs. 1 BauNVO dem Wohnen diene. ${ }^{67}$

Dies hat die weitere Konsequenz, dass bezüglich der Entwicklung eines urbanen Gebiets wegen der gebietstypisch zulässigen Nutzungsmischung von Wohnen mit gewerblicher Nutzung in Gestalt von zwar störenden,

64 BVerwG, NVwZ 2000, 197 = juris Rn. 21.

65 Siehe VGH BW BauR 2018, 1233 = juris Rn. 80.

66 So OVG SH, Urt. v. 29.04.2015, juris Rn. 48 und 49 und der HessVGH, Urt. v. 29.03.2012, 4 C 694/10.N, juris Rn. 54 bezüglich der Entwicklung eines allgemeinen Wohngebiets aus einer Darstellung im Flächennutzungsplan als gemischte Baufläche.

67 So ausdrücklich der HessVGH, Urt. v. 29.03.2012, 4 C 694/10.N, juris Rn. 53. 


\section{E. Bedeutung und Tragweite der Baugebietstypisierung}

aber nicht wesentlich störenden Handwerks- und Gewerbebetrieben zu nicht festgelegten Anteilen noch mit dem Entwicklungsgebot vereinbar sein dürfte, wenn ein solches urbanes Gebiet auch aus Gewerbeflächen entwickelt wird. Daraus folgt weiter, dass tendenziell Gewerbeflächenpotentiale, die sich für die Standortentwicklung von Handwerksbetrieben eignen, verloren gehen, wenn urbane Gebiete, wie sich aufgrund der bisherigen Praxiserfahrungen abzeichnet, weniger zur Entwicklung gewerblicher Nutzung als vielmehr zur Erweiterung der Wohnnutzung in städtischem Ambiente eingesetzt werden. Dies kann vor allem deshalb zu einer Schieflage führen, weil dieser Verlust schleichend ohne Verstoß gegen das Entwicklungsgebot des $\mathbb{8}$ Abs. 2 S. 1 BauGB eintreten kann und zudem, ohne dass dazu für das gesamte Gemeindegebiet eine gesamträumliche Entwicklungsüberprüfung auf der Ebene der Flächennutzungsplanung stattgefunden haben muss.

II. Das System der baugebietstypischen Differenzierung innerhalb der städtebaulichen Planung und der Planersatzregelungen und dessen Relevanz für die Zulässigkeit von Handwerksbetrieben

1. Die Bedeutung der Typisierung von Handwerksbetrieben und Baugebieten für die Wahl und Sicherung von Standorten für handwerksbetriebliche Vorhaben

Nach dem der BauNVO zugrundeliegenden System der Baugebietstypisierung folgt die gebietstypische Umweltvorsorgestandardisierung einem Stufenmodell, wonach der Umweltvorsorgestandard vom reinen Wohngebiet hin zum Industriegebiet abnimmt. Die Typisierung ist weiterhin ein tragender Systembaustein der BauNVO. Angereichert wurden durch die Einführung der urbanen Gebiete lediglich die Mischgebietsformen, indem zwischen das Mischgebiet und das Gewerbegebiet eine weitere Form der gebietsbezogenen Nutzungsmischung eingefügt und damit auch die bisherige, relativ strikte Trennung von Wohn- und gewerblicher Nutzung gelockert wurde. Damit ist im Rahmen der Verfolgung der Innenentwicklungsstrategie auch in gewissem Umfang Raum für die Schaffung von Standorten für Handwerksbetriebe geschaffen worden.

Soweit bezüglich der Anwendung der urbanen Gebiete bislang noch teilweise die Vorstellung besteht, dass dieser Baugebietstyp auf städtische Räume beschränkt sei, ist diese strategische städtebauliche Umsteuerung in Richtung stärkerer Nutzungsmischung noch nicht überall angekom- 
men. Es stellt sich überdies die Frage, ob diese veränderte Weichenstellung nicht auch Rückwirkung auf die bisherigen Grenzziehungen in Bezug auf andere Baugebietstypen hat bzw. aufgrund weiterer gesetzlicher Schritte in dieser Richtung noch haben kann.

2. Die bauplanungsrechtliche Zulässigkeit von Handwerksbetrieben nach ihrem typischen Erscheinungsbild innerhalb der verschiedenen Baugebiete

Auf die Frage, ob sich die Handwerksbetriebe in ihrem Erscheinungsbild gewandelt haben, kommt es nach der Typisierungslehre nicht an. Dies wäre nur dann anders, wenn es die allgemeinen, baugebietstypisch umschriebenen Formen der Handwerksbetriebe gar nicht mehr gäbe oder wenn die Handwerksbetriebstypen sich so geändert hätten, dass eine gebietstypische Zuordnung nach ihrem handwerkstypischen Erscheinungsbild nicht mehr möglich wäre oder sich grundlegend geändert hätte.

Allein die Tatsache, dass die Handwerksbetriebe ein weiter differenziertes Erscheinungsbild aufweisen, hat keine Auswirkung auf die dem Modell gebietstypisch differenzierter Umweltvorsorgestandards folgende Ordnungsstruktur, welche der Typisierung der BauNVO zugrunde liegt. Dies ist der Grund, warum es nach dem geltendem Ordnungsmodell nicht gerechtfertigt ist, Betrieben, die von dem Standardmodell eines bestimmten Handwerksbetriebstyps abweichen, aufgrund einer Einzelfallbetrachtung den Zugang in Baugebiete zu eröffnen, in denen solche Handwerksbetriebe ausgeschlossen sind. So hat es das BVerwG ${ }^{68}$ nach der geltenden Typisierungslehre folgerichtig als nicht gerechtfertigt angesehen, für Tischlereien in Kleinbetriebsform den Weg zur bauplanungsrechtlichen Zulässigkeit in einem Wohn- oder Mischgebiet auf der Basis einer Einzelfallprüfung zu eröffnen. Entsprechendes gilt für Gerüstbaubetriebe und Kfz-Werkstätten in allgemeinen Wohngebieten, ${ }^{69}$ für die Zulassung eines Nagelstudios im reinen Wohngebiet, bei dem die Abgeltung einer handwerklichen Tätigkeit als im Vordergrund stehend erachtet wurde ${ }^{70}$ und für die genehmi-

68 Siehe BVerwG, Beschl. v. 27.06.2018, 4 B 10/17, ZfBR 2018, 685 anknüpfend an das Urteil des BVerwG v. 03.02.1984, BVerwGE 68, 342; vgl. auch VG Würzburg, Urt. v. 09.10.2014, W 5 K 13.140, juris.

69 Vgl. dazu VG Schwerin, Urt. v. 14.07.2017, 2 A 3091/15, SN juris Rn. 27 und VG Ansbach, Urt. v. 16.10.2014, AN 3 K 14.00594, BauR 2015, 307.

70 Siehe BayVGH, Beschl. v. 29.05.2015, 9 ZB 14.2580, juris Rn. 14. 


\section{E. Bedeutung und Tragweite der Baugebietstypisierung}

gungsfreie Zulassung eines Bildhauer- und Steinmetzbetriebs in einem in einem allgemeinen Wohngebiet gelegenen Gebäude (siehe dazu $\mathbb{} 13$ BauNVO). Wie das BVerwG auf der Basis des bestehenden Systems der Typisierung zutreffend hervorgehoben hat, kommt es nach der Typisierungslehre nicht darauf an, ob der konkrete Betrieb gebietsverträglich ist, sondern darauf, ob ein Betrieb des jeweiligen Handwerkstyps bei funktionsgerechter Nutzung üblicherweise für die Umgebung innerhalb des jeweiligen Baugebietstyps einen nicht verträglichen Störungsgrad aufweist. ${ }^{71}$

Es ist allerdings die Frage, ob noch die Anknüpfung an das Erscheinungsbild bestimmter überkommener Handwerkstypen gerechtfertigt ist, wenn sich für bestimmte Bereiche veränderte Handwerksstrukturen mit neuen Typenbildern herausgebildet haben. So könnte es durchaus gerechtfertigt sein, nicht nur einzelne Handwerksbetriebe wegen ihrer Gebietsversorgungsfunktion in reinen Wohngebieten ausnahmsweise und in Dorfgebieten generell als zulässig zu betrachten, sondern entsprechend der gewandelten Rahmenbedingungen im Handwerksbereich in erweitertem Umfang auch haushaltsnahe Handwerkerpools bzw. moderne haushaltsnahe Alleskönner, die sich in diesen Gebieten niederlassen wollen, um in diesen Gebieten den Handwerkerbedarf zu decken. Bei solchen Betrieben kann zwar vor allem wegen des An- und Abfahrtverkehrs der Störungsgrad höher als der eines bestimmten gebietsverträglichen Handwerksbetriebs sein, die Öffnung für solche gebietsversorgende Handwerksbetriebe könnte jedoch vor allem in größeren Wohnsiedlungen funktionsgerecht sein, soweit dadurch kein deutlich erhöhter Störungsgrad ausgelöst wird. Dies gilt wiederum vor allem in Großstädten und Ballungsräumen, in denen große Wohnsiedlungen entstanden sind und noch entstehen werden. Deshalb ist fraglich, ob es in Großstädten und Ballungsräumen noch gerechtfertigt ist, in einem reinen Wohngebiet weiterhin nur nicht störende Handwerksbetriebe, die zur Deckung des üblichen Bedarfs für die Bewohner des Gebiets dienen, als zulässig einzustufen. Denn dies hat zur Folge, dass grundsätzlich eine Büro- und Lagernutzung für einen Heizungs- und Sanitärbetriebs ausgeschlossen ist. ${ }^{72}$ Zwar kann im Interesse des Bestandsschutzes solchen Nutzungen, falls sie dennoch bereits in einem reinen

71 In diesem Sinne BVerwG ZfBR 2018, 685 und ebenso die ständige Rechtsprechung auf der Basis der Entscheidung des BVerwG, Buchholz 406.11 $\$ 35$ BBauG Nr. 23 sowie der herrschenden Lehre; vgl. dazu Söfker, in: Ernst/Zinkahn/Bielenberg/Krautzberger, BauGB, Stand Februar 2018, $\$ 6$ BauNVO Rn. 27 sowie Roeser, in: König/Roeser/Stock, BauNVO, 3. Aufl., 2014, \$ 6 Rn. 13.

72 So zutreffend VG Cottbus, Urt. v. 20.09.2018, 3 K 1273/16, juris Rn. 55. 
Wohngebiet vorhanden sind, unter den Voraussetzungen des $\$ 10$ BauNVO aufgrund eines Bebauungsplans eine Fremdkörperfunktion mit einer begrenzten Erweiterungsmöglichkeit eingeräumt werden, diese Korrekturmöglichkeit kann jedoch nicht dafür herangezogen werden, weitere handwerkliche Nutzungen, die nicht der Versorgung eines reinen Wohngebiets dienen, zuzulassen.

Ob die Einschränkung durch die Typisierung der Baugebiete und im Fall der reinen Wohngebiete durch Begrenzung auf die Gebietsversorgung noch zeit- und sachgerecht ist, kann, soweit es Großstädte und Ballungsräume anbelangt, durchaus fraglich sein, zumal digital spezialisierte Handwerksbetriebe, die ihre Handwerksleistungen nicht innerhalb des reinen Wohngebiets anbieten können, in der Regel keinen höheren Störgrad aufweisen als ein als Fremdkörper zulassungsfähiger Heizungs- und Sanitärbetrieb mit Büro- und Lagernutzung.

Hinsichtlich der Grenzziehung könnte daher durchaus räumlich differenziert nach Großstädten und Ballungsräumen einerseits und ländlichen Räumen andererseits ein dem Baugebietstypus der nächsten Stufe entsprechender, geringfügig reduzierter Umweltvorsorgestandard zum Maßstab gemacht werden, also etwa für das reine Wohngebiet in einer Großstadt oder in Ballungsräumen der Umweltvorsorgestandard, der bei allgemeinen Wohngebieten einzuhalten ist. Eine den Bestimmtheitsanforderungen genügende Abgrenzung der Ballungsräume könnte durch eine regionalplanerische Festlegung von Entwicklungsschwerpunkten in Form eines Ziels der Raumordnung vorgenommen werden.

Es ist auch durchaus die Frage, ob die Begrenzung der Zulassung von Handwerksbetrieben auf nicht wesentlich störende Handwerksbetriebe und auf die der Gebietsversorgung dienenden Handwerksbetriebe noch gerechtfertigt ist oder ob nicht generell eine Ausdehnung auf nicht störende Handwerksbetriebe vorzunehmen wäre, zumal die klassischen Dorfgebiete, die zu allererst der Unterbringung der Wirtschaftsstellen land- und forstwirtschaftlicher Betriebe dienen, immer seltener werden und es wiederum nicht selten vorkommt, dass gerade bei der Ausweisung von Dorfgebieten Etikettenschwindel zur Rechtfertigung eines für das Gebiet zu erwartenden erhöhten Störungsgrads betrieben wird. Warum z. B. die Zulassung einer Sondermaschinenbaufirma und eines Kunsthandwerksbetriebs in einem Dorfgebiet nur deshalb nicht zulässig sein soll, weil diese Betriebe nicht der Versorgung der Bevölkerung dienen, ist zwar eine Folge der Typisierungslehre, aber im Ergebnis kaum nachvollziehbar und dürfte dem heutigen Typus eines Dorfgebiets in seinem gewandelten Erschei- 


\section{E. Bedeutung und Tragweite der Baugebietstypisierung}

nungsbild nicht mehr gerecht werden. ${ }^{73}$ Diesbezüglich ist zudem nicht zu erkennen, warum die Sondermaschinenbaufirma unzulässig, hingegen ein Betrieb, der Landmaschinen verleiht, zulässig sein soll, obwohl von diesem im Einzelfall weitaus mehr Luftschadstoffe freigesetzt werden als von einer Sondermaschinenfirma.

3. Die Zulässigkeit von Handwerksbetrieben bei Gemengelagen infolge Nutzungsmischung

In vielen Fällen werden Standorte für Handwerksbetriebe nicht durch die Ausweisung von Neubaugebieten als vielmehr im Rahmen der Innenentwicklung der Städte und Gemeinden auf Bestandsflächen oder in Bestandgebäuden entwickelt, erweitert oder geändert. Dies führt häufig zu Gemengelagen, weil Handwerksbetriebe im Rahmen der Innenentwicklung zwangsläufig auf andere Nutzungen treffen und dadurch auch Nutzungskonflikte in Bezug auf Lärm, Luftschadstoff- und/oder Geruchsbelästigungen entstehen. Deshalb ist es heute in Anbetracht der Planungsprämisse, dass die städtebauliche Innenentwicklung Vorrang vor der Außenentwicklung hat, in der Stadtentwicklung nicht ungewöhnlich, dass in Anbetracht der damit verbundenen Nachverdichtung und Nutzungsmischung Konflikte zwischen den unterschiedlichen Nutzungen in unbeplanten Bereichen und in aneinander angrenzenden Gebieten auftreten.

Eine Gemengelageproblematik kann dadurch eintreten, dass infolge einer gewollten oder zugelassenen Nutzungsmischung ein Nebeneinander von störenden und störempfindlichen Nutzungen entsteht bzw. entstanden ist. Dieser Fall tritt insbesondere auf, wenn im Wege der städtebaulichen Planung ein reines Wohngebiet an ein Gewerbegebiet herangeführt wird oder wenn innergebietlich infolge einer planerisch gezielt herbeigeführten oder zugelassenen Nutzungsmischung in gemischten faktischen (siehe $₫ 34$ Abs. 2 BauGB) oder geplanten Baugebieten ein Nebeneinander von störenden und störempfindlichen Nutzungen entstanden ist.

Das Vorhandensein einer solchen Gemengelage und die damit verbundenen Nutzungskonflikte sind grundsätzlich hinzunehmen. Die Umweltvorsorge und die grundrechtliche Schutzpflicht können jedoch ein planerisches Tätigwerden zur Vermeidung von Gemengelagen erforderlich machen. Außerdem kann es kraft der gemeindlichen Planungshoheit ein städ-

73 Siehe dazu VG München, Urt. v. 25.07.2017, M 1 K 16.5925, juris Rn. 28. 
tebaulich-planerisches Anliegen der Gemeinde sein, das Entstehen von Gemengelagen zu vermeiden und zu entschärfen.

\section{Der Bestandsschutz bei Fortführung der Nutzungsmischung in Gemengelagen}

Ist bereits eine Gemengelage vorhanden, genießen grundsätzlich auch die bereits vorhandenen Nutzungen, die sich in einer Gemengelagensituation und dabei in einer Konfliktsituation befinden, Bestandsschutz, sodass im Fall der Bestandsüberplanung zur Entschärfung der Gemengelage oftmals der Frage nachgegangen werden muss, ob und inwieweit es in der jeweiligen Bestandssituation gerechtfertigt sein kann, die eine oder die andere Bestandsnutzung einzuschränken. Dabei gibt es keine Regel, die es rechtfertigen würde, eine Nutzungsbeschränkung im Verhältnis der im Konflikt stehenden Nutzungen nur zugunsten der gebietstypischen Hauptnutzung, die zugleich eine störempfindliche Nutzung ist, vorzusehen. Denn eine bereits vorhandene störende Nutzung genießt genauso Bestandsschutz wie die störempfindliche Nutzung. Maßgebend für die Nutzungsbeschränkung der einen oder der anderen Nutzung sind vielmehr städtebauliche Gründe und ggf. welche zur Entschärfung der Konfliktsituation erforderliche Beschränkung mit dem geringsten Aufwand und am schnellsten zu vollziehen ist.

Dass der Gesetzgeber in das grundsätzlich von Gleichrang geprägte Beziehungsverhältnis zwischen den verschiedenen Bestandsnutzungen eingreift, ist die Ausnahme; Einschränkungen des Bestandsschutzes und des Nutzungsrechts bestimmter Nutzungen zugunsten einer anderen Nutzung können jedoch im Fall des Bestehens besonderer städtebauliche Gründe, insbesondere zur Abwehr von Gefahren und im Interesse der Risikominimierung gerechtfertigt sein.

Auf dieser Vorüberlegung basieren die neu eingeführten stadtplanerischen Gestaltungsmöglichkeiten des $\$ 9$ Abs. 1 Nr. 23c BauGB und des $\$ 9$ Abs. 2c BauGB. Diese Vorschriften erlauben es ausgehend von dem Bestandsschutz bestimmter Betriebe mit gefährlichen Betriebsbereichen im Sinne der Seveso III-Richtlinie bzw. des darauf basierenden $\$ 3$ Abs. 5a BImSchG zulasten der Nachbarschaft solcher Betriebsbereiche, bestimmte bauliche oder technische Maßnahmen im Zusammenhang mit der Errichtung, Änderung oder Nutzungsänderung von nach Art, Maß oder Nutzungsintensität zu bestimmenden Gebäuden oder sonstigen Anlagen festzusetzen, um damit den Seveso III-Richtlinienanforderungen zur Vermei- 


\section{E. Bedeutung und Tragweite der Baugebietstypisierung}

dung oder Minderung der Folgen etwaiger Störfälle Rechnung zu tragen. Dies kann nach $\$ 9$ Abs. 2c BauGB auch dazu führen, dass zulasten bestimmter Nachbarnutzungen, Arten von Nutzungen oder für nach Art, Maß oder Nutzungsintensität zu bestimmende Gebäude oder sonstige bauliche Anlagen in einem Bebauungsplan festgesetzt werden kann, dass diese zulässig, nicht zulässig oder nur ausnahmsweise zulässig sind. Diese Festsetzungen können für Teile des räumlichen Geltungsbereichs des Bebauungsplans unterschiedlich getroffen werden. Diese maßnahmen-, gebäudeund nutzungsbezogenen Beschränkungen und Ausschlüsse können zu einer Modifikation von Baugebietstypen führen, in denen eine Nutzungsmischung besteht. Tendenziell werden solche Maßnahmen und die damit verbundenen Nutzungsbeschränkungen eher zu einer Veränderung des Gebietstyps in Richtung Gewerbe- oder gar Industriegebiet führen. Dem Bestandsschutz von Betrieben mit derartigen Betriebsbereichen und damit der betrieblichen Standortsicherung wird insofern der Vorrang vor dem individuellen Nutzungsinteresse bestimmter, risikobehafteter Gebiete gegeben. Dies erscheint sachgerecht, weil für die schutzbedürftigen Nachbarnutzungen städtebaulich eher anderweitige Ausweichmöglichkeiten angeboten werden können als für Risikobetriebe und weil betriebsbezogene Beschränkungen auf der Basis immissionsschutzrechtlicher nachträglicher Anordnungen möglich sind. Soweit Nutzungen in der Nachbarschaft noch nicht ausgeführt sind, ist die planerische Einschränkung und der Ausschluss der benachbarten Nutzungen unter den genannten Voraussetzungen städtebaurechtlich entschädigungslos hinzunehmen (siehe dazu $\$ 42$ Abs. 3 S. 1 BauGB); anderenfalls ist eine Entschädigung zu gewähren. Auch dies kann bei Bestehen eines erheblichen Störfallrisikos im Einzelfall einen Nutzungsausschluss im Sinne des $\$ 9$ Abs. 2c BauGB rechtfertigen.

Planerische Einschränkungen des Bestandsschutzes drohen bestimmten Nutzungen nicht nur im Fall der Erforderlichkeit von Schutzvorkehrungen zur Vermeidung und Verringerung von Störfallrisiken, die von SevesoBetrieben ausgehen, sondern auch zur Vermeidung anderer Risiken, wie der Vermeidung und Verringerung von Hochwasserschäden einschließlich Schäden durch Starkregen (vgl. $\$ 9$ Abs. 1 Nr. 16c und Nr. 16d BauGB) sowie wegen des Erfordernisses zur Sicherstellung von Lärmschutz- und Luftreinhalteanforderungen (vgl. $\$ 9$ Abs. 1 Nr. 24 BauGB).

Die gesetzliche Lösung zur Bewältigung des Konflikts zwischen SevesoBetriebsbereichen und benachbarten schutzwürdigen Nutzungen im Rahmen des Städtebaurechts bewegt sich auf der Linie der Konfliktlösung, welche die Rechtsprechung hinsichtlich der Beurteilung von Störpotentialen im Fall von Gemengelagen vorgezeichnet hat. Denn in der Rechtspre- 
chung ist anerkannt, dass, soweit sich die Wohnnutzung an einen vorhandenen störenden Gewerbebetrieb heranentwickelt hat, wie z. B. in einem Dorfgebiet das Wohnen an einen störenden Sägewerksbetrieb, die Schutzwürdigkeit der Wohnnutzung wegen der vorgefundenen Vorbelastung geringer einzustufen ist. ${ }^{74}$ Zur Entschärfung der Seveso-Problematik können daher gegenüber dem betreffenden Betrieb unter den Voraussetzungen des Immissionsschutzrechts nachträgliche Anordnungen ergriffen werden, auf städtebaulicher Basis können zulasten der Nachbarschaftsnutzung unter den oben genannten Voraussetzungen Vorkehrungen und Nutzungseinschränkungen vorgesehen werden, wenn dies zur Vermeidung oder Minderung von Störfallfolgen erforderlich ist.

Zur Lösung von Gemengelagenproblemen zwischen verschiedenen vorhandenen Nutzungen im unbeplanten Innenbereich und im Fall angrenzender Baugebiete ermittelt die ständige Rechtsprechung die Schutzwürdigkeit zur Bewältigung einer Gemengelageproblematik unter Berücksichtigung des Aspekts der Vorbelastung und der wechselseitigen Pflicht zur Rücksichtnahme. Handelt es sich bei dem betroffenen räumlichen Bereich, in dem die Gemengelagenproblematik auftritt, um eine unbeplante nähere Umgebung im Sinne von $\$ 34$ BauGB oder treffen bei gebietsüberschreitendem Lärm verschiedene Nutzungen aufeinander, welche in aneinandergrenzenden Gebieten mit unterschiedlicher Schutzwürdigkeit ausgeübt werden, wird zur Bestimmung der Schutzwürdigkeit der sensiblen Nutzung, um der heterogenen Planungssituation gerecht zu werden, ein Mittelwert gebildet. ${ }^{75}$ Dabei wird dieser Wert nicht mathematisch durch arithmetische Mittelung errechnet, sondern dadurch, dass ausgehend von dem Aspekt der gegenseitigen Rücksichtnahme ein Zwischenwert ermittelt wird, welcher die Zumutbarkeitsschwelle im Einzelfall markiert. ${ }^{76} \mathrm{Da}$ es sich dabei oftmals um Gemengelagen handelt, bei denen die Wohnnutzung mit einer wesentlich störenden Nutzung aus dem benachbarten Gewerbe- und Industriegebiet kollidiert, führt die Mittelwertbildung dazu, dass Immissionsrichtwerte für Kern-, Dorf- und Mischgebiete als schrankensetzende Maßstäbe herangezogen werden, die nach den bisherigen Maßstäben der Rechtsprechung unter Zumutbarkeitsgesichtspunkten auch nicht überschritten werden sollen. ${ }^{77} \mathrm{Ob}$ dies sich durch die Zulassung des urbanen Gebiets geändert hat, bei dem nunmehr von vorn-

74 Siehe dazu BayVGH, Urt. v. 19.02.1999, 14 B 98.297.

75 So BVerwGE 50, 49.

76 So ausdrücklich BVerwG, NVwZ-RR 1994, 139.

77 So ausdrücklich BayVGH, Urt.v. 19.02.1999, 14 B 98.297, juris Rn. 42. 


\section{E. Bedeutung und Tragweite der Baugebietstypisierung}

herein Tag-Werte oberhalb der von Kerngebieten, Dorfgebieten und Mischgebieten vorgesehenen Immissionsrichtwerte für Immissionsorte auBerhalb von Gebäuden erreicht werden, ist fraglich.

Bei logischer Fortführung der vorstehend genannten Rechtsprechung zur Mittelwertbildung dürfte dies aber dazu führen, dass die Zumutbarkeitsschwelle für Lärm durch die gesetzgeberische Entscheidung für die Einführung des urbanen Gebiets und durch die entsprechende Änderung der TA Lärm, wodurch das urbane Gebiet in Bezug auf die genannten Immissionsrichtwerte zwischen die Kerngebiete, Dorfgebiete und Mischgebiete einerseits und die Gewerbegebiete andererseits platziert wurde, mit der Folge angehoben wurde, dass künftig auch noch Werte, wie sie im Gewerbegebiet zumutbar wären, beim Zusammentreffen verschiedener Nutzungen in Gemengelagen in unbeplanten Bereichen und bei aneinander angrenzenden urbanen Gebieten und Gewerbe- und Industriegebieten hinzunehmen sein könnten (zu den Grenzen des Gesundheitsschutzes siehe aber unten E. II. 1.).

\section{Entschärfung der Gemengelagenproblematik durch die Fortentwicklung der planerischen allgemeinen und speziellen Feinsteuerungsmöglichkeiten}

Städtebaulich können im Vorfeld der oben beschriebenen worst-case-Szenarien einige planerische Gestaltungsmöglichkeiten ergriffen werden, um eine Extremsituation zu vermeiden und die Gemengelagenproblematik mit all ihren schwerwiegenden Nachteilen und Risiken zu vermeiden.

Durch eine Bestandsüberplanung lassen sich Nutzungskonflikte in der Regel vermeiden bzw. lösen. Zur Bewältigung der Gemengelagenproblematik stehen die planerischen Feinsteuerungsmöglichkeiten gem. $\mathbb{S} 1$ Abs. 4 bis 9 BauNVO und überdies zugunsten vorhandener, in einem Gebietstyp an sich unzulässiger Anlagen im Einzelfall auch bestandssichernde Festsetzungen aufgrund $\mathbb{S} 1$ Abs. 10 BauNVO zur Verfügung. Dazu kommen spezielle gebietsbezogene Feinsteuerungsmöglichkeiten bezüglich der Baugebiete mit Mischnutzung nach den $\mathbb{S} \mathbb{4} 4 \mathrm{a}$ Abs. 4, 6a Abs. 4, 7 Abs. 4 und $12 \mathrm{Abs.} 4 \mathrm{BauNVO}^{78}$. So ist für besondere Wohngebiete, deren Eigenart dadurch geprägt ist, dass in diesen Gebieten neben der Wohnnutzung auch wohnnutzungsverträgliche gewerbliche Nutzungen, also auch handwerkliche Nutzungen, untergebracht werden können, gem. $\mathbb{\$} 4 \mathrm{a}$ Abs. 4

78 Siehe dazu Spannowsky, ZfBR 2018, 447 ff. 
BauNVO die Möglichkeit vorgesehen, dass bei Vorliegen besonderer städtebaulicher Gründe im Bebauungsplan auch eine vertikale Nutzungsgliederung vorgenommen werden kann, indem im Bebauungsplan bestimmt wird, dass oberhalb bestimmter Geschosse nur Wohnungen zulässig sind oder indem bestimmt wird, dass in Gebäuden ein bestimmter Anteil der zulässigen Geschossfläche oder eine bestimmte Größe der Geschossfläche für Wohnungen zu verwenden ist.

Entsprechende gebietsbezogene spezielle Feinsteuerungsmöglichkeiten sind für die Bebauungsplanung auch in Bezug auf die urbanen Gebiete in $\$ 6$ abs. 4 BauNVO und in Bezug auf die Kerngebiete in $\$ 7$ Abs. 4 BauNVO vorgesehen. So sind in Bezug auf urbane Gebiete folgende Feinsteuerungsmöglichkeiten vorgesehen: Es kann in einem Bebauungsplan festgesetzt werden, dass in einem Erdgeschoss an der Straßenseite eine Wohnnutzung nicht oder nur ausnahmsweise zulässig ist. Außerdem kann wie bei einem besonderen Wohngebiet nach $\$ 4$ a Abs. 4 Nr. 2 BauNVO auch bei einem urbanen Gebiet nach $₫ 6$ a Abs. 4 Nr. 3 BauNVO festgesetzt werden, dass ein bestimmter Anteil der zulässigen Geschossfläche oder eine im Bebauungsplan bestimmte Größe der Geschossfläche für Wohnnutzungen zu verwenden ist. Überdies kann in einem urbanen Gebiet nach $\$ 6$ a Abs. 4 Nr. 4 BauNVO eine entsprechende Festsetzung auch zugunsten der gewerblichen Nutzungen, also auch zugunsten handwerklicher Nutzungen, getroffen werden. Entsprechende Festsetzungen sind in einem Bebauungsplan bezüglich Kerngebieten nach $\$ 7$ Abs. 4 zugunsten der Wohnnutzung möglich. Ohne diese gebietsbezogenen Feinsteuerungsmöglichkeiten wird bei der Festsetzung eines urbanen Gebiets in der Regel nicht auszukommen sein, da gerade bei diesem Gebiet die Einhaltung der Gesundheitsschutzvorsorge in Bezug auf Lärm zu prüfen und ggf. Schutzvorkehrungen gegen die Überschreitung der Lärmschutzschwelle zu ergreifen sind. Denn insofern gilt, dass die Gemeinde alle Möglichkeiten zur Vermeidung der Überschreitung der gesundheitskritischen Schwelle ergreifen muss. ${ }^{79}$

Angesichts des erhöhten Parkplatzbedarfs bei handwerklichen Nutzungen ist überdies $\mathbb{1 2}$ Abs. 4 BauNVO von erheblicher Bedeutung. Danach kann unabhängig von der Art des Baugebiets, weil gem. $\$ 12$ Abs. 1 BauNVO Stellplätze und Garagen in allen Baugebieten zulässig sind, in einem Bebauungsplan bei Vorliegen besonderer städtebaulicher Gründe festgesetzt werden, dass in bestimmten Geschossen nur Stellplätze oder

79 So zutreffend BVerwG, NVwZ 2007, 831 und Hornmann, in: Spannowsky/Hornmann/Kämper, Kommentar zur BauNVO, 2018, \$ 6a Rn. 49c. 
Garagen und zugehörige Nebeneinrichtungen zulässig sind ( $\$ 12$ Abs. 4 S. 1 BauNVO). Eine entsprechende Festsetzung kann außerdem auch für Geschosse unterhalb der Geländeoberfläche getroffen werden.

Mittels dieser allgemeinen und speziellen gebietsbezogenen Festsetzungen können Gemengelageprobleme in der Regel planerisch gelöst werden, soweit nicht besonders störende, belästigende gewerbliche Nutzungen mit besonders störempfindlichen Nutzungen, z. B. bei angrenzender reiner Wohnnutzung, in einem Nutzungskonflikt stehen.

Eine Ausweitung dieser speziellen gebietsbezogenen Festsetzungen ist meiner Ansicht nach, ohne dass die am Trennungsprinzip und der Umweltvorsorge orientierte Gebietstypisierung an sich angetastet werden müsste, bezüglich der gemischten Gebiete insofern denkbar, als für die Dorf- und Mischgebiete eine vergleichbare Möglichkeit der gebäudeinternen Mischung verträglicher Nutzungen geschaffen werden könnte. Denn es ist nicht einleuchtend, wieso dies für die besonderen Wohngebiete, die urbanen Gebiete und die Kerngebiete vorgesehen ist, nicht aber für die Dorf- und Mischgebiete, obwohl gerade auch dort das Bedürfnis für eine gebäudeinterne wohnverträgliche Handwerksnutzung gegeben sein kann.

Die beschriebenen Möglichkeiten der planerischen Feinsteuerung stoßen freilich an verschiedene rechtliche Grenzen. Diese zu kennen, ist zur Vermeidung handwerksbetrieblicher Nutzungskonflikte für die Planungspraxis bedeutsam. Insofern stellen sich folgende weitere Fragen,

a) ob und welche rechtlichen Grenzen für die Anwendung der planerischen Feinsteuerungsmöglichkeiten bestehen und

b) ob diese im Interesse der Förderung der Erhaltung und Erweiterung handwerklicher Nutzungen im Bereich der Innenentwicklung der Städte und Gemeinden zugunsten der Erweiterung der Zulässigkeit von Handwerksbetrieben verschoben werden könnten.

6. Die Begrenzung der planerischen Feinsteuerung durch den Gebietswahrungsanspruch

Für die feinsteuernde Bestandsbebauungsplanung resultiert aus dem Anspruch auf Wahrung des Gebietscharakters eine bedeutsame einfachgesetzliche Grenze. Diese ist vor allem von Bedeutung, soweit Nutzungen Baugebiete tangieren, welche vorwiegend einer bestimmten Nutzungsart dienen sollen, wie die reinen, die allgemeinen und die besonderen Wohngebiete, aber auch die Gewerbe- und Industriegebiete sowie Sondergebiete. 
Dagegen ist umstritten, ${ }^{80}$ ob ein Gebietserhaltungsanspruch auch in Bezug auf ein durch Feinsteuerung bereits modifiziertes Baugebiet gegeben sein kann. Dies ist jedoch mit der herrschenden Rechtsprechung und Lehre zu bejahen, denn es ist in der Regel aus der städtebaulichen Konzeption ein plangebietsinterner oder gebietsübergreifender Nachbarschutz abzuleiten. Dies kommt vor allem hinsichtlich Fallgestaltungen in Betracht, bei denen bereits nach der städtebaulichen Konzeption, welche der Modifikation des Baugebiets zugrunde liegt, Lärmschutz- oder Luftreinhalteanforderungen zugunsten der Nachbarschaft oder ein eigentumsrelevanter Nutzungsausschluss vorgesehen ist. Im Übrigen sind Grundstückseigentümer auch gegenüber einer "schleichenden Umwandlung“ geschützt. ${ }^{81}$

Die subjektiv-rechtliche Gewährleistung eines Gebietserhaltungsanspruchs ist eine Konsequenz, welche aus der Ordnungsfunktion resultiert, die dem System der Baugebietstypen innewohnt. Denn dieses System trägt nicht nur dem Trennungsprinzip, sondern auch der grundrechtlichen Schutzfunktion zugunsten der verschiedenen Nutzungen Rechnung. Infolgedessen geht der Gebietserhaltungsanspruch in seiner Schutzfunktion über die bloße Möglichkeit der Abwehr unzumutbarer Beeinträchtigungen wie im Fall des nachbarlichen Rücksichtnahmegebots hinaus. ${ }^{82}$ Deshalb wird dieser Anspruch schon dadurch ausgelöst, dass eine mit dem festgesetzten Baugebietstyp, der vorwiegend einer bestimmten Hauptnutzungsart dient, entgegenstehende Nutzung zugelassen wird, durch die eine Störung des nachbarlichen Austauschverhältnisses bzw. eine Verfremdung des Gebietscharakters eintreten könnte. ${ }^{83}$ Der bloße Ausschluss einer oder aller Ausnahmen verändert grundsätzlich den Gebietscharakter noch nicht. ${ }^{84}$ Dies kann nur dann anders sein, wenn bereits ein verändertes Baugebiet entstanden ist, das nach den planerischen Vorstellungen der ge-

80 Dazu einerseits OVG Münster BeckRS 2017, 103312 und Brügelmann/Ziegler, BauGB, Stand April 2016, BauNVO $\mathbb{S} 1$ Rn. 479 sowie Bönker/Bischopink/ Pützenbacher, BauNVO, 2014, $\$ 8$ Rn.38 und andererseits OVG Hambrug NVwZ-RR 2013, 990 und BauR 2016, 950 sowie Fickert/Fieseler, BauNVO,1995, \8 Rn. 3.12.

81 So zutreffend BVerwGE 94, 151 und NVwZ 2002, 1384 sowie VGH München BauR 2012, 49.

82 Dazu Spannowsky, in: Spannowsky/Hornmann/Kämper, BauNVO, 2018, $\$ 1$ Rn. 144.

83 Vgl. dazu Gatz, juris PR-BVerwG 10/2008 Anm. 2 und Marschke, Der Gebietserhaltungsanspruch, 2009, $147 \mathrm{f}$.

84 Dies ist aber dann anders, wenn ein allgemeines Wohngebiet durch Ausschluss aller anderen Nutzungen so modifiziert wird, dass nur ein reines Wohngebiet übrigbleibt, siehe dazu OVG Bln-Bbg, BeckRS 2016, 54143. 
meindlichen Planung eine Schutzfunktion zugunsten einer bestimmten Nutzungskombination beinhaltet. ${ }^{85}$

III. Anlassbezogene gesetzgeberische Systemkorrekturen auf der Basis von Übergangsregelungen zur Erleichterung der Unterbringung von Flüchtlingen und Asylanten und deren Konsequenzen für die Standortentwicklung von Handwerks- und Gewerbebetrieben

Aufgrund der neueren gesetzlichen Übergangsregelungen ist diese Balance bei der Nutzungsverteilung vor allem zulasten der handwerklichen und gewerblichen Nutzungen in Gefahr geraten. Denn sowohl die Übergangsregelungen in $\$ 246$ BauGB mit Sonderregelungen für Flüchtlingsunterkünfte als auch die befristete Einführung des $\$ 13 \mathrm{~b}$ BauGB greifen auf räumliche Entwicklungskontingente zu, welche mittelfristig für die Schaffung von Handwerks- und Gewerbebetriebe verfügbar waren und bereitgehalten wurden.

So wurden aufgrund des Gesetzes über Maßnahmen im Bauplanungsrecht zur Erleichterung der Unterbringung von Flüchtlingen v. 20.11.2014 (BGBl. I S. 1748) zulässigkeitserweiternde Sonderregelungen für Flüchtlingsunterkünfte geschaffen, die zunächst dem städtebaulichen Zweck dienten, die Schaffung von Wohnraum für Flüchtlinge und Asylbegehrende in Gewerbegebieten zu erleichtern. Danach wurde diese Sonderregelung aufgrund Art.6 des Asylverfahrensbeschleunigungsgesetzes v. 20.10.2015 (BGB1. I S. 1722) auch auf andere Baugebiete ausgedehnt, indem der Vorschrift des $\$ 246$ BauGB die weiteren Abs. 11-17 zum Zweck der Erleichterung der Schaffung von Flüchtlings- und Asylbewerberunterkünften angefügt worden sind. Es handelt sich um Übergangsregelungen, die bis zum 31.12.2019 befristet sind und bis dahin in bauaufsichtlichen Zulassungsverfahren Anwendung finden ( $\$ 246$ Abs. 17 BauGB). Die Sonderregelung des $₫ 246$ Abs. 10 BauGB aufgrund des Gesetzes über Maßnahmen im Bauplanungsrecht zur Erleichterung der Unterbringung von Flüchtlingen brachte zunächst Zulässigkeitserleichterungen für Gewerbegebiete. Diese Regelungen schränkten infolge der erweiterten Zulässigkeit von Flüchtlings- und Asylantenunterkünften in Gewerbegebieten zunächst die Standortpotentiale für Handwerks- und Gewerbegebieten in den diesen Betrieben zu dienen bestimmten Gebieten ein. Die nachfolgende Aus-

85 Ähnlich Gatz, jurisPR-BVerwG 10/2008 Anm.2; dazu auch Spannowsky in: Spannowsky/Hornmann/Kämper, BauNVO, 2018, $\mathbb{1}$ Rn. 264. 
dehnung dieser Zulässigkeitstatbestände auf andere Plangebiete und faktische Baugebiete iSv $\$ 34$ Abs. 2 BauGB sowie auf Flächen im Außenbereich führten zwangsläufig zu einer weiteren Verknappung der für störende Handwerks- und Gewerbebetriebe bereitstehenden Nutzungspotentiale. Diese Problematik wurde durch die Sonderregelung des $\$ 13 \mathrm{~b}$ BauGB, die für die Übergangszeit Verfahrenserleichterungen hinsichtlich der Einbeziehung von Außenbereichsflächen in das beschleunigte Verfahren vorsieht, weiter verschärft, weil dadurch die Schaffung von Wohnraumpotentialen an den Rändern der Städte und Gemeinden, die an sich für die Entwicklung von Gewerbe- und Handwerksbetrieben in Betracht kommen, gefördert und damit eine weitere Verknappung zulasten der Standortentwicklung für störende Gewerbe- und Handwerksbetriebe ausgelöst worden ist.

Mittels dieser extensiven Feinsteuerung durch die genannten anlassbedingten gesetzlichen Sonder- und Übergangsregelungen ist die der Baugebietstypisierung zugrundeliegende Ordnungsstruktur verschoben und der Gebietswahrungsanspruch anlassbezogen eingeschränkt worden. Grundsätzlich ist zwar davon auszugehen, dass die gesetzlich vorgesehenen planerischen Feinsteuerungsmöglichkeiten das Beziehungsgefüge zwischen den verschiedenen Eigentumsinteressen und Grundrechtsgewährleistungen so ausgestalten, dass damit allen Nutzungsinteressen angemessen Rechnung getragen werden kann. Die differenzierte Gebietstypisierung mit den damit verbundenen "Nutzungsschablonen“ stellte bislang sicher, dass ein ausgeglichenes Austauschverhältnis sowie eine Balance zwischen den verschiedenen Nutzungen bei der Schaffung von Nutzungsmöglichkeiten hergestellt werden kann. Durch die Konzentration auf die Innenentwicklung und die Erhöhung der Nutzungskonkurrenzen an den Rändern der Städte und Gemeinden gerät jedoch auch die bisherige Ordnungsstruktur unter Anpassungsdruck. Um aus diesem Dilemma herauszukommen, ist die Erleichterung der Nutzungsmischung eine zwangsläufige Folge. Es stellt sich aber durchaus die Frage, ob dies ausreicht, um in Anbetracht des Strukturwandels im Handwerksbereich, flexibel auf die veränderten Standortanforderungen reagieren zu können.

IV. Gesetzgeberische Systemkorrekturen zur Entwicklung und Erhaltung erweiterter Standortpotentiale zugunsten von Handwerks- und Gewerbebetrieben

Der Bundesgesetzgeber hat zwischenzeitlich zwar auch Systemkorrekturen vorgenommen, welche dem Interesse an der Entwicklung und Erhaltung 


\section{E. Bedeutung und Tragweite der Baugebietstypisierung}

von Standorten für Handwerksbetriebe dienen sollen, es bleibt jedoch die Frage, ob diese Systemkorrekturen den Anforderungen genügen, welche an eine den Bedürfnissen des Handwerks ausgerichtete zukunftsfähige und flexible Planungs- und Entwicklungsstruktur zu stellen sind. Um diese Frage sachlich fundiert beantworten zu können, müssen zunächst die Weichenstellungen analysiert werden, welche im Interesse der Entwicklung und Erhaltung von Standorten für Handwerksbetriebe angebahnt worden sind und bereits zu einer Modifikation des Planungssystems geführt haben.

1. Entschärfung der Gemengelagenproblematik durch die Einführung der urbanen Gebiete?

Durch die Einführung der urbanen Gebiete ist zum einen die Nutzungsmischung an sich erleichtert worden, weil anders als bei den Mischgebieten planerisch nicht sichergestellt werden muss, dass die Nutzungsmischung zwischen dem Wohnen und der Unterbringung von Gewerbebetrieben annähernd gleich ist; es muss nur an sich eine Nutzungsmischung sichergestellt werden. Da die Nutzungsmischung bei einem urbanen Gebiet, bei dem gem. $\$ 6$ a Abs. 1 BauNVO nicht nur Wohnen und die Unterbringung von Gewerbebetrieben zu den gebietstypischen Hauptnutzungsarten gehört, sondern auch die Unterbringung sozialer, kultureller und anderer Einrichtungen, ist damit nicht zwangsläufig auch eine Steigerung der Unterbringungsquote für Handwerksbetriebe verbunden. Vielmehr kann bei einem urbanen Gebiet auch der Fall eintreten, dass überwiegend Wohnen mit kulturellen und sozialen Einrichtungen gemischt wird und nur geringe Anteile für gewerbliche Nutzungen verbleiben.

Zum anderen ist mit der Einführung der urbanen Gebiete eine Nutzungsmischung ermöglicht worden, bei der die Lärmschutzanforderungen auf das Niveau des Umweltvorsorgestandards zwischen Kerngebieten, Dorfgebieten und Mischgebieten einerseits und Gewerbegebiete sowie Industriegebiete andererseits abgesenkt worden sind. Damit sollen wohnungsnah auch Standorte für unter Lärmschutzaspekten störende Handwerks- und Gewerbebetriebe entwickelt werden können. Dies sieht zunächst einmal so aus, als ob dadurch gesetzgeberisch ein Schritt zur Förderung der Standortmobilisierung zugunsten störender Handwerksbetriebe getan worden sei. Es ist jedoch zweifelhaft, ob dieser Schritt diesen Zweck erreichen kann und ob damit die oben aufgezeigten nachteiligen Folgen der Systemveränderungen, die zu einer Verknappung der für störende 
Handwerks- und Gewerbebetriebe geeigneten Flächen geführt haben, kompensiert werden. Denn zum einen ist in urbanen Gebieten nicht sichergestellt, dass überhaupt ein gewisser Anteil an Bauflächen für störende Handwerks- und Gewerbebetriebe zur Verfügung steht und zum anderen bestehen selbst dann, wenn für störende Handwerks- und Gewerbebetriebe in urbanen Gebiete Standorte vorgesehen würden, sowohl für die Gemeinden als auch für die Handwerker und Gewerbetreibenden, die in diesem Gebiet einen störenden Handwerks- oder Gewerbebetrieb errichten, erweitern oder ändern wollen, große Rechts- und damit auch Planungsunsicherheiten.

Dieser kritische Befund ergibt sich aus folgenden Erwägungen: Tatsächlich zeichnet sich schon jetzt ab, dass urbane Gebiete wegen den im Vergleich mit Mischgebietsfestsetzungen verbundenen planerischen Erleichterungen an die Stelle von Mischgebieten treten. Wie häufig bei Mischgebieten dürfte auch bei urbanen Gebieten der Wohnnutzungsanteil deutlich überwiegen. Wegen der Absenkung des Umweltvorsorgestandards können zwar grundsätzlich auch störende Handwerks- und Gewerbebetriebe zugelassen werden, es werden dadurch jedoch eher Nutzungskonflikte geschaffen als gelöst. Denn die rechtlichen Grenzen, wonach durch die städtebauliche Planung dauerhaft gesunde Wohnverhältnisse sichergestellt sein müssen, gelten weiterhin. Von Bedeutung ist insofern die in der TA Lärm festgelegte sog. Kappungsgrenze. Danach muss die Einhaltung der Immissionsrichtwerte auch ohne besonderen passiven Schallschutz sichergestellt sein. ${ }^{86}$ Abgesehen davon liegt der Lärmwert von $63 \mathrm{~dB}$ (A) tags in einem überwiegend durch Wohnnutzung geprägten Bereich, wie es bei einem urbanen Gebiet der Fall sein kann, entweder schon jenseits der gesundheitskritischen Schwelle (siehe dazu E. II. 1.) oder doch zumindest so nah an dem gesundheitskritischen Bereich, dass dadurch im Einzelfall auch das Rücksichtnahmegebot und die Eignung des Gebiets als Wohnstandort in Frage gestellt sein kann.

86 So zutreffend Battis/Mitschang/Reidt, NVwZ 2017, 817 und Hornmann, in: Spannowsky/Hornmann/Kämper, BauNVO, 2018, \$6a, Rn. 34, 34.3. Siehe dazu auch Nr. 2.3 und 6.8 der TA Lärm (Sechste Allgemeine Verwaltungsvorschrift zum Bundes-Immissionsschutzgesetz v. 26. August 1998 (GMBl Nr. 26/1998 S. 503), zuletzt geändert durch Verwaltungsvorschrift vom 01.06.2017 (BAnz AT 08.06.2017 B5) i. V. mit Anlage A.1.3 und 6.7 S.2 TA Lärm. Danach sollen die Immissionsrichtwerte für Kern-, Dorf-, und Mischgebiete bei der Bildung von Zwischenwerten der für die aneinandergrenzenden Gebietskategorien geltenden Wert nicht überschritten werden; dazu wiederum BayVGH, Beschl. v. 23.02.2017, 9 ZB 14.1914, juris Rn. 6. 


\section{E. Bedeutung und Tragweite der Baugebietstypisierung}

Dazu kommt in den eigentlichen „städtischen Gebieten“ und in den Ballungsräumen, dass in den Problembereichen nicht nur Lärmbelastungen vorhanden sind, sondern dass vielfach parallel dazu auch die Schutzanforderungen der Luftqualitätsstandards der 39. BImSchV nicht eingehalten werden können. Bei der Festsetzung urbaner Gebiete ist nicht nur der Trennungsgrundsatz gem. $₫ 50$ S. $1 \mathrm{BImSchG}$, es sind vielmehr gem. $\$ 50$ S. 2 BImSchG auch die nach $\mathbb{4} 48$ a Abs. 1 BImSchG festgelegten Immissionsgrenzwerte und Zielwerte zu berücksichtigen. Oftmals werden Lärmschutz- und Luftreinhalteprobleme gebietsbezogen zusammentreffen. ${ }^{87}$ Diese Problematik lässt sich durch die schlichte Absenkung der Umweltvorsorgestandards für den Lärmbereich nicht lösen. In den städtischen Problemgebieten muss damit gerechnet werden, dass neben Lärmvorkehrungen auch gebietsbezogene Maßnahmen bezüglich der Luftreinhaltung ergriffen werden müssen. Dadurch kann es wiederum auch zu Einschränkungen für die innergebietlichen handwerklichen Nutzungen kommen, weil eine rechtskonforme Reaktion auf der Basis des aus der Luftreinhalteplanung abzuleitenden Maßnahmenprogramms nach dem Verhältnismäßigkeitsprinzip voraussetzt, dass sämtliche Verursacher entsprechend ihres Verursachungsanteils im Rahmen der Umweltfachplanung erfasst und zur Erfüllung der daraus abzuleitenden erforderlichen Maßnahmen herangezogen werden (dazu bereits oben unter C. I. 6.).

\section{Wohnen neben dem Handwerksbetrieb?}

Bislang wurde in Gewerbegebieten nur Wohnen für Aufsichts- und Bereitschaftspersonen sowie für Betriebsinhaber und Betriebsleiter zugelassen. Deshalb war es nach den Umwelt- und Gesundheitsvorsorgestandards, welche dem System der Typisierung der Baugebiete mit der damit verbundenen Nutzungszuordnung zugrundelagen, zunächst folgerichtig, dass bei der befristeten Zulassung von Ausnahmen gem. $\$ 246$ Abs. 10 BauGB in Gewerbegebieten zur Schaffung von Aufnahmeeinrichtungen, Gemeinschaftsunterkünften und sonstigen Unterkünften für Flüchtlinge oder Asylbegehrende nicht an der Wohnnutzung in Gewerbegebieten angeknüpft wurde, sondern an den für kirchliche, soziale und gesundheitlichen Zwecken dienenden Anlagen; und gesetzlich begrenzt auch nur dann, wenn solche Anlagen als Ausnahmen zugelassen werden können oder im geltenden Bebauungsplan zugelassen sind.

Ebenso Hornmann, a.a.O., Rn. $51 \mathrm{ff}$. 
Mit der Einführung der urbanen Gebiete wurde diese Situation allgemein auf die Kombination von Wohnen und die Unterbringung von Handwerks- und Gewerbebetrieben ausgedehnt, obwohl die Sonderregelung des $\$ 246$ Abs. 10 BauGB nur als Übergangsregelung bis zum 31.12.2019 gedacht war. Gerechtfertigt sein dürfte dies, soweit auch in Gewerbegebieten, in denen störende Handwerks- und Gewerbebetriebe untergebracht werden, für Betriebsinhaber und Betriebsleiter Ausnahmen zugelassen werden. Fragwürdig erscheint jedoch aus den oben genannten Gründen, wenn jetzt auf der Basis des $₫ 6 \mathrm{a}$ BauNVO, generell die räumliche Kombination sonstiger Wohnnutzung mit einer anteilig überwiegenden Anzahl von Handwerks- und Gewerbebetrieben ermöglicht werden soll, weil damit Nutzungskonflikte vorprogrammiert sind, die sich auch noch bei den Nachfolgenutzungen manifestieren können. Denn obgleich in einem urbanen Gebiet nur Gewerbebetriebe untergebracht werden sollen, welche nicht wesentlich störend wirken, kann durch die Kumulation nicht wesentlich, aber immerhin störender Gewerbebetriebe in der Nachbarschaft der Wohnnutzung ein wesentlich störender Effekt ausgelöst werden, der für die Wohnnutzung nicht zumutbar sein kann, zumal durch die Anhebung des in einem solchen Gebiet zu duldenden Störungsgrads der gesundheitskritische Effekt in Bezug auf die gebietsinterne und benachbarte Wohnnutzung nicht beseitigt wird.

Dazu kommen weitere Bedenken in Bezug auf die Unsicherheiten, welche hinsichtlich der Festlegung der maßgeblichen Zumutbarkeitsgrenzen bezüglich des Dauerwohnens in urbanen Gebieten in der Nachbarschaft von Gewerbe- und Industriegebieten auftreten. Fraglich dürfte nämlich sein, wo ausgehend von Art. 2 Abs. 1 GG und der staatlichen Schutzplicht unter Gesundheitsschutzaspekten überhaupt die Zumutbarkeitsgrenze hinsichtlich der aus handwerklichen und gewerblichen Nutzungen herrührenden Lärmeinwirkungen für die in urbanen Gebieten zulässige Wohnnutzung verläuft (siehe dazu unter E. II. 1.). Diese Frage stellt sich nicht nur dann mit einiger Brisanz, wenn die Wohnnutzung innerhalb dieses Baugebiets mit nicht wesentlich störenden Handwerks- und Gewerbebetrieben in vorher nicht feststehender Zahl zusammentrifft, sondern vor allem auch dann, wenn urbane Gebiete mit dominierender Wohnnutzungsstruktur an Gewerbe- und Industriegebiete heranrücken, weil in diesen Fällen nach den Maßstäben der Beurteilung von Gemengelagen nach der Methode der Mittelwertbildung die unter Zumutbarkeitsgesichtspunkten maßgeblichen Immissionswerte mit denen eines Gewerbegebiets übereinstimmen dürften (dazu oben unter E. II. 4.). 


\section{E. Bedeutung und Tragweite der Baugebietstypisierung}

Dieses Ergebnis gerät mit der gesetzlichen Wertung, welche in Bezug auf Gewerbegebiete getroffen worden ist, in Widerspruch. Denn in Gewerbegebieten soll dauerhaft nur betriebsbezogenes Wohnen zulässig sein und sonstiges Wohnen im Zusammenhang mit der Unterbringung von Flüchtlingen und Asylbewerbern aufgrund $\$ 246$ Abs. 10 BauGB nur übergangsweise bis 31.12.2019. Die in dieser gesetzlichen Grenzziehung zum Ausdruck kommende gesetzgeberische Wertung hinsichtlich der begrenzten Zulässigkeit der Dauerwohnnutzung in Gewerbegebieten dürfte demgemäß auch für die Bestimmung der Zumutbarkeitsgrenze für die Lärmschutzvorsorge hinsichtlich einer Gemengelage zwischen einer Wohnnutzung im urbanen Gebiet und der lärmbelastenden Einwirkung eines im benachbarten Industrie- und Gewerbegebiets gelegenen Bestandsbetriebs maßgeblich sein.

3. Entwicklung und Erhaltung von Standorten für Handwerksbetriebe im Rahmen städtebaulicher Gesamtmaßnahmen

Städtebauliche Gesamtmaßnahmen sind Kombinationsinstrumentarien der Planung und Planverwirklichung, die nach dem BauGB für die Verwirklichung der Zwecke der Stadt- und Dorferneuerung zur Verfügung stehen. ${ }^{88}$ Dazu gehören vor allem die städtebaulichen Sanierungsmaßnahmen gem. $\int S 136 \mathrm{ff}$. BauGB und die städtebaulichen Entwicklungsmaßnahmen gem. $\int \$ 165 \mathrm{ff}$. BauGB. Bisher wurden städtebauliche Sanierungsmaßnahmen dazu eingesetzt, städtebauliche Missstände zu beheben, wenn Gebiete nach ihrer vorhandenen Bebauung oder nach ihrer sonstigen Beschaffenheit den allgemeinen Anforderungen an gesunde Wohn- und Arbeitsverhältnisse oder an die Sicherheit der in ihnen wohnenden oder arbeitenden Menschen nicht entsprechen ( $\$ 136$ Abs. 2 S. 2 Nr. 1 BauGB) oder das Gebiet in der Erfüllung der Aufgaben, die ihm nach seiner Lage und Funktion obliegen, erheblich beeinträchtigt ist. Förmliche städtebauliche Entwicklungsmaßnahmen können dazu eingesetzt werden, Ortsteile und andere Teile des Gemeindegebiets entsprechend ihrer besonderen Bedeutung erstmalig zu entwickeln oder im Rahmen einer städtebaulichen Neuordnung einer neuen Entwicklung zuzuführen. Beide städtebaulichen Gesamtmaßnahmen können auch dazu eingesetzt werden, städtebauliche Strukturprobleme in problembehafteten Gebieten zu lösen, in denen unzuträgliche Nutzungskonflikte bestehen, wenn es infolgedessen zu Beein-

88 Siehe dazu eingehender Spannowsky, DVBl. 2013, 752, $754 \mathrm{ff}$. 
trächtigung der gesunden Wohn- und Arbeitsverhältnisse kommt. Die städtebauliche Sanierungsmaßnahme kann nicht nur zur Behebung von substantiellen Missständen an Gebäuden und baulichen Anlagen, sondern auch zur Behebung von gebietsbezogenen Funktionsverlusten eingesetzt werden. Sie kann zum Beispiel auch zur Anwendung gebracht werden, um den fließenden oder ruhenden Verkehr und damit die Mobilität in einer Stadt wiederherzustellen. Denn die Einbuße der Funktionsfähigkeit eines Gebiets, die darauf beruht, dass der Verkehr nicht mehr fließen kann oder dass nicht ausreichende Parkflächen vorhanden sind, kann ein schwerwiegender städtebaulicher Missstand sein, der zugleich die wirtschaftliche Situation und die Entwicklungsfähigkeit des Gebiets und der Stadtentwicklung insgesamt negativ beeinflusst (siehe dazu $\mathbb{1} 136 \mathrm{Abs} .3 \mathrm{Nr} .2 \mathrm{BauGB}$ ).

Die städtebauliche Entwicklungsmaßnahme kann zur Verfolgung verschiedener städtebaulicher Zwecke der Erstentwicklung oder Neuordnung von Gebieten eingesetzt werden, ist aber nur unter eng begrenzten Voraussetzungen anwendbar, weil sie als sog. schärfste Waffe des Städtebaurechts den Automatismus der Enteignung zu Zwecken einer möglichst effizienten Entwicklung im Wege des gemeindlichen Zwischenerwerbs zum Tragen bringt. Deshalb darf sie nur angewendet werden, wenn das Wohl der Allgemeinheit die Durchführung der städtebaulichen Entwicklungsmaßnahme erfordert, insbesondere zur Deckung eines erhöhten Bedarfs an Wohn- und Arbeitsstätten, zur Errichtung von Gemeinbedarfs- und Folgeeinrichtungen und zur Wiedernutzung brachliegender Flächen.

Beide städtebaulichen Gesamtmaßnahmen sind bei der Zweckverfolgung allerdings auf die städtebaulichen Planungsmöglichkeiten beschränkt, welche ihnen planinhaltlich $₫ 9$ BauGB i. V. mit der BauNVO bietet. Daraus folgt, dass diese städtebaulichen Gesamtmaßnahmen zwar auch dazu eingesetzt werden können, im Zuge der Stadtentwicklungs- und -erneuerungsmaßnahmen dafür zu sorgen, dass innerhalb der jeweiligen zu entwickelnden bzw. zu ändernden Baugebiete Flächen für Handwerksbetriebe geschaffen werden können. Dafür zu sorgen ist allerdings weder als Zwecksetzung noch als zu berücksichtigender Belang explizit hervorgehoben. Dies könnte allerdings ein Aspekt sein, der gerade im Rahmen der Stadterneuerung und des Umbaus der Städte das handwerkspezifische Bedürfnis zur Sicherstellung räumlicher Entwicklungsoptionen für Handwerksbetriebe in den Städten und das öffentliche Interesse an der Nachhaltigkeit der Stadtentwicklung durch Förderung der Handwerksentwicklung verbindet. 
4. Verbesserung der Standortqualität auf der Basis Privater Initiativen zur Stadtentwicklung

Mit der Einführung der Privaten Initiativen in das Städtebaurecht ist gem. $\$ 171$ BauGB eine Entwicklung aufgenommen worden, welche in den USA beobachtet wurde, die Bildung sog. „business-improvement-districts“. Im Rahmen dieser Privaten Initiativen sollen in privater Verantwortung standortbezogene Maßnahmen zur Qualitätsverbesserung von betrieblichen Standorten in Innenstädten, Stadtteilzentren, Wohnquartieren und Gewerbezentren realisiert werden. Teilweise wurden auf landesrechtlicher Basis entsprechende Regelungen zur Finanzierung solcher Maßnahmen geschaffen. Diese Möglichkeit der Inwertsetzung und Entwicklung von Standorten wird jedoch bislang nur selten genutzt. Der Erfolg solcher Privater Initiativen hängt maßgeblich von der Ausgestaltung und der Art und Weise ab, wie diese organisiert und wie groß das Engagement der beteiligten Privaten ist. Maßnahmen im Rahmen solcher Privater Initiativen bewegen sich eher im Bereich des Stadtmarketings als im Bereich der städtebaulichen Planung. 


\section{F. Denkbare weitergehende gesetzgeberische Steuerungsoptionen zur Sicherung und Schaffung erweiterter Standortpotentiale zugunsten von Handwerks- und Gewerbebetrieben}

I. Förderung der Standortentwicklung zugunsten störender, aber nicht wesentlich störender Handwerksbetriebe in Baugebieten, welche „vorwiegend dem Wohnen dienen“, durch eine gesetzliche Einschränkung des Gebietserhaltungsanspruchs?

Denkbar wäre eine gesetzliche Einschränkung des Gebietserhaltungsanspruchs durch Einfügung eines erweiterten gesetzlichen Befreiungstatbestands zur Förderung der Zulassung handwerklicher Nutzungen in bestimmten Gebieten, wie es übergangsweise gem. $\$ 246$ Abs. 10 BauGB a. F. und jetzt $\$ 246$ Abs. 12 BauGB zur Förderung der Unterbringung von Flüchtlingen und Asylbewerbern geschehen ist. So könnten die bisherigen, für Handwerks- und Gewerbebetriebe geltenden Einschränkungen nach den $\mathbb{S} 2$ Abs. 2 Nr. 2, 3 Abs. 3 Nr. 1 und 4 Abs. 2 Nr. 2 BauNVO, wonach Handwerksbetriebe zulässig bzw. in reinen Wohngebieten auch nur ausnahmsweise zugelassen werden können, soweit sie als die Wohnnutzung nicht störende Betriebe einzustufen sind, und nach $\$ 4$ a BauNVO, wonach die handwerkliche Nutzung mit der Wohnnutzung vereinbar sein muss, in der Weise geändert werden, dass auch störende, aber nicht wesentlich störende Handwerksbetriebe zulässig sind, und dass in Dorf- und Mischgebieten nach Maßgabe von Festsetzungen des Bebauungsplans ausnahmsweise auch wesentlich störende Handwerksbetriebe auf Teilgebiete eingegrenzt zugelassen werden könnten.

Allerdings bedürfen solche Abweichungen von bauplanungsrechtlichen Systemanforderungen einer Rechtfertigung durch das Vorliegen dringender Gemeinwohlaufgaben oder gewichtiger städtebaulicher Gründe, weil das der Gebietstypisierung der BauNVO zugrunde liegende Trennungsprinzip nicht lediglich eine Ordnungsfunktion erfüllt, sondern gleichzeitig eine Ausprägung eines grundrechtsrelevanten Schutzkonzepts zur Wahrung gesunder Wohnverhältnisse und der Umweltvorsorge ist.

$\mathrm{Ob}$ eine solche Rechtfertigung für die Einschränkung des Gebietserhaltungsanspruchs durch weitere Modifikationen der Wohngebiete zugunsten der Förderung der Ansiedlung von störenden, aber nicht wesentlich 
störenden Handwerksbetrieben, etwa durch gestaffelte Anhebung der gebietsbezogenen Immissionsrichtwerte und/oder Änderung der Regel-Ausnahme-Systematik der Gebietstypologie, gegeben sein kann, ist angesichts der im BauGB und der BauNVO angelegten, umfangreichen planerischen Differenzierungsmöglichkeiten zweifelhaft, zumindest solange trotz innenentwicklungs-strategischer Nachverdichtung und Nutzungsmischung ausreichende planerische Gestaltungsmöglichkeiten vorhanden sind, die sicherstellen, dass Standorte für alle Erscheinungsformen handwerklicher Betriebe verfügbar sind.

Mit dem flächenpolitischen Reduzierungsziel des $₫ 2$ Abs. 2 Nr. 6 S. 3 ROG, wonach die erstmalige Inanspruchnahme von Freiflächen für Siedlungs- und Verkehrsflächen zu verringern ist, und der nationalen Nachhaltigkeitsstrategie, wonach die tägliche Flächeninanspruchnahme des Freiraums bis zum Jahr 2030 auf 30 ha zurückgeführt werden soll, ist zwangsläufig eine Konzentration der Standortentwicklung für die verschiedenen Nutzungen auf die Siedlungsbereiche verbunden. Deshalb ist in $\mathbb{1}$ Abs. 5 S. 3 BauGB zutreffend das Leitprinzip, wonach die städtebauliche Entwicklung vorrangig durch Maßnahmen der Innenentwicklung erfolgen soll, verankert worden und deshalb sind entsprechende Begründungsanforderungen in $\mathbb{1}$ a Abs. 2 BauGB vorgesehen. Da dies nicht ausreicht, um das angestrebte flächenpolitische Reduzierungsziel zu erreichen, ist nunmehr mit dem gesetzlichen Planungsauftrag den Trägern der Raumordnungsplanung aufgegeben, die notwendige Reduzierung der Flächenneuinanspruchnahme im Freiraum für Siedlungs- und Verkehrszwecke durch quantitative Vorgaben in Raumordnungsplänen sicherzustellen (siehe da-

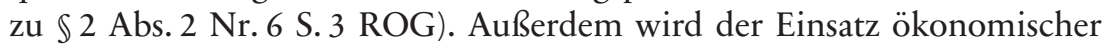
Steuerungsmittel zur Förderung des flächenpolitischen Ziels geprüft, insbesondere die Einführung einer flächenpolitisch ausgerichteten Bodenwertsteuer oder einer Baulandausweisungsabgabe oder einer Grundsteuer oder gar der Einführung eines Zertifikatehandels zur flächenpolitischen Steuerung der Neuinanspruchnahme der Flächenressourcen.

Diese Ansätze führen allesamt zu einer Verknappung der Flächenverfügbarkeit für die Neuentwicklung von Standorten. Damit wird zwangsläufig das Erfordernis der Nutzungsmischung im Städtebau verstärkt und es kommt gleichzeitig zu einer Wettbewerbsintensivierung im Verhältnis der verschiedenen Nutzungen um verfügbare Flächenpotentialen in den verschiedenen Baugebietstypen.

Vor diesem flächenpolitisch-entwicklungsstrategischen Hintergrund ist es für die Handwerks- und Gewerbeflächenentwicklung problematisch, wenn es, wie durch die nachfolgend aufgeführten gesetzgeberischen Maß- 
nahmen, zu einer Verdrängung der Handwerks- und der Gewerbebetriebe aus den ihnen nach der Baugebietstypologie der BauNVO zugeordneten Entwicklungsbereichen und zu einer Nutzungseinschränkung in den Zwischenräumen zwischen vorhandenen Gewerbe- und Wohngebieten kommt bzw. kommen kann:

a) die Ausnahmeregelung des $\$ 246$ Abs. 10 BauGB bzw. jetzt Abs. 12 BauGB (befristet bis 31.12.2019, siehe dazu auch die oben unter B. III. 2. und 3. sowie E. III. angeführte Rechtsprechung und Literatur hier$\mathrm{zu},{ }^{89}$

b) die mögliche Umnutzung von Gewerbeflächen im Flächennutzungsplan zu urbanen Gebieten im Sinne des $₫$ 6a BauNVO,

c) die mögliche erleichterte Entwicklung von Außenbereichsflächen zu Wohnflächen aufgrund des $\mathbb{1} 13 \mathrm{~b}$ BauGB (befristet bis 31.12.2019, wobei die Diskussion um die Verlängerung oder gar Einführung als Dauerlösung läuft).

In Anbetracht der Verfolgung der bundesgesetzlichen Strategie zur Schonung der Freiraumflächenressourcen, wonach einerseits innenentwicklungsstrategisch eine Nachverdichtung und Nutzungsmischung der Siedlungsbereiche verbunden ist und andererseits die Neuinanspruchnahme von Freiraumressourcen zu verringern ist ( $\$ 2$ Abs. 2 Nr. 6 S. 3 ROG), kann der logischen Schlussfolgerung, dass damit auch die Umweltvorsorgestandards der Wohngebiete eingeschränkt werden müssen, um störenden, aber nicht wesentlichen störenden Handwerksbetrieben hier und dort ausreichende räumliche Entfaltungsmöglichkeiten bieten zu können, nur begegnet werden, wenn geeignete räumliche Entwicklungspotentiale möglichst durch Bildung von Handwerksclustern an geeigneten Standorten gefördert und raumordnungsplanerisch gesichert werden.

Damit die Raumordnungsplanung diese in ihren Aufgabenbereich fallende bedeutsame räumliche Entwicklungsaufgabe gemeindeübergreifend und überörtlich sachgerecht erfüllen kann, muss sie freilich in personeller und finanzieller Hinsicht entsprechend ausgestattet sein. Insofern ist die Problematik der Flächenverknappung auch dadurch verschärft worden, dass die kurzzeitig in großer Zahl hinzugekommenen Migranten vor allem

89 Dazu auch Der Tagesspiegel v. 07.03.2018, 13:16 Uhr, Berlin-Kreuzberg, Handwerkerdorf fürchtet Verdrängung durch Flüchtlingsunterkünfte, https://www.tag esspiegel.de/berlin/berlin-kreuzberg-handwerkerdorf-fuerchtet-verdraengung-dur ch-fluechtlingsunterkuenfte/21041380.html, abgerufen am 13.12.2018. 
in die Städte und Ballungsräume ${ }^{90}$ strömten und auch strömen durften, obwohl zumindest in den schrumpfenden Bereichen des ländlichen Raums Überkapazitäten vorhanden sind.

Städtebaurechtlich kann der oben genannten Schlussfolgerung, wonach die Umweltvorsorgestandards für die Wohnnutzung eingeschränkt werden müssen, damit Städte und Ballungsräume dem Nachfragedruck standhalten können, nur dadurch begegnet werden, dass auch diejenigen Gemeinden, die von der hohen Nachfrage nach Wohnbauflächen im Umfeld von Ballungsräumen und Städten profitieren, im Interesse des Freiraumressourcenschutzes veranlasst werden müssen, bei Maßnahmen der Innenentwicklung und auch im Fall der erstmaligen Inanspruchnahme von Freiraumflächen für Zwecke der Wohnnutzung dafür zu sorgen, dass die Dichtewerte an die der benachbarten Ballungsräume und Städte angenähert werden, da nur so der verschwenderischen Inanspruchnahme von Freiraumflächen entgegengewirkt werden kann. Da es städtebaurechtlich keine zwingenden Vorgaben in dieser Richtung gibt, sollte den Trägern der Raumordnungsplanung explizit die Befugnis eingeräumt werden, für Teilräume, in denen Gemeinden erstmals angrenzend an Siedlungsbereiche, die mit Ballungsräumen und Städten um die Ausweisung von Freiraumflächen für Zwecke der Wohnnutzung konkurrieren, höhere Dichtewerte als diejenigen, die bisher im Gemeindegebiet zugrunde gelegt werden, für die Bauleitplanung vorzugeben.

Denkbar wäre auch, dass im Städtebaurecht als Abwägungsdirektive in $\$ 1$ a Abs. 2 S. 1 BauGB ergänzend verankert wird, dass die Gemeinden zur Schonung der Inanspruchnahme von Freiraumflächenressourcen und zur Erhaltung angrenzender, für die zukünftige Entwicklung von Gewerbeund Handwerksstandorten im Flächennutzungsplan vorgesehener Außenbereichsflächen prüfen sollen, ob die Möglichkeiten zur Überplanung der bestehenden Baugebiete mit einer höheren Dichte durch die Festsetzung einer höheren GFZ, einer größeren Zahl der Vollgeschosse, einer Erhöhung der Zahl der Wohneinheiten und einer Änderung der ggf. festgesetzten Gebäudehöhe geprüft worden sind.

90 Schon bisher war der Migrantenanteil in deutschen Großstädten am höchsten. Dieser wächst weiterhin, siehe dazu www.bpb.de/gesellschaft/migration/newslett er/148820/migrantenanteil-in-deutschen-grossstaedten-waechst, abgerufen am 13.12.2018. 
II. Förderung der Standortentwicklung für das Wohnen störender Handwerksbetriebe durch eine die Wohnnutzung einschränkende Modifikation des Gebietstyps „urbanes Gebiet“?

Innenentwicklungsstrategisch könnte es sinnvoll sein, den Anwendungsbereich der „urbanen Gebiete“ wirklich auf Ballungsräume und städtische Gebiete zu beschränken, weil es nicht sinnvoll erscheint, in schrumpfenden ländlichen Räumen, in denen ohnehin Leerstände festzustellen sind, zur Nutzungsmischung von den „urbanen Gebieten“ Gebrauch zu machen. Der Anwendungsbereich der urbanen Gebiete ist nicht auf städtische Räume begrenzt (siehe dazu oben B. III. 8.).

Das Wohnen in einem urbanen Gebiet sollte meiner Ansicht nach im Interesse der Sicherung von Flächenentwicklungspotentialen zugunsten derjenigen Handwerksbetriebe, welche typischerweise Störungen für die Wohnnutzung mit sich bringen, aus den nachfolgend aufgeführten Gründen eingeschränkt werden:

1. Es steht in einem gewissen Widerspruch zu den gesetzgeberischen Wertungen in Bezug auf die Wohnnutzung in den anderen der Wohnnutzung dienenden Baugebieten, dass in urbanen Gebieten mit $63 \mathrm{~dB}$ (A) bei den Immissionsrichtwerten für Immissionsorte außerhalb von Gebäuden deutlich höhere Tagwerte erreicht werden dürfen als in Kerngebieten, Dorfgebieten und Mischgebieten $(60 \mathrm{~dB}(\mathrm{~A}))$, obwohl nach $\$ 6 \mathrm{a}$ BauNVO wie in diesen Mischgebietstypen wesentlich störende, aber nicht erheblich belästigende Handwerksbetriebe ausgeschlossen und diese weiterhin auf Industrie- und Gewerbegebiete verwiesen sind, die nach Maßgabe der Regionalpläne grundsätzlich nur städtischen Räumen und Zentralen Orten vorbehalten sind. Faktisch bedeutet dies, dass in urbanen Gebieten Handwerksund Gewerbetriebe zugelassen werden müssen, die die Wohnnutzung so wesentlich stören können, dass grundsätzlich zwar noch nicht die Immissionsrichtwerte wie in einem Gewerbegebiet erreicht werden, dass diese aber durchaus Lärm erzeugen können, der nahezu daran heranreicht und der andererseits deutlich höher ist als dies bislang in Kerngebieten, Dorfund Mischgebieten zulässig war.

Ob die Zulassung einer Überschreitung der für Kerngebiete, Dorf- und Mischgebiete geltenden Immissionsrichtwerte von $60 \mathrm{~dB}$ (A) in einem Gebiet, das in einem nicht quantifizierten Umfang auch dem Wohnen dienen kann, verfassungsrechtlich überhaupt gerechtfertigt ist, erscheint fraglich. Denn nach den Ergebnissen der Lärmforschung löst eine Dauerbelas- 
tung oberhalb von $60 \mathrm{~dB}(\mathrm{~A})$ gesundheitliche Beeinträchtigungen aus. ${ }^{91}$ Verfassungsrechtlich dürfte es im Lichte der grundrechtlichen Gewährleistung der körperlichen Unversehrtheit gem. Art. 2 Abs. 2 S. 1 GG kaum zu rechtfertigen sein, dass der Umweltvorsorgestandard für Teile der Bevölkerung, die in urbanen Gebieten wohnen müssen, in gleichheitswidriger Weise so weit abgesenkt wird, dass nach den vorliegenden medizinischen Erkenntnissen Gesundheitsbeeinträchtigungen die Folge sind. In dieses Grundrecht darf nur aufgrund eines Gesetzes eingegriffen werden. Zwar ist der Gesetzesvorbehalt aufgrund des Gesetzes zur Umsetzung der Richtlinie 2014/52/EU im Städtebaurecht und zur Stärkung des neuen Zusammenlebens in der Stadt vom 04.05.2017 (BGBl. I S. 1057) gewahrt, es ist jedoch fraglich, ob dabei die durch das Verhältnismäßigkeitsprinzip gezogenen Schranken und das aus dem Gleichbehandlungsgrundsatz abzuleitende Postulat der Belastungsgerechtigkeit im Verhältnis der verschiedenen Gruppen der Wohnnutzer gewahrt wurden. Denn es dürfte kaum zu rechtfertigen sein, dass in reinen Wohngebieten höchste Umweltvorsorgestandards gelten und in einem anderen Wohngebiet bereits die für die Wohnnutzung geltende Gesundheitsgefährdungsschwelle überschritten werden darf; und dies nur deshalb, weil keine anderen geeigneteren, sachgerechten Alternativlösungen, die sich aufgedrängt haben, in Betracht gezogen wurden.

Vor diesem Hintergrund können im Einzelfall, wenn die Gesundheitsschwelle in einem geplanten urbanen Gebiet erreicht werden kann, erhebliche Planungsunsicherheiten entstehen, die die Zulassung von Handwerksbetrieben in urbanen Gebieten im Einzelfall erschweren können.

2. Um den handwerksbetrieblichen und gewerblichen Interessen besser gerecht werden zu können, müsste das Wohnen in einem urbanen Gebiet eingeschränkt sein. Die Wohnbauflächenentwicklung sollte auf die anderen Baugebiete, die bereits dem Wohnen dienen, konzentriert werden. Nur durch eine weiterhin klare Trennung kann sichergestellt werden, dass infolge der innenentwicklungsstrategisch bedingten Nachverdichtung und Nutzungsmischung sowie der damit verbundenen Flächenverknappung die bisherigen hohen Umweltvorsorgestandards von Wohngebieten weiterhin im Wesentlichen unangetastet bleiben. In einem urbanen Gebiet sollte infolgedessen lediglich das unmittelbar betriebsbezogene Wohnen oder das Wohnen im Zusammenhang mit sozialen und kulturellen Einrichtungen oder sonstigen Einrichtungen zulässig sein. Nach dieser vorge-

91 So auch das Bayerische Landesamt, siehe www.lfu.bayern.de/buerger/doc/uw_34 _laerm_messen_bewerten.pdf, S. 1 (6), abgerufen am 13.11.2018. 
schlagenen Änderung der Zwecksetzung des urbanen Gebiets würde dieser Baugebietstyp dann hauptsächlich eine den nicht wesentlich störenden Handwerks- und Gewerbebetrieben dienende Nutzungsmischung ermöglichen. Dies hätte zur Folge, dass die nicht wesentlich störenden Handwerks- und Gewerbebetriebe in den urbanen Gebieten Standorte finden würden, während die wesentlich störenden, aber nicht erheblich belästigenden Gewerbebetriebe weiterhin auf die Gewerbegebiete verwiesen wären. Die Entwicklung urbaner Gebiete käme dann vor allem in den Zwischenbereichen zwischen Wohngebieten einerseits und Gewerbe- sowie Industrieflächen andererseits in Betracht.

Diese vorgeschlagene Änderung des Baugebietstyps urbanes Gebiet würde sich durchaus in das bisherige System der Baugebietstypologie integrieren lassen. Zwar ist das urbane Gebiet gem. \$6a BauNVO nach der Regelungssystematik der BauNVO nach den dem Wohnen dienenden Baugebietstypen der $\$ \$ 2$ bis 4 a BauNVO und den auch dem Wohnen dienenden Dorf- und Mischgebieten, welche dem Wohnen und der Unterbringung nicht wesentlich störender Gewerbebetriebe gleichermaßen dienen, eingegliedert, wegen der gebietstypologischen Verknüpfung mit dem Umweltvorsorgestandard nach der TA Lärm ist das urbane Gebiet aber unter Lärmschutzgesichtspunkten zwischen den für Kern-, Dorf- und Mischgebieten und dem Gewerbegebiet einsortiert.

Meinem Vorschlag zufolge könnte man, wie es bezüglich eines Kerngebiets gem. $\mathbb{} 7$ Abs. 2 Nr. 7 BauNVO 2017 geregelt ist, eine Einschränkung bezüglich der nicht betriebsbezogenen sonstigen Wohnnutzung in der Weise herbeiführen, dass diese nur zulässig ist, wenn dies aufgrund von Festsetzungen in einem Bebauungsplan vorgesehen ist.

Dagegen könnte zwar eingewendet werden, dass dies durch eine auf die Planungssituation zugeschnittene feinsteuernde Modifikation des Baugebietstyps „urbanes Gebiet“ auch erreicht werden kann, indem nach $\$ 6 \mathrm{a}$ Abs. 2 BauNVO generell Wohngebäude gem. $\$ 1$ Abs. 5 BauNVO als nicht zulässig oder nur ausnahmsweise zulässig eingestuft werden. Ob dies zulässig wäre, ist jedoch zweifelhaft, weil damit die allgemeine Zweckbestimmung des Baugebiets in Frage gestellt sein dürfte, zumal das Wohnen nach der Beschreibung der Hauptnutzungsarten in $\$$ 6a Abs. 1 BauNVO ein Wesensmerkmal des Gebietscharakters ist. Abgesehen davon wäre dies jedoch lediglich eine von den einzelnen Gemeinden für bestimmte Bereiche realisierbare Standortförderungskonzeption für Handwerksbetriebe und keine generelle städtebaulich-strategische Gesamtlösung.

Würde das urbane Gebiet dagegen in der vorgeschlagenen Weise generell umstrukturiert, würde damit zugleich der diesem Gebietstyp innewoh- 
nenden Gefahr vorgebeugt, die in der bisherigen Struktur des $\$ 6 a$ BauNVO angelegt ist, dass das urbane Gebiet lediglich dazu eingesetzt wird, möglichst rasch und unter Vernachlässigung einer ausgeglichenen Nutzungsmischung in erster Linie die Zulässigkeit von Wohngebäuden zu begründen. Denn nach geltendem Recht kann ein Baugebiet als urbanes Gebiet kreiert werden, um dann auf dieser Basis von bis zu neunzig Prozent Baurecht für Wohngebäude zu schaffen, wenn nur sichergestellt ist, dass bei den restlichen zehn Prozent die von $\$$ 6a Abs. 1 BauNVO geforderte Nutzungsmischung mit den dort aufgeführten Hauptnutzungen sichergestellt ist.

Dies kann zudem, soweit keine raumordnungsplanerischen Festlegungen im Sinne von $\$ 2$ Abs. 2 Nr. 6 S. 3 ROG zum Zweck der Verringerung der erstmaligen Inanspruchnahme von Freiflächen Siedlungs- und Verkehrszwecke ergriffen werden, dazu führen, dass ggf. im Zusammenhang mit $₫ 13$ b BauGB mit der Ausweisung von urbanen Gebieten gerade auf Flächenpotentiale zugegriffen wird, die für die Standortentwicklung für handwerkliche und gewerbliche Nutzungen geeignet sind und die vielleicht sogar schon in einem Flächennutzungsplan als Gewerbeflächen vorgesehen waren.

Würde das urbane Gebiet dagegen als Baugebietstyp in dem vorgeschlagenen Sinne umgebaut, würde dadurch der Verdrängungs- bzw. Verknappungseffekt zulasten der Unterbringung von störenden Handwerks- und Gewerbebetrieben, der durch die Einführung des $\$ 13 \mathrm{~b}$ BauGB und der durch die bisherige Innenentwicklungsstrategie infolge der strikter werdenden Umweltanforderungen eingetreten ist und der zudem durch die Möglichkeit der Entwicklung von urbanen Gebieten aus im Flächennutzungsplan ausgewiesenen Gewerbeflächen noch intensiviert werden kann, wieder abgemildert.

III. Erhaltung der Standortpotentiale an den Rändern der Städte und Gemeinden durch eine Abschaffung der wohnbaufördernden Planungserleichterungen mit Zugriffsmöglichkeiten auf diesen Bereich?

Außerdem sollte $₫ 13$ b BauGB nicht über den 31.12.2019 hinaus verlängert werden, um die generelle nachteilige Anreizfunktion zur Förderung der Wohnbauflächenentwicklung in kleinen Schritten am Rand der Städte und Gemeinden zum Nachteil störender Handwerks- und Gewerbebetriebe, die auf die Schaffung von Standorten in den Randbereichen der Sied- 
lungskörper angewiesen sind, nicht zu perpetuieren. Die Siedlungsflächenentwicklung sollte demgegenüber in stärkerem Maße über die Regionalplanung bzw. im Saarland über die Landesplanung und in den Stadtstaaten über die Flächennutzungsplanung gesteuert werden, weil vermieden werden sollte, dass in Ballungsräumen gerade in solchen Bereichen, in denen ohnehin schon kaum noch zu bewältigende Lärm- und Luftreinhalteprobleme bestehen, die Siedlungsflächenentwicklung über $₫ 13 \mathrm{~b}$ BauGB in der jetzigen Fassung noch verschlimmert wird. Deshalb ist es notwendig, dass die Wohnbau- und Gewerbeflächenentwicklung über die Regionalplanung gesteuert wird. Sollte $\$ 13 \mathrm{~b}$ BauGB über den Stichtag hinaus verlängert werden, wie es gegenwärtig von einigen Bundesländern gefordert wird, sollte dessen Anwendbarkeit davon abhängig gemacht werden, dass regionalplanerisch für die Wohnbauflächenentwicklung ein Entwicklungsschwerpunkt ausgewiesen ist. Dieser muss nicht am Stadtrandgebiet der großen Städte liegen, sondern kann auch in geeigneten peripheren Gebieten zu finden sein.

IV. Vorsorge hinsichtlich der Entwicklung von Standorten für Handwerksbetriebe durch die Raumordnungsplanung

Soweit für störende Handwerksbetriebe mit größerem Raumbedarf und für Gewerbe- bzw. Handwerksbetriebsparks ein dringender, im Rahmen der Innenentwicklung nicht zu befriedigender Flächenbedarf besteht, sollte den Trägern der Raumordnungsplanung in einem bundesgesetzlichen Grundsatz der Raumordnung im Sinne von $\$ 2$ Abs. 2 ROG aufgegeben werden, auf der Basis eines für die Landesebene aufzustellenden Entwicklungskonzepts zur Sicherung der Handwerksstruktur geeignete, diesem Zweck dienende Entwicklungsschwerpunkte festzulegen oder entsprechende Vorranggebiete auszuweisen. 


\section{G. Zusammenfassung in Thesen}

1. Veränderte Rahmenbedingungen im Bereich des Handwerks sind sowohl dadurch eingetreten, dass die Handwerkslandschaft einem dynamischen Wandel der betrieblichen Erscheinungsformen ausgesetzt ist, als auch dadurch, dass die umweltfachgesetz- und umweltfachplanerischen Restriktionen zum Nachteil der Standortentwicklung für Handwerksbetriebe angewachsen sind.

2. Dazu gekommen sind stadtentwicklungs- und flächenpolitische Veränderungen der Rahmenbedingungen durch Verfolgung des Freiraumressourcenschutzes und die daraus resultierende Innenentwicklungsstrategie sowie die damit verbundene Nachverdichtung und Nutzungsmischung. Mit dem Postulat der nachhaltigen städtebaulichen Entwicklung (vgl. $\mathbb{S} 1$ Abs. 5 S. 1 BauGB) und der nachhaltigen Raumentwicklung ( $\$ 2$ Abs. 1 ROG) nicht vereinbar ist ein verschwenderischer Umgang mit den begrenzten Flächenressourcen. Aus der Notwendigkeit des Schutzes der Freiraumflächenressourcen leitet sich zunächst die Anforderung der Innenentwicklungsstrategie $\mathrm{ab}$, wonach der Innenentwicklung bei der städtebaulichen Planung der Vorrang vor der Freiraumentwicklung einzuräumen ist. Die weitere strategische Folge dieser Maßgabe ist die Nachverdichtung des Siedlungsbestands und die Notwendigkeit der Nutzungsmischung. Dieser strategiebedingte Automatismus wurde jedoch durch weitere Veränderungen der Rahmenbedingungen verstärkt. Insbesondere infolge der Niedrigzinspolitik der Europäischen Zentralbank und des kurzzeitigen starken Anstiegs der Migrationsströme in den Großstädten und Ballungsräumen ${ }^{92}$ wurde die Nachfrage nach Neubauwohnungen in den Großstädten und Ballungsräumen so stark angeheizt, dass die Nachverdichtung und Nutzungsmischung bei gleichzeitiger Begrenzung der Neubauflächeninan-

92 Siehe dazu das Gutachten des Instituts der deutschen Wirtschaft Köln zum Thema „Zuwanderung in die Großstädte und resultierende Wohnungsnachfrage, https://www.iwkoeln.de/fileadmin/publikationen/2017/325122/IW_Gutachten_2 017_Zuwanderung_Grossstaedte_Wohnungsnachfrage.pdf, abgerufen am 12.12.2018 und Bundesinstitut für Bau-, Stadt- und Raumforschung (Hrsg.), Zuwanderung und Wohnungsbedarf für die Berechnungen der BBSR-Wohnungsmarktprognose 2030 hinaus, https://www.wohnungsmarktbeobachtung.de/bundund-laender/bak/ht2015/ht2015/pdf-bbsr, abgerufen am 12.12.2015. 
spruchnahme im Außenbereich intensiviert wurde. Dadurch, dass die $\mathrm{Zu}-$ wanderung sich vor allem auf Wohnraumentwicklung in den A- und BStädten auswirkt, ist dort der Wettbewerb um Flächen mit nachteiligen Auswirkungen auf das Handwerk und das Gewerbe am größten, zumal einige dieser Städte auch kaum mehr über Außenbereichsflächen verfügen. ${ }^{93}$

3. Vor dem Hintergrund der städtebaulichen Innenentwicklungsstrategie und der damit korrespondierenden Notwendigkeit der Begrenzung der Neuinanspruchnahme von Freiraumflächen im Außenbereich der Gemeinden wurde dadurch die Flächenverfügbarkeit für Handwerks- und Gewerbebetriebe im Wettbewerb um Flächen in Relation zu der Flächenmobilisierung für Zwecke der Wohnnutzungen zu Lasten der mittel- und langfristigen, an der Nachhaltigkeit ausgelegten Standortentwicklung bezüglich Handwerks- und Gewerbebetrieben verschlechtert. Vor allem folgende gesetzgeberische Entscheidungen haben insofern die Vorzeichen zu Lasten der Standortentwicklung für Gewerbe- und Handwerksbetriebe verändert:

a) die Ausnahmeregelung des $\$ 246$ Abs. 10 und Abs. 12 BauGB (befristet bis 31.12.2019, siehe dazu auch die oben unter B. III. 2. und 3. sowie E. III. angeführte Rechtsprechung und Literatur hierzu),

b) die mögliche Umnutzung von im Flächennutzungsplan ausgewiesenen Gewerbeflächen zu urbanen Gebieten im Sinne des $\$$ 6a BauNVO,

c) die mögliche erleichterte Entwicklung von Außenbereichsflächen zu Wohnflächen aufgrund des $\mathbb{1} 13 \mathrm{~b}$ BauGB (befristet bis 31.12.2019, wobei die Diskussion um die Verlängerung oder gar Einführung als Dauerlösung läuft).

d) Außerdem kann auch eine Beschränkung der Standortentwicklung im bisherigen Freiraum eintreten, soweit auf der Basis des $\$ 2$ Abs. 2 Nr. 6 S. 3 ROG, wie danach vorgesehen, regionalplanerische Festlegungen in Gestalt quantitativer Vorgaben auch zur Begrenzung der erstmaligen Inanspruchnahme von Freiraumressourcen für Zwecke der Gewerbeflächenentwicklung getroffen werden.

93 WealthCap Marktbericht Büroimmobilien Deutschland, Ausgabe Nr. 3, Stand 2017, Fokusthema: Städte an ihren Grenzen, https:/www.hdb-hamburg.de/filead min/user_upload/Broschueren_und_Marktberichte/201701_WMC_Martkbericht _Bueroimmo_D_final.pdf, abgerufen am 12.12.2018. 
4. Ob auf der Basis der bisherigen gesetzlichen Rahmenbedingungen eine nachhaltige Standortentwicklung von Handwerksbetrieben im Spannungsfeld zwischen der Verringerung der Flächenneuinanspruchnahme im Freiraum einerseits und der die Wohnbauflächenentwicklung im Bestand begünstigenden Innenentwicklungsstrategie andererseits gewährleistet werden kann, wenn nicht Korrekturen vorgenommen werden, ist angesichts der dynamischen Veränderungen im Bereich des Handwerks zweifelhaft.

5. Die durch die oben genannten Gesetzesänderungen herbeigeführten Verdrängungseffekte zulasten der Gewerbe- und Handwerksbetriebe wurden zwar dadurch in gewissem Maße kompensiert, dass

a) gem. $\$ 34$ Abs. 3a BauGB unter Abweichung vom Erfordernis des Einfügens in die Eigenart der näheren Umgebung im Innenbereich die Erweiterung, Änderung, Nutzungsänderung oder Erneuerung eines zulässigerweise errichteten Gewerbe- und Handwerksbetriebs zugelassen werden und dass

b) durch die Einführung des neuen Baugebietstyps urbanes Gebiet gem. $\$ 6 \mathrm{a}$ BauNVO unter anderem auch eine Nutzungsmischung derart zugelassen wird, dass lärmintensive gewerbliche und handwerkliche Nutzungen bis zur Gesundheitsgefahrenschwelle ermöglicht werden. Dadurch wurde das differenzierte und bislang gut austarierte städtebaurechtliche, auf dem Trennungsprinzip zwischen Wohnen und gewerblicher Nutzung aufgebaute System der BauNVO verändert.

Die Modifikation des $₫ 34$ Abs. 3a BauGB kann allerdings nur im Einzelfall eine erweiterte Zulässigkeit für Gewerbe- und Handwerksbetriebe begründen, erlaubt aber keine Abweichung zum Zweck der Errichtung von Gewerbe- und Handwerksbetrieben. Es kann auch nicht systematisch auf der Basis der Planersatzregelung des $\$ 34$ BauGB unter Zuhilfenahme der Abweichungsregelung im vorhandenen Bestand eine Standortentwicklung zugunsten mehrerer Gewerbe- und Handwerksbetriebe, die sich nach den maßstabsbestimmenden Kriterien objektiv nicht einfügen, betrieben werden; so weit reicht der gesetzliche Zulässigkeitstatbestand der Planersatzregelung nicht.

Der Baugebietstyp des urbanen Gebiets begünstigt zudem nicht zwangsläufig die Entwicklung von Standorten für Gewerbe- und Handwerksbetriebe, weil es nicht ausgeschlossen ist, dass die Wohnnutzung in einem urbanen Gebiet deutlich überwiegen kann, wenn in der Planungsphase wenigstens eine Mischung der in der gebietstypischen Zwecksetzung genannten Hauptnutzungen realisierbar erscheint. Die zugunsten der Standort- 
entwicklung lärmintensiverer Handwerks- und Gewerbebetriebe in urbanen Gebieten vorgesehene Modifikation des Lärmvorsorgestandards kann infolgedessen nur bedingt erreicht werden und stößt überdies an Grenzen. Denn Planungsunsicherheiten sind vorprogrammiert, soweit in dem Baugebiet die Immissionsrichtwerte über $60 \mathrm{db}$ (A) liegen (dazu oben). Dazu kommt, dass das Abwägungsgebot und das Rücksichtnahmegebot im Einzelfall zum Nachteil der Wohnnutzungen verletzt sein können, wenn die in $\ 6 \mathrm{a}$ Abs. 4 BauNVO vorgesehenen Feinsteuerungsmöglichkeiten nicht erwogen und nicht sachgerecht angewendet worden sind und infolgedessen unzumutbare Beeinträchtigungen zum Nachteil der Wohnnutzer herbeigeführt worden sind. Schließlich ist zu beachten, dass mit der Einführung der urbanen Gebiete lediglich der Lärmschutzvorsorgestandard abgesenkt wurde, nicht aber die Luftreinhalteanforderungen.

6. Es stellen sich unter dem Aspekt der nachhaltigen Entwicklung von Standorten für Handwerks- und Gewerbebetriebe folgende grundsätzliche Fragen,

a) ob und inwieweit in Großstädten und Ballungsräumen wegen innenentwicklungsstrategisch infolge der Nachverdichtung und Nutzungsmischung ausgelösten Problemen und wegen des Erfordernisses der Herstellung gleichwertiger Lebensverhältnisse regional differenzierte Entscheidungen zur Umsteuerung vorgenommen werden müssen,

b) ob und inwieweit als Asylberechtigte anerkannte Personen künftig stärker räumlich verteilt und vermehrt auch in ländlichen Räumen angesiedelt werden müssen, wo Leerstände und eine Unternutzung der vorhandenen Versorgungseinrichtungen zu verzeichnen sind und

c) ob die urbanen Gebiete nochmals in der Weise modifiziert werden sollten, dass die sonstige, nicht betriebsbezogene Wohnnutzung nur nach Maßgabe von Festsetzungen des Bebauungsplans zugelassen können soll (wie in $\$ 7$ Abs. $2 \mathrm{Nr} .7$ BauNVO vorgesehen).

Wenn in den Städten und Ballungsräumen eine weitere Ausweisung der Flächenentwicklung in den Freiraum hinein und damit zusammenhängende weitere Negativfolgen der räumlichen Verdichtung vermieden werden sollen, sind die vorstehend aufgeworfenen Fragen meiner Ansicht nach in rechtspolitisch-strategischer Hinsicht zu bejahen, weil in diesem Fall nur durch die genannten Umsteuerungsmaßnahmen der inzwischen eingetretenen Verknappung der Standortentwicklungspotentiale für Gewerbe- und Handwerksbetriebe entgegengewirkt werden kann.

Außerdem sollten die in $\$ 246$ Abs. 10 und 12 BauGB sowie in $₫ 13 \mathrm{~b}$ BauGB geregelten Übergangsregelungen wegen ihres Verdrängungseffekts 
zum Nachteil der Standortentwicklung für Handwerks- und Gewerbebetriebe gesetzlich nicht verlängert werden.

Eine weitere Absenkung des gebietstypischen differenzierten Umweltvorsorgestandards in den verschiedenen Baugebieten im Interesse der Verfolgung der innenentwicklungsstrategischen Nachverdichtung und Nutzungsmischung in der Weise, dass der Störungsgrad durch systematische baugebietsübergreifende Erhöhung der gebietstypischen Immissionsrichtwerte generell erhöht wird, sollte meiner Ansicht nach in rechtspolitischer Hinsicht vermieden werden, weil damit der Wohnqualitätsstandard in Deutschland generell in Frage gestellt würde und eine systematische Einschränkung des Eigentumsrechts bzw. der Gesundheitsvorsorge zulasten der Wohnnutzer herbeigeführt würde.

Stattdessen wird man für im Rahmen der Innenentwicklung nicht zu befriedigende gewerbliche und handwerksbetriebliche Standortentwicklungen, insbesondere für Handwerksbetriebe, die störende Betriebe mit größerem Raumbedarf sind, und für die Entwicklung von Gewerbe- bzw. Handwerksbetriebsparks begrenzte Ausnahmen im Rahmen der raumordnungsplanerischen Steuerung der Neuinanspruchnahme von Freiraumflächenressourcen einkalkulieren und sobald und soweit erforderlich ausweisen müssen (dazu vorstehend unter F. IV.).

7. Außerdem sollten folgende kleinere Korrekturen der BauNVO vorgenommen werden: Es sollte die Möglichkeit der gebäudeinternen Mischung verträglicher Nutzungen nicht nur für besondere Wohngebiete, urbane Gebiete und Kerngebiete, sondern auch für Dorf- und Mischgebiete als gebietsbezogene Feinsteuerungsmöglichkeit vorgesehen werden, ohne dass es hierfür gem. $\$ 1$ Abs. 7 BauNVO des Nachweises des Vorliegens besonderer städtebaulicher Gründe bedarf.

8. Außerdem sollten die städtebaulichen Gesamtmaßnahmen in stärkerem Maße zum Zweck der Entwicklung, Erhaltung und Erweiterung von Standortpotentialen für Handwerksbetriebe, insbesondere zur Planung und Realisierung von Handwerks- bzw. Gewerbeparks eingesetzt werden; dies sollte durch Städtebaufördermittel unterstützt werden.

9. Schließlich sollte der expansive Drang der Wohnnutzung in den Bereich der Freiraumressourcen dadurch eingedämmt werden, dass die in den Innenbereichen der Städte oftmals noch vorhandenen „Aufstockungsreserven" mobilisiert werden. Dafür reichen die Möglichkeiten der erweiterten Vorhabenzulassung durch Zulassung von Befreiungen nach $\$ 31$ Abs. 2 BauGB und die Abweichungsmöglichkeiten nach $\$ 34$ Abs. 3 BauGB nicht aus. Die Mobilisierung der Aufstockungsreserven im Innenbereich der Städte sollte vielmehr in den Grenzen einer Nachverdichtung 
unterhalb der gesundheitlichen Gefährdungsschwelle dadurch erleichtert werden, dass Planungserleichterungen geschaffen werden. Denkbar wäre dies z. B. dadurch, dass die Aufstockung im Innenbereich im Wege einer Gesetzesänderung auf der Basis eines einfachen Bebauungsplans oder ggf. nach der Festlegung der dafür in Frage kommenden Entwicklungsbereiche (z. B. zweigeschossige Reihenhaussiedlungen zwischen mehrgeschossigen Hochhauskomplexen) durch Satzung unter bestimmten Voraussetzungen allein auf der Basis eines Städtebaukonzepts zugelassen wird. Dadurch kann der Nachfragedruck der Immobilienwirtschaft auf Konversionsflächen der Handwerksbetriebe und auf bisherige Gewerbeflächen sowie auf Flächen, die für gewerbliche Entwicklungen im Randbereich von Städten und Gemeinden vorgesehen waren, in den Städten und Ballungsräumen bzw. Räumen mit Wohnraumknappheit und dadurch bedingtem erhöhtem Nachfragedruck im Bereich des Wohnens etwas abgeschwächt werden.

10. In gesamträumlich-strategischer Hinsicht sollte zugleich im Interesse der Stärkung der Staatsgrenzen übergreifenden Grenzregionen der EU erwogen werden, dort gezielt Gewerbe- und Handwerksbetriebe, auch zur Förderung der besseren "Verlinkung" der an den Staatsgrenzen verlaufenden Verkehrswege zu entwickeln. Denn für die "digital-begeisterten Spezialisten" und die "Modernen Alleskönner" im Handwerksbereich können gerade die Staatsgrenzen überschreitenden Grenzregionen Entwicklungspotentiale bieten. Die Verbesserung der Kooperation in den Grenzräumen dürfte zukünftig in der EU einen bedeutenderen Stellenwert erlangen, weil in dem Abbau der Strukturschwäche dieser Grenzräume nicht nur Entwicklungspotentiale in Bezug auf die Verbesserung der Kooperation der Nachbarstaaten der EU liegen, sondern auch noch gewisse Wachstumseffekte zugunsten der kooperierenden Nachbarstaaten erzeugt werden können. Da die "digital-begeisterten Spezialisten" und die "Modernen Alleskönner" weniger an bestimmte Orte gebunden sein dürften, könnten die Grenzregionen durchaus Chancen für eine betriebliche Standortentwicklung bieten. Dies könnte sowohl raumordnungsrechtlich als auch durch Veränderung der EU-rechtlichen Rahmenbedingungen zur Förderung der Entwicklung von Grenzregionen oder durch bi- und multilaterale Staatsverträge auf mitgliedstaatlicher Ebene stärker gefördert werden (siehe hierzu die in dem am 22.01.2019 zwischen der Bundesrepublik und der Französischen Republik abgeschlossenen Aachener Vertrag vorgesehenen Modalitäten zur Anwendung des einfacheren Rechts in Grenzräumen und dem Vorschlag der Europäischen Kommission für eine Verordnung des Europäischen Parlaments und des Rates über einen Mechanismus zur 
Überwindung rechtlicher und administrativer Hemmnisse in einem grenzübergreifenden Kontext, vgl. COM 2018/273 final v. 29.05.2018).

Kaiserslautern, den 14.12.2018

will gamonsty 


\section{Literaturverzeichnis}

Battis, Ulrich/Mitschang, Stephan/Reidt, Olaf, Das Gesetz zur Umsetzung der Richtlinie 2014/52/EU im Städtebaurecht und zur Stärkung des neuen Zusammenlebens in der Stadt (BauGB-Novelle 2017), NVwZ 2017, $817 \mathrm{ff.}$

Burgi, Martin/Pöhlmann, Marinus, Diesel-Verkehrsverbote mit Einschränkungen und Ausnahmen für Handwerker, GewArch 2018, $361 \mathrm{ff}$.

Classen, Claus Dieter, Strukturunterschiede zwischen deutschem und europäischem Verwaltungsrecht - Konflikt oder Bereicherung?, NJW 1995, $2457 \mathrm{ff}$.

Couzinet, Daniel, Die Schutznormtheorie in Zeiten des Feinstaubs, DVBl. 2008, $754 \mathrm{ff}$.

Decker, Andreas, in: Simon/Busse (Hrsg.), Bayerische Bauordnung, Kommentar, 131. EL, Art. 82, München 2018.

Detterbeck, Steffen, Handwerksordnung, Kommentar, 4. Aufl., München 2008.

Fickert, Hans Carl/Fieseler, Herbert, BauNVO, Kommentar, Köln 1995.

Gatz, Stephan, jurisPR-BVerwG 10/2008 zu BVerwG, Beschl. v. 18.12.2007, 4 B $55 / 07$.

Hornmann, Gerhard, Spannowsky/Hornmann/Kämper (Hrsg.), BauNVO, Kommentar, \$ 6a, München 2018.

Hornmann, Gerhard, Spannowsky/Hornmann/Kämper (Hrsg.), BauNVO, Kommentar, $\mathbb{3}$, München 2018.

Hornmann, Gerhard, Spannowsky/Hornmann/Kämper (Hrsg.), BauNVO, Kommentar, $\mathbb{\$}$ 3, München 2018.

Jarass, Hans D, Bundes-Immissionsschutzgesetz, Kommentar, 12. Aufl., $₫ 47$, München 2017.

Karber, Bernd, Spannowsky/Hornmann/Kämper (Hrsg.), BauNVO, Kommentar, \$5, München 2018.

Kment, Martin, Die Stellung nationaler Unbeachtlichkeits-, Heilungs- und Präklusionsvorschriften im europäischen Recht, EuR 2006, $201 \mathrm{ff}$.

Kormann, Joachim, Zur Situation von Handwerksbetrieben nach geltendem Bauplanungsrecht, GewArch 2010, 396 ff.

Marschke, Simon, Der Gebietserhaltungsanspruch, Hamburg 2009.

Müller, Klaus, Strukturentwicklungen im Handwerk, in: Wirtschaftsdienst, Zeitschrift für Wirtschaftspolitik, 93. Jahrgang, 2013, Heft 9, S. $636 \mathrm{ff}$.

Murswiek, Dietrich, Urteilsbesprechung - EuGH, Urt. v. 25.07.2008, C-237/07, JuS 2009, 74.

Pützenbacher, Stefan, Bönker/Bischopink (Hrsg.), BauNVO, Kommentar, Baden-Baden 2014. 
Roeser, Thomas, König/Roeser/Stock, BauNVO, Kommentar, 3. Aufl., $\$ 6$, München 2014.

Scheidler, Alfred, Abweichungen vom Bebauungsplan für Handwerks-, Gewerbeund Industriebetriebe, GewArch Beilage WiVerw Nr. 02/2016, 65 ff.

Scheidler, Alfred, Bauen im Außenbereich auf der Grundlage einer Satzung nach $\$ 35$ Abs. 6 BauGB, ZfBR 2018, $444 \mathrm{ff}$.

Scheidler, Alfred, Die bauplanungsrechtliche Zulässigkeit kleinerer Handwerks- und Gewerbebetriebe auf Grundlage einer Außenbereichssatzung, GewArch 2018, $455 \mathrm{ff}$.

Scheidler, Alfred, Die bauplanungsrechtliche Zulässigkeit von Handwerks- und Gewerbebetrieben im unbeplanten Innenbereich nach $\$ 34$ BauGB, GewArch Beilage WiVerw Nr. 02/2018, 89 ff.

Seitz, Claudia, Grundrechtsschutz durch Verfahrensrecht, EuZW 2015, $273 \mathrm{ff}$.

Sobotta, Christoph, EuGH: Neue Verfahren im Umweltrecht, ZUR 2018, $174 \mathrm{ff}$.

Söfker, Wilhelm, Ernst/Zinkahn/Bielenberg, (Hrsg.), BauGB, Kommentar, $\$ 35$, München, Stand: 2017.

Söfker, Wilhelm, Spannowsky/Uechtritz (Hrsg.), BauGB, Kommentar, 3. Aufl., $\mathbb{} 35$ München 2018

Spannowsky, Willy, Spannowsky/Uechtritz (Hrsg.), BauGB, Kommentar, 3. Aufl., \$246, München 2018.

Spannowsky, Willy, Spannowsky/Uechtritz (Hrsg.), BauGB, Kommentar, 3. Aufl., \$34, München 2018.

Spannowsky, Willy, Allgemeine Feinsteuerungsmöglichkeiten nach $₫ 1$ Abs. 4 bis 10 BauNVO und deren Verhältnis zu speziellen gesetzlichen Festsetzungsmöglichkeiten zur Art der baulichen Nutzung, ZfBR 2018, $447 \mathrm{ff}$.

Spannowsky, Willy, Der Ausschlussgrund für die Anwendung des beschleunigten Verfahrens der Bebauungsplanung, ZfBR 2018, $544 \mathrm{ff}$.

Spannowsky, Willy, Lärmschutz- und luftreinhaltungsrelevante Änderungen im Bauplanungsrecht, ZfBR 2018, $25 \mathrm{ff}$.

Spannowsky, Willy, Stadt- und Dorferneuerung im Zeichen der Innenentwicklung, DVB1. 2013, $752 \mathrm{ff}$.

Spannowsky, Willy/Porger Karl-Wilhelm, Die Auswirkungen von Truppenübungsplätzen, in: Schriften zur Raumordnung und Landesplanung, Bd. 9, Augsburg/ Kaiserslautern 2002.

Ziegler, Jürgen, Brügelmann (Hrsg.), BauGB, Kommentar, 108 EL, $\mathbb{1}$, Stuttgart 2016. 
Internet-Quellen:

https://www.destatis.de/DE/ZahlenFakten/GesamtwirtschaftUmwelt/Unternehmen Handwerk/Handwerk/Handwerk.html\#Tabellen, abgerufen am 10.11.2018.

https://www.destatis.de/DE/ZahlenFakten/GesamtwirtschaftUmwelt/Unternehmen Handwerk/Handwerk/AktuellStruktur.html, abgerufen am 10.11.2018.

http://www.ifh.wiwi.uni-goettingen.de/de/content/auf-dem-land-mehr-handwerksb etriebe-als-den-st $\% \mathrm{C} 3 \% \mathrm{~A} 4 \mathrm{dten}$-ergebnisse-einer-untersuchung-\%C3\%BCber-regi o, abgerufen am 10.11.2018.

www.ifh.wiwi.uni-goettingen.de/de/content/handwerksentwicklung-im-spannungs feld-zwischen-stadt-und-land-eine-empirische-analyse, abgerufen ebenfalls am 10.11.2018.

https:/wirtschaftslexikon.gabler.de/definition/handwerk-51988/version-275139, abgerufen am 12.10.2018.

http:/www.meistertipp.de/aktuelles/news/neues-handwerker-verhalten-beeinflusstbauzulieferer, abgerufen am 11.10.2018.

http://www.meistertipp.de/aktuelles/news/neue-handwerkertypen-wie-sie-die-baubr anche-veraendern, abgerufen am 11.10.2018.

https://www.tagesspiegel.de/berlin/berlin-kreuzberg-handwerkerdorf-fuerchtet-verd raengung-durch-fluechtlingsunterkuenfte/21041380.html, abgerufen am 13.12.2018.

www.bpb.de/gesellschaft/migration/newsletter/148820/migrantenanteil-in-deutsche n-grossstaedten-waechst, abgerufen am 13.12.2018.

www.lfu.bayern.de/buerger/doc/uw_34_laerm_messen_bewerten.pdf, S. 1 (6), abgerufen am 13.11.2018.

https://www.iwkoeln.de/fileadmin/publikationen/2017/325122/IW_Gutachten_201 7_Zuwanderung_Grossstaedte_Wohnungsnachfrage.pdf, abgerufen am 12.12.2018.

https://www.wohnungsmarktbeobachtung.de/bund-und-laender/bak/ht2015/ht201 5/pdf-bbsr, abgerufen am 12.12.2015.

https://www.hdb-hamburg.de/fileadmin/user_upload/Broschueren_und_Marktberi chte/201701_WMC_Martkbericht_Bueroimmo_D_final.pdf, abgerufen am 12.12.2018. 
